\title{
A Global Review of Empirical Models for Estimating Photosynthetically Active Radiation
}

\author{
Samuel Chukwujindu Nwokolo ${ }^{1},{ }^{*}$ Solomom Okechukwu Amadi ${ }^{2}$ \\ 1: Department of Physics, University of Calabar, Calabar, Nigeria \\ 2: Department of Physics/Geology/Geophysics, Federal University Ndufu-Alike Ikwo, Nigeria
}

Received August 6, 2018; Accepted August 24, 2018; Published October 4, 2018

\begin{abstract}
A good working knowledge of photosynthetically active radiation (PAR) is of vital requirement for determining the terrestrial photosynthesis, primary productivity calculation, ecosystem-atmosphere carbon dioxide, plant physiology, biomass production, natural illumination in greenhouses, radiation climate, remote sensing of vegetation, and radiation regimes of plant canopy, photosynthesis, productivity models of vegetation, etc. However, routine measurement of PAR is not available in most location of interest across the globe. During the past 77 years in order to estimate PAR on hourly, daily and monthly mean basis, several empirical models have been developed for numerous locations globally. As a result, numerous input parameters have been utilized and different functional forms applied. This study was aim at classifying and reviewing the empirical models employed for estimating PAR across the globe. The empirical models so far utilized were classified into ten main categories and presented base on the input parameters applied. The models were further reclassified into numerous main sub-classes (groups) and finally presented according to their developing year. In general, 757 empirical models, 62 functional forms and 32 groups were reported in literature for estimating PAR across the globe. The empirical models utilized were equally compared with models developed using different artificial neural network (ANN); and the result revealed that ANN models are more suitable for estimating PAR across the globe. Thus, this review would provide solar energy researchers with input parameters and functional forms that have been widely used to up to date, and recognizing their importance in estimating PAR globally.
\end{abstract}

Keywords: Photosynthetically active radiation; empirical models; classification; functional forms; world review

\section{Introduction}

Photosynthetically active radiation (PAR) is a component of global solar radiation $(\mathrm{H})$ that covers both photon and energy terms between 400-700 $\mathrm{nm}$ waveband incident per unit time on a unit surface. This radiometric flux (PAR) is both photon and energy term capable for driving electron transport within the photosynthetic process used by plants in synthesizing their food as shown by the chemical equation given by Nwokolo [1] and Nwokolo and Ogbuezie [2]: 


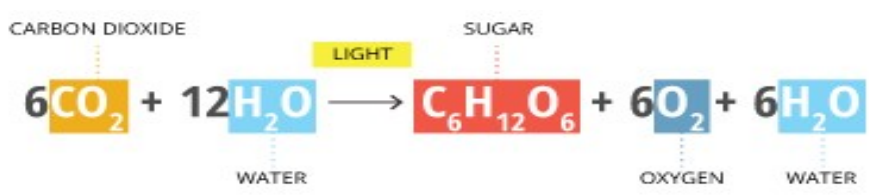

where the light (PAR) represents light energy wavelength range $(400-700 \mathrm{~nm})$ that is the best fit for photosynthesis to occur.

PAR is not only important for single plant leaves, plant communities and modeling vegetation growing due to its relationship with botanical photosynthesis process but a viable irradiance energy needed as a baseline for estimating and understanding PAR parameters such as gross primary productivity (GPP), light use efficiency (LUE) and net ecosystem exchange of carbon dioxide (NEE) for agricultural and ecological studies, etc.

The accurate determination and clear understanding of PAR is needed for many applications such as analyzing terrestrial photosynthesis, primary productivity calculation and ecosystem-atmosphere carbon dioxide [3,4]; plant physiology, biomass production and natural illumination in greenhouses [5]; comprehensive studies of radiation climate, remote sensing of vegetation, radiation regimes of plant canopy, photosynthesis and productivity models of vegetation [6]; carbon dynamic, agricultural productivity, and atmospheric Physics [7-9]; terrestrial photosynthesis modeling [10-12]; radiation forcing effect, energy management, hydrological process and biometeorology [13-14]; studies of crop production, remote sensing of vegetation and carbon cycle modeling [15-16]; evolution of environmental and agricultural fields [17]; agriculture, atmospheric physics, forestry, ecology, energy management and photon science [18-19]; plant physiology, crop growth, biomass production and agricultural meteorology [20-21]; controlling the exchange of carbon between atmosphere, oceans and the terrestrial biosphere [22-25]; radiation intercepted by the canopy, the establishment of leaf photosynthesis and the productivity of agricultural crops and forests [26-27]; and calculating the euphotic depth in the ocean [28].

PAR as a component of solar radiation spectrum is extremely important because it is the solar energy source for vegetative photosynthesis to provide mankind with products such as food and fiber sources, biofuels carriers and additional materials sources that support industrial process. PAR also plays significant roles in plant growth, and it is the principal factor in the rate of solar energy conversion into biological mediated energy.

Therefore, PAR is an indispensable atmospheric radiometric flux nature needed for balance distribution of varieties of plants and perfecting the ecosystem in the horizons across different climatic and geographical regions of the world. The oxygen $\left(\mathrm{O}_{2}\right)$ needed by man for respiration is powered by PAR. Thus, the study of PAR is a necessity for understanding how plants, animals and mankind interact and relate with its immediate ecosystem.

Measurement of PAR have been performed in many parts of the world using a variety of instrument such as Eppley precision spectral pyrometer (PSP) and PAR lite. Apart from these radiometric flux instruments, quantum sensor often used for PAR measurement have problems, such as cosine errors, spectral errors, and the lack of a standard absolute PAR value [29-31].

As a result of cost of measuring equipment, its maintenance and calibration requirements, in rural and developing countries in Africa and several places around the 
world, a worldwide routine network for the measurement of PAR on like global solar radiation is not yet established. In order to correct these anomalies, different empirical models have been developed [32-34], few of them using satellite data [22, 35]. In another technique, PAR is commonly estimated as a constant ratio of the global solar radiation $(\mathrm{H})$. Numerous authors have studied this ratio [36-43].

Therefore, empirical models that estimate PAR based on global solar radiation $(\mathrm{H})$ are important and are classified into two types. One employed the constant ratio of the global solar radiation $(\mathrm{PAR} / \mathrm{H})$. Depending on weather PAR is expressed in energy units $\left(\mathrm{PAR}^{\mathrm{e}} \mathrm{Wm}^{-2}, \mathrm{MJm}^{-2}\right.$ etc.) or photon units $\left(\mathrm{PAR}^{\mathrm{P}}, \mathrm{E} / \mathrm{mJ}, \mu \mathrm{Em}^{-2} \mathrm{~S}^{-1}\right.$ etc. $)$, there are two types of ratios:

$$
\begin{aligned}
& \frac{P A R^{e}}{H} \text { (unitless) } \\
& \left.\frac{P A R^{p}}{H} \text { (Unit: } \mu \mathrm{molJ} \mathrm{J}^{-1}, \mathrm{E} / \mathrm{mJ}, \mu \mathrm{Em}^{-2} \mathrm{~S}^{-1} \text { etc. }\right)
\end{aligned}
$$

According to Walczak et al. [44], since the photosynthetic efficiency of green plants is directly proportional to the number of photons absorbed in the spectral range (400$700 \mathrm{~nm}$ ) and not to their energy, therefore, it is more convenient to express PAR using photon number e.g. $\mu \mathrm{Em}^{-2} \mathrm{~S}^{-1}$ (quanta $\mathrm{mol}^{-1} \mathrm{~s}^{-1}$ or $\mu \mathrm{mol}^{-1} \mathrm{~s}^{-1}$ ) than radiant energy $\left(\mathrm{Wm}^{-2}\right.$, $\left.\mathrm{MJm}^{-2}\right)$.

In addition to the above mentioned ratio, the following conversion ratio has been employed [4, 45-46]:

$$
\frac{P_{P A R^{p}}}{P_{A R}^{e}} \text { (Unit: } \mu \mathrm{molJ}^{-1}, \mathrm{E} / \mathrm{mJ}, \mu \mathrm{Em}^{-2} \mathrm{~S}^{-1} \text { etc.) }
$$

McCree [45] recorded the value of $P A R^{p} / P A R^{e}$ as $4.57 \mu \mathrm{molJ}^{-1}$. Assuming this value to be constant, many studies [47-48] have applied it. However, Jacovides et al. [46] and Dye [4] reported slightly different values $-4.53 \mu \mathrm{molJ}^{-1}$ and $4.56 \mu \mathrm{molJ}^{-1}$, respectively. Although these values are quite similar, the influence of ${ }_{A A R} p / \operatorname{PAR}^{e}$ on climatic conditions is not well documented. As a result, Akitsu et al. [49] observed that $P A R P / P_{A} e$ may change within $3 \%$ around McCree's constant value $\left(4.57 \mu \mathrm{molJ}^{-1}\right)$ in response to changes in water vapour pressure, solar zenith angle and clearness index. Thus, Akitsu et al. [49] recommended the use of McCree's value as it have been accepted by numerous researchers, though the ratio is not strictly constant.

However, numerous researchers have observed that PAR ratio varied according to location [48]; seasons [43, 50]; sky conditions [51-53]; sky clearness, sky brightness and atmospheric depth for the solar beam [54-55]; relative sunshine duration and water vapour pressure [50, 55]; altitude [56]; irradiance intensity [57]; day length [57-58]; Ozone and other atmospheric gases [53, 58-59]; relative humidity [60], minimum and maximum temperature [61]; optical air mass [62-64]; cloud amount and turbidity [55]; global solar radiation [41, 65-67]; clearness index [48, 68-73]; site, season, local time and weather conditions [49]. Thus, each ratio remains incompletely understood as to how it varies with 
climatic factors such as water vapour pressure (WVP); solar zenith angle ( $\Theta$ ) and sky cloudiness. Therefore, it is practically difficult to assume reasonable values of these ratio at specific sites and in specific seasons.

For these reasons, numerous studies have employed meteorological parameters, geographical parameters, geometrical factors and astronomical parameters as a single variable or combine parameters to relate with $\mathrm{PAR}, \mathrm{PAR} / \mathrm{H}, \mathrm{PAR}$ fraction $\left(\mathrm{PAR} / \mathrm{PAR} \mathrm{R}_{\mathrm{o}}\right.$ ) or PAR coefficient $\left(\mathrm{PAR} / \mathrm{H}_{\mathrm{o}}\right.$ ) etc. (where $\mathrm{H}_{\mathrm{o}}$ and $\mathrm{PAR}_{\mathrm{o}}$ are the extraterrestrial solar radiation and extraterrestrial PAR respectively) for their estimation [41, 50, 55,61-62, 64-67, 74].

However, solar radiation components have been estimated using different artificial neural network (ANN) techniques in recent decades which constitute a widely accepted method offering an alternative way to synthesize complex problems associated with solar energy estimation such as applying only calculable atmospheric, meteorological, astronomical, geographical, geometrical parameters such as extraterrestrial solar radiation, latitude, altitude, longitude, maximum sunshine duration, azimuth angle, solar declination, cosine of solar zenith angle, and hour angle to estimate PAR. The capacity of ANN technique to accept many input parameters for a particular model which is not possible applying empirical technique that strengthened its reliability is one of highest discoveries and attainment of solar energy researchers in recent times. Moreover, the technique of applying ANN models compared to conventional techniques according to recent studies [75-77] have offer greater accuracy with estimation error in a range (less than $20 \%$ ) and could be very good in terms of PAR estimation as much more ANN and other soft computing approaches are demanding in the domain of renewable energy resource estimation.

Therefore, the main purpose of the study was to review empirical models fitted in literature for estimating PAR at numerous geographical locations distributed around the globe and its objectives are identifying several input parameters and functional forms ever applied for estimating PAR across the globe; classify the empirical models commonly employed across the globe according to the main input parameters; compare the performance of empirical and ANN computing models applied and decide the best technique that can yield high accuracies of estimation for future purposes and finally identify the research gap.

Thus, this review would be helpful to solar energy researchers to identify and determine to a large extent the numerous utilized input parameters and functional forms with their corresponding categories ever applied for estimating PAR across the globe and also recognize their significance.

\section{Model Parameters}

Basic parameters such as maximum sunshine duration, daily and hourly extraterrestrial solar radiation on the horizontal surfaces, hourly and daily PAR, standard atmospheric pressure at sea level $(1013 \mathrm{hPa})$, solar constant, zenith angle, clearness of the sky $(\varepsilon)$, and brightness of the skylight $(\Delta)$ are significant for the models employed in this 
review for estimating PAR. The maximum sunshine duration is expressed mathematically as:

$$
\begin{aligned}
& S_{o}=\frac{2}{15} \cos ^{-1}[-\tan \delta \tan \phi] \\
& \delta=23.45 \sin \left[\frac{360(n+284)}{365}\right]
\end{aligned}
$$

where $\phi$ is the latitude, $\delta$ is the solar declination given by Yaniktepe and Genc [78] and $\mathrm{n}$ the number of days of the year starting from first January. The daily extraterrestrial solar radiation is the solar radiation intercepted by horizontal surface during a day without the atmosphere and hourly extraterrestrial radiation has similar definition.

Hourly extraterrestrial solar radiation on the horizontal surface is given by Zhang et al. [79] as:

$$
I_{O}=\frac{12 \times 3600 \times I_{S C}}{\pi}\left(1+0.033 \cos \frac{360 n}{365}\right) \times\left(\cos \phi \cos \delta\left(\sin \omega_{2}-\sin \omega_{1}\right) \sin \omega_{S}+\frac{\pi\left(\omega_{2}-\omega_{1}\right)}{180} \sin \phi \sin \delta\right)
$$

While the daily extraterrestrial solar radiation on the horizontal surface is given by Yaniktepe and Genc [78] as:

$$
H_{O}=\frac{24}{\pi} I_{S C}\left(1+0.033 \cos \frac{360 n}{365}\right) \times\left(\cos \phi \cos \delta \sin \omega_{S}+\frac{2 \pi \omega_{S}}{360} \sin \phi \sin \delta\right)
$$

Where the mean sunrise hour angle $\left(\omega_{s}\right)$ can be evaluated as:

$$
\omega_{s}=\cos ^{-1}[-\tan \delta \tan \phi]
$$

ISC is the solar constant, $\omega_{1}$ and $\omega_{2}$ are the limit hour angle of an hour, in which $\omega_{2}$ is the larger, all in degrees and other symbols retain their usual meaning.

Hourly extraterrestrial PAR flux $\left(\mathrm{PAR}_{\mathrm{o}}\right)$ according to Frouin and Pinker [15] and $\mathrm{Hu}$ et al. [80] can be estimated from extraterrestrial solar radiation $\left(\mathrm{H}_{\mathrm{o}}\right)$, with a fraction of 0.5 . Therefore, hourly and daily $\mathrm{PAR}_{\mathrm{o}}$ can be calculated by multiplying the ratio 4.57 of the energy flux density to photosynthetic photon flux density as suggested by Dye [4].

Thus, the hourly $\mathrm{PAR}_{\mathrm{o}}$ can be expressed as:

$$
P A R_{O}=0.5 \times 4.57\left(I_{O}\right)
$$

And daily $\mathrm{PAR}_{0}$ can be calculated as:

$$
P A R_{O}=0.5 \times 4.57\left(H_{O}\right)
$$

The sky clearness $(\varepsilon)$ and brightness of the skylight $(\Delta)$ can be evaluated as proposed by Wang et al. [71]:

$$
\begin{aligned}
& \varepsilon=\frac{H_{d}+H_{b}}{H_{d}} \\
& \Delta=\frac{H_{d}}{H_{b} \cos (\theta)}
\end{aligned}
$$

The cosine of sun zenith angle $(\theta)$ is expressed as:

$$
\cos (\theta)=(\cos \delta \cos \phi \cos \omega+\sin \delta \sin \phi)
$$


While the relative optical mass $(m)$ can be calculated as proposed by Wang et al. [71]:

$$
m=\frac{1}{\cos (\theta)+0.15(93.885-\theta)^{-1.253}}
$$

Where $H_{d}$ and $H_{b}$ are the diffuse and direct radiation on the earth horizontal surface and other symbols retain their usual meaning.

\section{Evaluation Metrics}

Evaluation, principally, compares how good the observed and estimated fit each other. This evaluation is applied at numerous steps of the computing model development as for instance during the evaluation of the estimation model itself (during the training of a statistical model for instance), for judging the improvement of the computing model after some modifications and for comparing numerous computing models. As previously mentioned, this performance comparison is not easy for numerous reasons such as different estimated time horizons, numerous time scale of the estimated data and variability of the meteorological conditions from one site to another one. It works by comparing the estimated outputs $\hat{y}$ ) with observed data y which are also measured data themselves linked to an error (or precision) of a measure.

Graphic tools are available for estimating the adequacy of the computing model with the experimental measurements via:

1. Time series of estimated global radiation in comparison with measured global radiation which allows to visualize easily the prediction quality. In Fig. 1a, for instance, a high estimate accuracy in clear-sky conditions and a low one in partly cloudy conditions can be seen.

2. Scatter plots of estimated over measured global radiation (as shown in Fig. 1b) which can reveal systematic bias and deviations depending on the global radiation conditions and show the range of deviations that are related to the estimates.

3. Receiver Operating Characteristic (ROC) curves which compare the rates of true positives and false positive. 

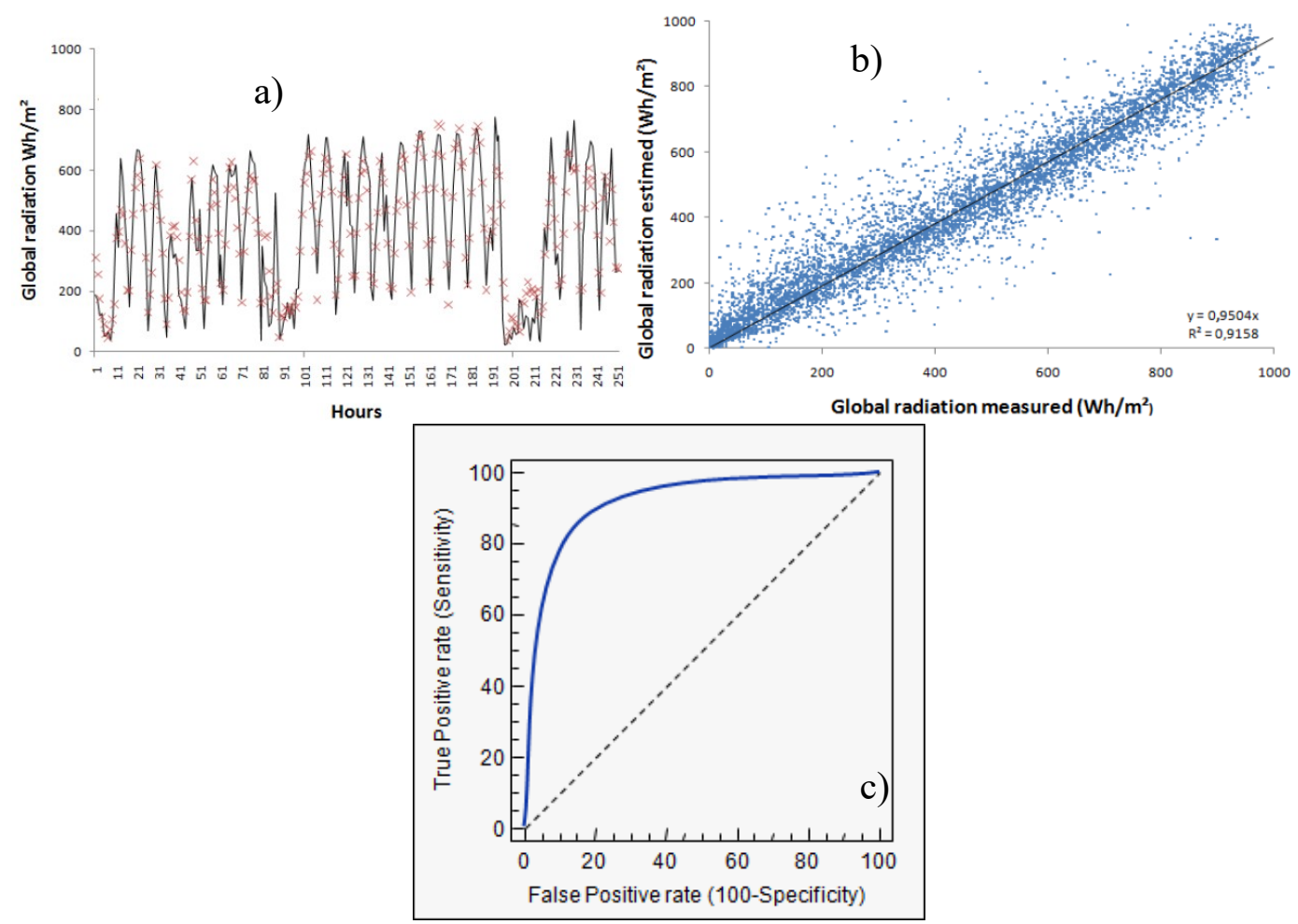

Figure 1: a) Time series of predicted and measured global radiation for 2008 in Ajaccio (France); b) Scatter plot of predicted vs. measured global radiation in Ajaccio (France); c) Example of ROC curve (an ideal ROC curve is near the upper left corner) Lauret et al. [81].

Up till now, there is no standard evaluation measures accepted for photosynthetically active radiation measurement, which makes the comparison of the estimating methods difficult. Sperati et al. [82] presented a benchmarking exercise within the framework of the European Actions Weather Intelligence for Renewable Energies (WIRE) with the purpose of evaluating the performance of state of the art computing models for short term renewable energy estimation or forecasting. This research is a very good example of reliability parameter utilization. They concluded that: "More work using more test cases, data and computing models needs to be performed in order to achieve a global overview of all possible conditions. They also pointed out that test cases located all over Europe, the US and other relevant countries should be considered, in an effort to represent most of the possible meteorological conditions". This study therefore illustrates very well the difficulties of performance comparisons encountered for photosynthetically active radiation estimation.

The commonly applied statistics for photosynthetically active radiation estimation include the following:

The mean bias error (MBE) represents the mean bias of the estimation:

$$
M B E=\frac{1}{N} \times \sum_{i=1}^{N}(\hat{y}(i)-y(i))
$$


with $\hat{y}$ is the estimated photosynthetically active radiation, $\mathrm{y}$ the measured photosynthetically active radiation and $\mathrm{N}$ the number of observations. The estimation will under-estimate or over-estimate the observations. Thus, MBE is not a good statistical indicator for the relatability of a computing model because the errors compensate each other but it allows to see how much it overestimates or underestimates.

The mean absolute error (MAE) is appropriate for comparing photosynthetically active radiation estimation with linear cost functions, i.e., where the costs resulting from a poor estimation are proportional to the estimation error:

$$
M A E=\frac{1}{N} \times \sum_{i=1}^{N}|\hat{y}(i)-y(i)|
$$

The mean square error (MSE) applies the squared of the difference between observed and predicted data. This statistical indicator penalizes the highest gaps:

$$
M S E=\frac{1}{N} \times \sum_{i=1}^{N}(\hat{y}(i)-y(i))^{2}
$$

MSE is principally the statistical parameter which is minimized by the training algorithm.

The root mean square error (RMSE) is more sensitive to big estimation errors, and thus is good for applications where small errors are more tolerable and larger errors cause disproportionately high costs, as in the case of utility applications [83]. It is probably the reliability parameter that is most appreciated and employed:

$$
R M S E=\sqrt{M S E}=\sqrt{\frac{1}{N} \times \sum_{i=1}^{N}(\hat{y}(i)-y(i))^{2}}
$$

The mean absolute percentage error (MAPE) is close to the MAE but each gap between observed and predicted value is divided by the observed value so as to consider the relative gap.

$$
\text { MAPE }=\frac{1}{N} \times \sum_{i=1}^{N}\left|\frac{\hat{y}(i)-y(i)}{y(i)}\right|
$$

This statistical indicator has a challenge that it is unstable when $y(i)$ is near zero and it cannot be defined for $\mathrm{y}(\mathrm{i})=0$.

Of recent, these errors are normalized particularly for the RMSE; as reference the mean value of global radiation is generally employed but other definitions can be applied:

$$
n R M S E=\frac{\sqrt{\frac{1}{N} \times \sum_{i=1}^{N}(\hat{y}(i)-y(i))^{2}}}{\bar{y}}
$$

with $\bar{y}$ is the mean value of $y$. Other statistical indicators exist and can be employed as the correlation coefficient $(\mathrm{R})$, coefficient of determination $\left(\mathrm{R}^{2}\right)$, or the index of agreement $(\mathrm{d})$ which are normalized between 0 and 1 .

As the estimation accuracy strongly depends on the location and time period applied for evaluation and on other parameters, it is difficult to evaluate the quality of an estimation from accuracy metrics alone. Then, it is the best to compare the accuracy of different estimations against a common set of test data Pelland et al. [84]. "Trivial" estimation approach can be applied as a reference [83], the most common one is the 
persistence model ("things stay the same", Trapero et al. [85] where the estimation is always equal to the last known data point. The photosynthetically active radiation has a deterministic component due to the geometrical path of the sun. This characteristic may be included as a constraint to the simplest form of persistence in considering as an example, the measured data of the previous day or the previous hour at the same time as an estimation value. Other common reference forecasts include those based on climate constants and simple autoregressive methods. Such comparison with referenced NWP computing model is shown in Figure 2. Generally, after 1 hour the forecast is better than persistence. For forecast horizons of more than two days, climate averages show lower errors and should be preferred for photosynthetically active radiation estimation.

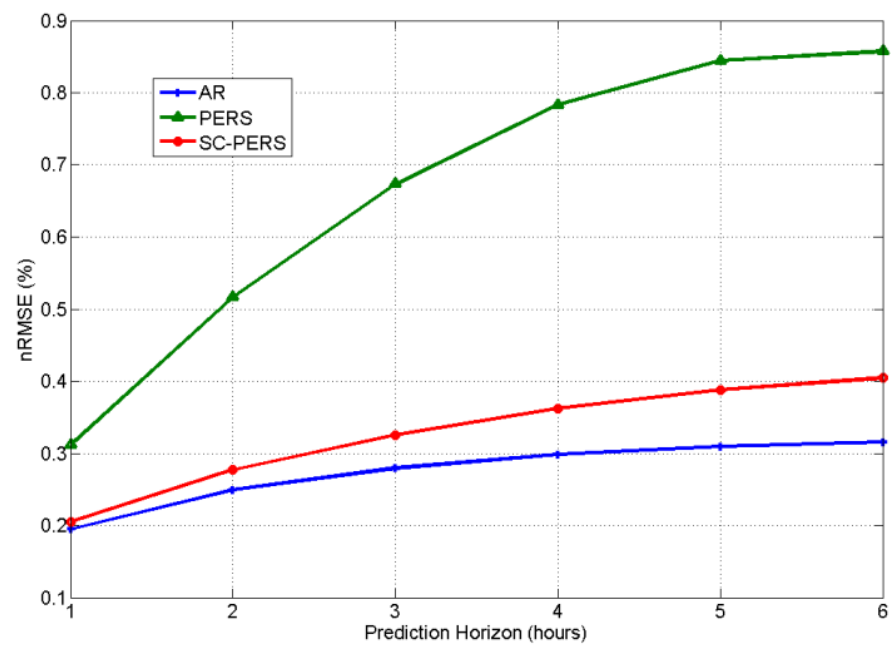

Figure 2: Relative RMSE of forecasts (persistence, auto regression, and scaled persistence) and of reference models depending on the forecast horizon Lauret et al. [81].

Classically, a comparison of performance is performed with a reference computing model and to do it, a skill factor is employed. The skill factor or skill score defines the difference between the forecast and the reference forecast normalized by the difference between a perfect and the reference forecast Lauret et al. [81]:

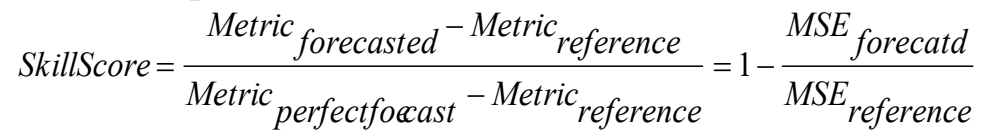

Its value thus ranges between 1 (perfect forecast) and 0 (reference forecast). A negative value indicates a performance which is even worse compared to the reference (observed data). Skill scores can be adopted not only for comparison between observed and estimated PAR values but also for inter-comparisons of different photosynthetically active radiation estimation techniques. 


\section{Empirical Models}

An empirical model correlates $\mathrm{PAR}, \mathrm{PAR} / \mathrm{H}, \mathrm{PAR} / \mathrm{PAR}$ and $\mathrm{PAR} / \mathrm{H}_{\mathrm{o}}$ with other easily measureable and calculable parameters such as clearness index, global solar radiation, relative humidity, minimum and maximum temperature, optical air mass, cloud amount, water vapour pressure, turbidity, sunshine duration and combination of the above parameters by employing concise mathematical functions. Numerous empirical models have been reported in literature for estimating PAR on the horizontal surface either on hourly mean basis (HB) or daily mean basis (DB) or monthly mean daily basis (MB) across the globe. In this review, the PAR models are classified according to the basis of their input parameters applied in correlating with $\mathrm{PAR}, \mathrm{PAR} / \mathrm{H}, \mathrm{PAR} / \mathrm{PAR}$ and $\mathrm{PAR} / \mathrm{H}_{0}$. it has been established that PAR is relatively influenced by meteorological parameters, astronomical factors, geographical factors, and geometrical factors. This could be attributed to the uniqueness of local climate in determining the atmospheric and meteorological parameters that best fit that particular locality. This also depends on the availability of input meteorological/atmospheric parameters that a given radiometric station or an individual is capable of measuring or calculating routinely which finally turned out to be the best input parameter at the disposal of the researcher for estimating PAR in that locality. Thus, in this review, the empirical models for estimating PAR can be classified into ten (10) following categories based on the applied meteorological and atmospheric parameters via:

1. Global solar radiation-based models

2. Relative humidity-based models

3. Temperature-based models

4. Optical air mass-based models

5. Cloud amount-based models

6. Water vapour pressure-based models

7. Turbidity-based models

8. Sunshine duration-based models

9. Clearness index-based models

10. Hybrid parameter-based models

\subsection{Global Solar Radiation-Based Models}

Since PAR is a component of global solar radiation $(\mathrm{H})$ on the horizontal surface, solar radiation researcher applied it for estimating PAR and the ratio of PAR/H as a result of its great important and influence for determining the PAR striking a particular location at the top of the atmosphere and its comprehensive impact on PAR on the horizontal surface. Thus, the functional forms and models employed across the globe are presented in this section.

\subsubsection{Group 1}

Empirical models from this group are parameterized as the ratio of photosynthetically active radiation $\left({ }_{P A R}^{p}\right)$ to global solar radiation $(H)$ expressed in photon 
units ( $\mu \mathrm{molJ}^{-1}, \mathrm{E} \mathrm{MJ}^{-1}$ etc.) according to their developing year. The functional form is given as:

$\operatorname{PAR}^{p}=a(H)$

Where a is the regression coefficient

McCree [36] developed the following MB model for New Zealand as:

$P A R^{p}=2.70(H)$

Monteith [86] developed the following DB model for the tropics under clear sky as:

$\operatorname{PAR}^{p}=2.23(H)$

Szeicz [57] proposed the following DB model from January-December for Cambridge, UK as:

$P A R^{p}=2.33(H)$

Britton and Dodd [56] developed the following DB model for January-December in College Station, TX, USA as:

$$
P_{A R}{ }^{p}=2.17(H)
$$

Kanas as:

Hodges and Kanemasu [87] proposed the following DB model for Manhattan,

$$
P_{A R}^{p}=2.17(H)
$$

Stanhill and Fuchs [88] obtained the following HB models for numerous locations.

For Rockeville, MD, USA (January-December)

${ } A R^{p}=2.24(H)$

For Washington DC (January-December)

$$
\text { PAR }^{p}=2.23(\mathrm{H})
$$

For Jerusalem, Isreal (January-December)

PAR $^{p}=2.19(H)$

For Dar es Salaan, Tanzania (October-January)

$$
\text { PAR }^{p}=2.33(H)
$$

For Washington, Rockville and Jerusalem

$$
\text { PAR }^{p}=2.24(H)
$$

Arkin et al. [89] stimulated the following DB model for Temple, Texas as:

$$
{ } A R^{p}=2.89(H)
$$

Hodges et al. [90] reported the following DB model for Manhattan, Kanas as:

$$
{ } A R^{p}=2.55(H)
$$
USA as:

Howell et al. [91] proposed the following DB models for University of California

$$
P_{A R}^{p}=2.058(H)
$$

Kvifte et al. [92] established the following DB models for several locations as follows: 
For Copenhagen, Denmark

${ } A R^{p}=2.239(H)$

For Aas, Norway

${ }_{P A R}{ }^{p}=2.194(H)$

For Ultuna, Sweden (May-October)

$\operatorname{PAR}^{p}=2.102(H)$

For Reykjavik, Iceland (May-October)

$P_{A R}{ }^{p}=2.102(H)$

For Sodankyla, Finland (May-October)

${ }_{P A R}{ }^{p}=2.194(H)$

For Tromso, Norway (May-October)

PAR $^{p}=2.056(H)$

Rodskjer [93] established the following DB model for Ultuna, Sweden as:

$\operatorname{PAR}^{p}=2.125(H)$

Meek et al. [41] obtained the following MB mo

$(42 \mathrm{~m})$

Finch et al. [43] obtained thee following DB models under various sky conditions for Lusaka, Zambia as follows:

For clear sky

$\operatorname{PAR}^{p}=1.914(H)$

For cloudy sky

$\operatorname{PAR}^{p}=2.111(H)$

Wang et al. [54] reported the following MB model for Naeba Mountain in China as:

${ } A R^{p}=1.94(H)$

Wang et al. [71] recorded the following MB models in Wuhan, China

For January

PAR $^{p}=1.70(\mathrm{H})$

For February

PAR $^{p}=1.73(\mathrm{H})$

For March

PAR $^{p}=1.78(H)$

For April

PAR $^{p}=1.87(H)$

For May

PAR $^{p}=1.92(H)$

For June

Tr Ren Energy, 2018, Vol.4, No.2, 236-327. doi: 10.17737/tre.2018.4.2.0079 
PAR $^{p}=1.97(H)$

For July

$P A R^{p}=2.00(H)$

For August

$P A R^{p}=2.06(H)$

For September

PAR $^{p}=1.96(H)$

For October

${ } A R^{p}=1.92(H)$

For November

PAR $^{p}=1.83(H)$

For December

PAR $^{p}=1.75(H)$

For January-December

PAR $^{p}=1.93(H)$

For Dry Seasons

PAR $^{p}=1.78(H)$

For Humid season

PAR $^{p}=1.95(H)$

For clear sky

$\operatorname{PAR}^{p}=1.78(H)$

For intermediate

PAR $^{p}=1.94(H)$

For cloudy

$P A R^{p}=2.01(H)$

Wang et al. [98] reported the following MB models for Wuhan in Central China.

For January

$\operatorname{PAR}^{p}=1.81(H)$

For July

$P A R^{p}=2.0(H)$

For December

$\operatorname{PAR}^{p}=1.83(H)$

For January-December

$\operatorname{PAR}^{p}=1.90(H)$

Anjorin et al. [99] fitted the following HB models for Jos, Nigeria as follows:

Tr Ren Energy, 2018, Vol.4, No.2, 236-327. doi: 10.17737/tre.2018.4.2.0079 
For January

PAR $^{p}=1.92(H)$

For February

PAR $^{p}=2.06(H)$

For March

PAR $^{p}=2.10(H)$

For April

PAR $^{p}=2.14(H)$

For May

PAR $^{p}=2.15(H)$

For June

PAR $^{p}=2.14(H)$

For July

PAR $^{p}=2.11(H)$

For August

PAR $^{p}=2.09(H)$

For September

$P_{A R}{ }^{p}=2.11(H)$

For October

PAR $^{p}=2.13(H)$

For November

PAR $^{p}=2.06(H)$

For December

PAR $^{p}=1.96(H)$

For January-December

PAR $^{p}=2.08(H)$

$\mathrm{Hu}$ and Wang [62] estimated the following MB models for Sangjiang, Hailun and Changbai Mountain in Northeast China.

For Sangjiang

For January

$\operatorname{PAR}^{p}=1.83(H)$

For February

$\operatorname{PAR}^{p}=1.82(H)$

For March

$P A R^{p}=1.83(H)$ 
For April

$P_{A R}{ }^{p}=1.89(H)$

For May

PAR $^{p}=1.97(H)$

For June

PAR $^{p}=1.99(H)$

For July

$\operatorname{PAR}^{p}=2.01(H)$

For August

${ } A R^{p}=1.97(H)$

For September

$\operatorname{PAR}^{p}=1.96(H)$

For October1

$P_{A R}{ }^{p}=1.91(H)$

For November

PAR $^{p}=1.85(H)$

For December

$P_{A R}{ }^{p}=1.86(H)$

For HB

$P{ }^{p}=1.81(H)$

For Hailun

For January

${ } A R^{p}=1.73(H)$

For February

${ } A R^{p}=1.74(H)$

For March

PAR $^{p}=1.79(H)$

For April

$P A R^{p}=1.93(H)$

For May

$P_{A R}{ }^{p}=1.92(H)$

For June

PAR $^{p}=1.98(H)$

For July

PAR $^{p}=2.00(H)$

Tr Ren Energy, 2018, Vol.4, No.2, 236-327. doi: 10.17737/tre.2018.4.2.0079 
For August

${ }_{P A R}{ }^{p}=1.93(H)$

For September

PAR $^{p}=1.87(\mathrm{H})$

For October

PAR $^{p}=1.92(H)$

For November

$\operatorname{PAR}^{p}=1.84(H)$

For December

${ } A R^{p}=1.81(H)$

For Changbai Mountain

For January

PAR $^{p}=1.84(H)$

For February

PAR $^{p}=1.89(H)$

For March

$\operatorname{PAR}^{p}=1.90(H)$

For April

$P_{A R}{ }^{p}=2.01(H)$

For May

$P_{A R}{ }^{p}=2.01(H)$

For June

PAR $^{p}=2.04(H)$

For July

PAR $^{p}=2.04(H)$

For August

$P_{A R}{ }^{p}=2.01(H)$

For September

$\operatorname{PAR}^{p}=1.98(H)$

For October

$P A R^{p}=1.93(H)$

For November

PAR $^{p}=1.92(H)$

For December

$P_{A R}{ }^{p}=1.92(H)$

Tr Ren Energy, 2018, Vol.4, No.2, 236-327. doi: 10.17737/tre.2018.4.2.0079 
Pankoew et al. [100] obtained the following HB model across UK using MSG SEVIRI data as:

$$
\text { PAR }^{p}=1.9455(H)
$$

Wang et al. [63] obtained the following HB and DB models for Inner Mongolia, China from 1990 to 2012

\section{Hourly basis (HB)}

For January

$$
\text { PAR }^{p}=1.78(H)
$$

For February

$$
{ }_{P A R^{p}}=1.84(H)
$$

For March

$$
{ }_{P A R^{p}}=1.80(H)
$$

For April

$$
{ }_{P A R^{p}}=1.74(H)
$$

For May

$$
{ } A R^{p}=1.76(H)
$$

For June

$$
{ } A R^{p}=1.83(H)
$$

For July

$$
P A R^{p}=1.86(H)
$$

For August

$$
{ }_{P A R^{p}}=1.89(H)
$$

For September

PAR $^{p}=1.88(H)$

For October

$$
{ } A R^{p}=1.87(H)
$$

For November

${ } A R^{p}=1.80(H)$

For December

$$
{ } A R^{p}=1.69(H)
$$

For January-December

$$
{ } A R^{p}=1.80(H)
$$

\section{Daily basis (DB)}

For January

$$
{ } A R^{p}=1.73(H)
$$

For February 
$\operatorname{PAR}^{p}=1.79(H)$

For March

${ }_{P A R}{ }^{p}=1.79(H)$

For April

PAR $^{p}=1.70(H)$

For May

PAR $^{p}=1.76(H)$

For June

PAR $^{p}=1.83(H)$

For July

PAR $^{p}=1.86(H)$

For August

PAR $^{p}=1.89(H)$

For September

PAR $^{p}=1.88(H)$

For October

${ } A R^{p}=1.85(H)$

For November

PAR $^{p}=1.80(H)$

For December

PAR $^{p}=1.68(H)$

For January-December

$\operatorname{PAR}^{p}=1.80(H)$

Akitsu et al. [49] stimulated the following MB models for Tsukuba, Japan.

For Summer period (a wet season):

$P A R^{p}=2.12(H)$

For Winter (a dry season)

$P A R^{p}=1.92(H)$

Peng et al. [101] proposed the following MB models for Lhasa located on the Tibetan Plateau in China as follows:

For January

$P_{A R}{ }^{p}=1.81(H)$

For July

$P A R^{p}=2.0(H)$

For December 
PAR $^{p}=1.83(H)$

For January-December

$\operatorname{PAR}^{p}=1.84(H)$

Hu et al. [64] fitted the following HB models for several stations in Beijing site as follows:

For Beijing

$P_{A R}{ }^{p}=1.88(H)$

For Luancheng

$\operatorname{PAR}^{p}=1.80(H)$

For Yuchen

$\operatorname{PAR}^{p}=1.87(H)$

For Jiaozhouwan

${ }_{P A R}{ }^{p}=1.95(H)$

For Changwu

$\operatorname{PAR}^{p}=1.89(H)$

For Fengqin

$\operatorname{PAR}^{p}=1.85(H)$

Nwokolo and Ogbulezie [70] calibrated the following MB models for several locations in Nigeria.

\section{Gusau}

For January

PAR $^{p}=1.921(H)$

For February

$\operatorname{PAR}^{p}=1.908(H)$

For March

PAR $^{p}=1.923(H)$

For April

$\operatorname{PAR}^{p}=1.933(H)$

For May

$\operatorname{PAR}^{p}=1.968(H)$

For June

$\operatorname{PAR}^{p}=1.954(H)$

For July

PAR $^{p}=1.984(H)$

For August 
$\operatorname{PAR}^{p}=1.982(H)$

For September

${ } A R^{p}=1.946(H)$

For October

${ }{ }_{A R}{ }^{p}=1.928(H)$

For November

PAR $^{p}=1.890(H)$

For December

PAR $^{p}=1.889(H)$

For January-December

$\operatorname{PAR}^{p}=1.936(\mathrm{H})$

For Rainy Seasons

$P_{A R}{ }^{p}=1.956(H)$

For Dry season

$P_{A R}{ }^{p}=1.909(H)$

Port Harcourt

For January

$P_{A R}{ }^{p}=1.950(H)$

For February

$P_{A R}{ }^{p}=1.955(H)$

For March

${ }_{P A R}{ }^{p}=1.980(H)$

For April

$P_{A R}{ }^{p}=1.987(H)$

For May

$P_{A R}{ }^{p}=2.010(H)$

For June

$P_{A R}{ }^{p}=2.052(H)$

For July

${ }_{P A R}{ }^{p}=2.060(H)$

For August

${ } A R^{p}=2.044(H)$

For September

${ }_{P A R}{ }^{p}=2.054(H)$

For October

Tr Ren Energy, 2018, Vol.4, No.2, 236-327. doi: 10.17737/tre.2018.4.2.0079 
PAR $^{p}=2.038(H)$

For November

${ }{ }^{p}{ }^{p}=1.999(H)$

For December

${ } A R^{p}=1.960(H)$

For January-December

PAR $^{p}=2.007(H)$

For Rainy Seasons

${ } A R^{p}=2.027(H)$

For Dry season

${ }_{P A R}{ }^{p}=1.980(H)$

Enugu

For January

${ } A R^{p}=1.985(H)$

For February

PAR $^{p}=1.973(H)$

For March

${ }_{P A R}{ }^{p}=1.972(H)$

For April

$P_{A R}{ }^{p}=1.961(H)$

For May

${ }_{P A R}{ }^{p}=1.966(H)$

For June

${ }_{P A R}{ }^{p}=1.976(H)$

For July

${ } A R^{p}=2.003(H)$

For August

$P_{A R}{ }^{p}=2.005(H)$

For September

$P_{A R}{ }^{p}=2.001(H)$

For October

${ }_{P A R}{ }^{p}=2.041(H)$

For November

${ }{ }_{A R}{ }^{p}=1.971(H)$

For December

Tr Ren Energy, 2018, Vol.4, No.2, 236-327. doi: 10.17737/tre.2018.4.2.0079 
$P_{A R}{ }^{p}=1.977(H)$

For January-December

${ }_{P A R}{ }^{p}=1.986(H)$

For Rainy Seasons

${ }_{P A R}{ }^{p}=1.983(H)$

For Dry season

${ } A R^{p}=1.989(H)$

Abeokuta

For January

${ } A R^{p}=1.938(H)$

For February

${ } A R^{p}=1.936(H)$

For March

${ }{ }_{A R}{ }^{p}=1.944(H)$

For April

${ } A R^{p}=1.968(H)$

For May

${ } A R^{p}=1.975(H)$

For June

$P_{A R}{ }^{p}=1.997(H)$

For July

PAR $^{p}=2.025(H)$

For August

${ }_{P A R}{ }^{p}=2.011(H)$

For September

${ }{ }_{A R}{ }^{p}=2.039(H)$

For October

$P_{A R}{ }^{p}=1.981(H)$

For November

${ }{ }_{A R}{ }^{p}=1.952(H)$

For December

${ }_{P A R}{ }^{p}=1.927(H)$

For January-December

${ } A R^{p}=1.975(H)$

For Rainy Seasons

Tr Ren Energy, 2018, Vol.4, No.2, 236-327. doi: 10.17737/tre.2018.4.2.0079 
$P_{A R}{ }^{p}=1.995(H)$

For Dry season

${ }_{P A R}{ }^{p}=1.947(H)$

(53aam)

Ilorin

For January

PAR $^{p}=1.917(H)$

For February

${ }{ }_{A R}{ }^{p}=1.922(H)$

For March

PAR $^{p}=1.923(H)$

For April

${ }_{P A R}{ }^{p}=1.934(H)$

For May

${ } A R^{p}=1.946(H)$

For June

${ } A R^{p}=1.966(H)$

For July

$P_{A R}{ }^{p}=1.989(H)$

For August

$P_{A R}{ }^{p}=2.005(H)$

For September

${ }_{P A R}{ }^{p}=2.004(H)$

For October

${ }_{P A R}{ }^{p}=1.946(H)$

For November

${ } A R^{p}=1.918(H)$

For December

${ } A R^{p}=1.906(H)$

For January-December

${ } A R^{p}=1.943(H)$

For Rainy Seasons

${ } A R^{p}=1.967(H)$

For Dry season

${ }{ }_{A R}{ }^{p}=1.922(H)$

Sokoto

Tr Ren Energy, 2018, Vol.4, No.2, 236-327. doi: 10.17737/tre.2018.4.2.0079 
For January

${ } A R^{p}=1.917(H)$

(53aaac)

For February

${ }_{P A R}{ }^{p}=1.907(H)$

For March

${ } A R^{p}=1.905(H)$

For April

${ } A R^{p}=1.915(H)$

For May

${ } A R^{p}=1.909(H)$

For June

${ } A R^{p}=1.919(H)$

For July

${ } A R^{p}=1.935(H)$

For August

${ } A R^{p}=1.955(H)$

For September

${ }_{P A R}{ }^{p}=1.934(H)$

For October

$P_{A R}{ }^{p}=1.926(H)$

For November

${ }{ }_{A R}{ }^{p}=1.911(H)$

For December

${ } A R^{p}=1.916(H)$

For January-December

PAR $^{p}=1.921(H)$

For Rainy Seasons

$P_{A R}{ }^{p}=1.931(H)$

For Dry season

$P_{A R}{ }^{p}=1.914(H)$

\subsubsection{Group 2}

Empirical models from this group are parameterized as the ratio of photosynthetically active radiation $\left(P A R^{e}\right)$ to global solar radiation $(H)$ expressed in energy (unitless) according to their developing year. The functional form is given as: 
$P A R^{e}=a(H)$

where $\mathrm{a}$ is the regression coefficient

Moon [36] computed spectral distribution of direct sunlight for sea level and suggested the ratio of PAR to $\mathrm{H}$ as:

$P A R^{e}=0.44(H)$

Yocum et al. [102] established the following MB model for Ithaca, NY, USA in the month of August as:

$P A R^{e}=0.47(H)$

Williams [103] obtained the following MB model for a wide variety of climatic conditions as:

$\operatorname{PAR}^{e}=0.45(H)$

Goldberg and Klein [104] fitted the following DB model between JanuaryDecember for Jerusalem, Israel and Rockeville, MD, USA.

For Jerusalem, Israel

$\operatorname{PAR}^{e}=0.45(H)$

For Rockeville, MD, USA

$P A R^{e}=0.45(H)$

Stigter and Musabilha [105] established the following HB models for Dar es

Salaam, Tanzania under various sky conditions

For clear sky

$P A R^{e}=0.510(H)$

For cloudy sky

$P A R^{e}=0.630(H)$

Rao [51] developed the following HB model for Corvallis, Oregon, USA under various sky conditions and from January-December.

For January-December

$P_{A R}{ }^{e}=0.46(H)$

For clear sky

$P A R^{e}=0.443(H)$

For partially cloudy sky

$P A R^{e}=0.447(H)$

For cloudy sky

$P A R^{e}=0.483(H)$

Hansen [106] reported the following DB model for Aas, Norway (May-August) as:

$\operatorname{PAR}^{e}=0.44(H)$ 
Papaioannou et al. [52] reported the following DB and HB models for Anthens, Greece under various sky conditions

\section{Hourly Basis (HB)}

For clear sky

$P A R^{e}=0.480(H)$

For cloudy sky

$P A R^{e}=0.490(H)$

Daily Basis (DB)

For clear sky

$P A R^{e}=0.463(H)$

For cloudy sky

$P_{A R}{ }^{e}=0.472(H)$

Papaioannou et al. [107] reported the following MB model for Anthens, Greece as:

$\operatorname{PAR}^{e}=0.43(H)$

Zhou et al. [108] fitted the following HB models for Yucheng, China under varying local standard time (hours).

For January, 1992 (08:00)

$P A R^{e}=0.39(H)$

For January, 1992 (09:00)

PAR $^{e}=0.42(H)$

For January, 1992 (10:00)

$P A R^{e}=0.43(H)$

For January, 1992 (11:00)

$\operatorname{PAR}^{e}=0.42(H)$

For January, 1992 (12:00)

$P_{A R}^{e}=0.43(H)$

For January, 1992 (13:00)

$P_{A R}{ }^{e}=0.43(H)$

For January, 1992 (14:00)

PAR $^{e}=0.43(H)$

For January, 1992 (15:00)

$P A R^{e}=0.42(H)$

For January, 1992 (16:00)

PAR $^{e}=0.42(H)$

For July, 1991 (07:00)

$P A R^{e}=0.47(H)$

Tr Ren Energy, 2018, Vol.4, No.2, 236-327. doi: 10.17737/tre.2018.4.2.0079 
For July, 1991 (08:00)

$P A R^{e}=0.50(H)$

For July, 1991 (09:00)

$\operatorname{PAR}^{e}=0.51(H)$

For July, 1991 (10:00)

$\operatorname{PAR}^{e}=0.52(H)$

For July, 1991 (11:00)

$\operatorname{PAR}^{e}=0.53(H)$

For July, 1991 (12:00)

$\operatorname{PAR}^{e}=0.51(H)$

For July, 1991 (13:00)

$P_{A R}^{e}=0.51(H)$

For July, 1991 (14:00)

$P_{A R}^{e}=0.51(H)$

For July, 1991 (15:00)

$\operatorname{PAR}^{e}=0.52(H)$

For July, 1991 (16:00)

$P A R^{e}=0.51(H)$

For July, 1991 (17:00)

$\operatorname{PAR}^{e}=0.49(H)$

For July, 1991 (18:00)

$\operatorname{PAR}^{e}=0.45(H)$

Jacovides et al. [53] stimulated the following DB and HB models for Athalassa, Cyprus under various sky conditions

Hourly Basis (HB)

For Cloudy Sky

$P A R^{e}=0.411(H)$

For cloudy sky

$$
P A R^{e}=0.440(H)
$$

\section{Daily Basis (DB)}

For Clear sky

$P A R^{e}=0.408(H)$

For intermediate sky

$P A R^{e}=0.421(H)$

For Overcast 
$\operatorname{PAR}^{e}=0.440(H)$

Tsubo and Walker [48] established the following HB and DB models for Bloemfontein, South Africa.

For Daily Basis (DB)

PAR $^{e}=0.48(H)$

For Hourly Basis (HB)

PAR $^{e}=0.49(H)$

Aguiar et al. [66] proposed the following MB models for Fazenda Noosa Sen hora in Rondonia.

For January

$P A R^{e}=0.48(H)$

For February

$P A R^{e}=0.48(H)$

For March

$P A R^{e}=0.48(H)$

For April

$P A R^{e}=0.47(H)$

For May

$P A R^{e}=0.47(H)$

For June

$P A R^{e}=0.46(H)$

For July

$P A R^{e}=0.46(H)$

For August

$P A R^{e}=0.44(H)$

For September

$P A R^{e}=0.43(H)$

For October

$P A R^{e}=0.46(H)$

For November

$P A R^{e}=0.47(H)$

For December

$P A R^{e}=0.47(H)$

For Dry Season

$P A R^{e}=0.43(H)$ 
For Rainy Season

$\operatorname{PAR}^{e}=0.48(H)$

Jacovides et al. [109] developed the following HB models for Athens, Greece under various sky conditions

For clear sky

$P_{A R}{ }^{e}=0.434(H)$

For intermediate sky

$P A R^{e}=0.442(H)$

For cloudy sky

$P A R^{e}=0.461(H)$

Escobedo et al. [110] developed the following DB and HB under various sky conditions at Botucatu, Brazil.

\section{Hourly Basis (HB)}

$$
\begin{array}{ll}
P A R^{e}=0.501(H) & H / H_{O} \leq 0.35 \\
P A R^{e}=0.495(H) & 0.35<H / H_{O} \leq 0.55 \\
P A R^{e}=0.490(H) & 0.55<H / H_{O} \leq 0.65 \\
P A R^{e}=0.489(H) & H / H_{O}>0.63 \\
P A R^{e}=0.491(H) & 0 \leq H / H_{O} \leq 1
\end{array}
$$

For clear sky

$P A R^{e}=0.489(H)$

For cloudy sky

$$
P A R^{e}=0.501(H)
$$

\section{Daily Basis (DB)}

$$
\begin{array}{ll}
P A R^{e}=0.512(H) & H / H_{O} \leq 0.35 \\
P A R^{e}=0.496(H) & 0.35<H / H_{o} \leq 0.55 \\
P A R^{e}=0.490(H) & 0.55<H / H_{o} \leq 0.65 \\
P A R^{e}=0.485(H) & H / H_{O}>0.63 \\
P A R^{e}=0.489(H) & 0 \leq H / H_{o} \leq 1
\end{array}
$$

For clear sky

$$
P A R^{e}=0.481(H)
$$

For cloudy sky

$$
P_{A R}^{e}=0.512(H)
$$


Li et al. [55] stimulated the following HB models for Wuhaoliang site in Northern Tibetan Plateau, China under various local standard time (hours).

For January, 1994-1997 (08:00)

$\operatorname{PAR}^{e}=0.50(H)$

For January, 1994-1997 (09:00)

$\operatorname{PAR}^{e}=0.46(H)$

For January, 1994-1997 (10:00)

$P A R^{e}=0.44(H)$

For January, 1994-1997 (11:00)

PAR $^{e}=0.43(H)$

For January, 1994-1997 (12:00)

$\operatorname{PAR}^{e}=0.42(H)$

For January, 1994-1997 (13:00)

$P_{A R}{ }^{e}=0.42(H)$

For January, 1994-1997 (14:00)

PAR $^{e}=0.41(H)$

For January, 1994-1997 (15:00)

PAR $^{e}=0.40(H)$

For January, 1994-1997 (16:00)

PAR $^{e}=0.39(H)$

For January, 1994-1997 (17:00)

PAR $^{e}=0.49(H)$

For July, 1994-1997 (07:00)

$P_{A R}{ }^{e}=0.50(H)$

For July, 1994-1997 (08:00)

$\operatorname{PAR}^{e}=0.48(H)$

For July, 1994-1997 (09:00)

$P A R^{e}=0.46(H)$

For July, 1994-1997 (10:00)

PAR $^{e}=0.45(H)$

For July, 1994-1997 (11:00)

$\operatorname{PAR}^{e}=0.44(H)$

For July, 1994-1997 (12:00)

$\operatorname{PAR}^{e}=0.43(H)$

For July, 1994-1997 (13:00)

Tr Ren Energy, 2018, Vol.4, No.2, 236-327. doi: 10.17737/tre.2018.4.2.0079 
$P A R^{e}=0.43(H)$

For July, 1994-1997 (14:00)

PAR $^{e}=0.43(H)$

For July, 1994-1997 (15:00)

$P_{A R}{ }^{e}=0.42(H)$

For July, 1994-1997 (16:00)

$P_{A R}{ }^{e}=0.41(H)$

For July, 1994-1997 (17:00)

$\operatorname{PAR}^{e}=0.38(H)$

For July, 1994-1997 (18:00)

$\operatorname{PAR}^{e}=0.36(H)$

Guefeng et al. [111] fitted the following DB model within the Poyang Lake National Nature Reserve, China as:

$\operatorname{PAR}^{e}=0.45(H)$

Escobedo et al. [112] fitted the following HB and DB models for Botucatu, Brazil

Hourly Basis (HB)

For 2001

$P A R^{e}=0.4896(H)$

For 2002

$P A R^{e}=0.4892(H)$

For 2003

$P A R^{e}=0.4866(H)$

For 2004

$P A R^{e}=0.5000(H)$

For 2001-2004

$P A R^{e}=0.491(H)$

Daily Basis (DB)

For 2001

$P_{A R}^{e}=0.4919(H)$

For 2002

$P A R^{e}=0.4887(H)$

For 2003

$P A R^{e}=0.4893(H)$

For 2004

$P A R^{e}=0.4926(H)$

Tr Ren Energy, 2018, Vol.4, No.2, 236-327. doi: 10.17737/tre.2018.4.2.0079 
For 2001-2004

$P A R^{e}=0.489(H)$

Wang et al. [9] stimulated the following MB models under different sky conditions in Wuhan, Central China

For January

$$
\begin{array}{ll}
P A R^{e}=0.3940(H) & H / H_{O} \leq 0.35 \\
P A R^{e}=0.3787(H) & 0.35 \leq H / H_{o}<0.65 \\
P A R^{e}=0.3764(H) & H / H_{O} \geq 0.65
\end{array}
$$

For February

$$
\begin{array}{ll}
P A R^{e}=0.3997(H) & H / H_{O} \leq 0.35 \\
P A R^{e}=0.3631(H) & 0.35 \leq H / H_{O}<0.65
\end{array}
$$

For March

$$
\begin{array}{ll}
P A R^{e}=0.3985(H) & H / H_{O} \leq 0.35 \\
P A R^{e}=0.3751(H) & 0.35 \leq H / H_{o}<0.65 \\
P A R^{e}=0.3745(H) & H / H_{O} \geq 0.65
\end{array}
$$

For April

$$
\begin{array}{ll}
P A R^{e}=0.41(H) & H / H_{O} \leq 0.35 \\
P A R^{e}=0.3848(H) & 0.35 \leq H / H_{o}<0.65 \\
P A R^{e}=0.3832(H) & H / H_{O} \geq 0.65
\end{array}
$$

For May

$$
\begin{array}{ll}
P A R^{e}=0.4156(H) & H / H_{O} \leq 0.35 \\
P A R^{e}=0.3919(H) & 0.35 \leq H / H_{o}<0.65 \\
P A R^{e}=0.3877(H) & H / H_{O} \geq 0.65
\end{array}
$$

For June

$$
\begin{array}{ll}
P A R^{e}=0.4217(H) & H / H_{o} \leq 0.35 \\
P A R^{e}=0.3947(H) & 0.35 \leq H / H_{o}<0.65
\end{array}
$$

For July

$$
\begin{array}{ll}
P A R^{e}=0.4377(H) & H / H_{O} \leq 0.35 \\
P A R^{e}=0.4114(H) & 0.35 \leq H / H_{o}<0.65 \\
P A R^{e}=0.4011(H) & H / H_{O} \geq 0.65
\end{array}
$$

For August 


$$
\begin{array}{ll}
P A R^{e}=0.4236(H) & H / H_{O} \leq 0.35 \\
P A R^{e}=0.4107(H) & 0.35 \leq H / H_{o}<0.65 \\
P A R^{e}=0.4146(H) & H / H_{O} \geq 0.65
\end{array}
$$

For September

$$
\begin{array}{ll}
P A R^{e}=0.4313(H) & H / H_{O} \leq 0.35 \\
P_{A} R^{e}=0.3994(H) & 0.35 \leq H / H_{O}<0.65 \\
P A R^{e}=0.3838(H) & H / H_{O} \geq 0.65
\end{array}
$$

For October

$$
\begin{array}{ll}
P A R^{e}=0.4245(H) & H / H_{O} \leq 0.35 \\
P A R^{e}=0.3847(H) & 0.35 \leq H / H_{o}<0.65 \\
P A R^{e}=0.3771(H) & H / H_{O} \geq 0.65
\end{array}
$$

For November

$$
\begin{array}{ll}
P A R^{e}=0.4173(H) & H / H_{O} \leq 0.35 \\
P A R^{e}=0.3751(H) & 0.35 \leq H / H_{o}<0.65 \\
P A R^{e}=0.3885(H) & H / H_{O} \geq 0.65
\end{array}
$$

For December

$$
\begin{array}{ll}
\operatorname{PAR}^{e}=0.3966(H) & H / H_{o} \leq 0.35 \\
\operatorname{PAR}^{e}=0.3639(H) & 0.35 \leq H / H_{o}<0.65
\end{array}
$$

Bat-Oyun et al. [59] reported the following MB models for Mongolian grassland.

For January

$P A R^{e}=0.425(H)$

For February

$P A R^{e}=0.437(H)$

For March

$$
P A R^{e}=0.427(H)
$$

For April

$P A R^{e}=0.420(H)$

For May

$$
P A R^{e}=0.421(H)
$$

For June

$$
P A R^{e}=0.448(H)
$$

For July 
$P A R^{e}=0.459(H)$

For August

$P A R^{e}=0.439(H)$

For September

$P_{A R}{ }^{e}=0.438(H)$

For October

$P A R^{e}=0.449(H)$

For November

$P A R^{e}=0.429(H)$

For December

$P A R^{e}=0.423(H)$

For January-December

$P A R^{e}=0.435(H)$

For Growing Seasons (May-August)

$P A R^{e}=0.442(H)$

For cloudy sky

$P A R^{e}=0.456(H) \quad H / H_{o}<0.33$

For partly cloudy sky

$P A R^{e}=0.439(H) \quad 0.33<H / H_{O} \leq 0.67$

For clear sky

$P A R^{e}=0.430(H) \quad H / H_{O}>0.67$

For All sky

$$
P A R^{e}=0.434(H) \quad 0 \leq H / H_{o} \leq 1
$$

Abolfazi [61] obtained the following MB model for Southern Iran (JanuaryDecember) as:

$P A R^{e}=0.584(H)$

$\mathrm{Yu}$ and Guo [76] fitted the following HB models for Bonville, Illinois and Sioux Falls, South Dakota in Midwestern United States under various sky conditions.

For Bonville, Illinois

$$
\begin{array}{ll}
P A R^{e}=0.463(H) & H / H_{O} \leq 0.35 \\
P A R^{e}=0.429(H) & 0.35 \leq H / H_{o}<0.65 \\
P A R^{e}=0.416(H) & H / H_{O} \geq 0.65 \\
P A R^{e}=0.422(H) & 0 \leq H / H_{O} \leq 1
\end{array}
$$

For Sioux Falls, South Dakota 


$$
\begin{array}{ll}
P A R^{e}=0.475(H) & H / H_{o} \leq 0.35 \\
P A R^{e}=0.446(H) & 0.35 \leq H / H_{o}<0.65 \\
P A R^{e}=0.433(H) & H / H_{o} \geq 0.65 \\
P A R^{e}=0.438(H) & 0 \leq H / H_{o} \leq 1
\end{array}
$$

Akitsu et al. [49] recorded the following MB models for Tsukuba, Japan.

For Summer Period (a wet season)

$$
P A R^{e}=0.465(H)
$$

For Winter Period (a dry season)

$$
P A R^{e}=0.420(H)
$$

Yu et al. [113] established the DB model for several locations in the contiguous United States under various sky conditions.

For Bonville, Illinois

$$
\begin{array}{ll}
P A R^{e}=0.4642(H) & H / H_{o} \leq 0.3 \\
P A R^{e}=0.4271(H) & 0.3<H / H_{o}<0.7 \\
P A R^{e}=0.4169(H) & H / H_{o} \geq 0.7 \\
P A R^{e}=0.4169(H) & \text { All Sky }
\end{array}
$$

For Desert Rock, Nevada

$$
\begin{array}{ll}
P A R^{e}=0.4906(H) & H / H_{o} \leq 0.3 \\
P A R^{e}=0.4486(H) & 0.3<H / H_{o}<0.7 \\
P A R^{e}=0.4346(H) & H / H_{o} \geq 0.7 \\
P A R^{e}=0.4371(H) & \text { All Sky }
\end{array}
$$

For Fort Pecks, Montana

$$
\begin{array}{ll}
P A R^{e}=0.4767(H) & H / H_{o} \leq 0.3 \\
P A R^{e}=0.4447(H) & 0.3<H / H_{o}<0.7 \\
P A R^{e}=0.4360(H) & H / H_{o} \geq 0.7 \\
P A R^{e}=0.4415(H) & \text { All Sky }
\end{array}
$$

For Goodwin Creek/Mississippi

$$
\begin{array}{ll}
P A R^{e}=0.4623(H) & H / H_{o} \leq 0.3 \\
P A R^{e}=0.4317(H) & 0.3<H / H_{o}<0.7 \\
P A R^{e}=0.4220(H) & H / H_{o} \geq 0.7 \\
P A R^{e}=0.4284(H) & \text { All Sky }
\end{array}
$$

Tr Ren Energy, 2018, Vol.4, No.2, 236-327. doi: 10.17737/tre.2018.4.2.0079 
For Penn, State University, Pennsylvania

$$
\begin{array}{ll}
P A R^{e}=0.4519(H) & H / H_{o} \leq 0.3 \\
P A R^{e}=0.4221(H) & 0.3<H / H_{o}<0.7 \\
P A R^{e}=0.4116(H) & H / H_{o} \geq 0.7 \\
P A R^{e}=0.4196(H) & \text { All Sky }
\end{array}
$$

For Sioux Falls, South Dakota

$$
\begin{array}{ll}
P A R^{e}=0.4714(H) & H / H_{o} \leq 0.3 \\
P A R^{e}=0.4452(H) & 0.3<H / H_{o}<0.7 \\
P A R^{e}=0.4370(H) & H / H_{o} \geq 0.7 \\
P A R^{e}=0.4409(H) & \text { All Sky }
\end{array}
$$

For Table Mountain, Boulder, Colorado

$$
\begin{array}{ll}
P A R^{e}=0.4626(H) & H / H_{o} \leq 0.3 \\
P A R^{e}=0.4301(H) & 0.3<H / H_{o}<0.7 \\
P A R^{e}=0.4231(H) & H / H_{o} \geq 0.7 \\
P A R^{e}=0.4266(H) & \text { All Sky }
\end{array}
$$

For All Sites

$$
\begin{array}{ll}
P A R^{e}=0.4638(H) & H / H_{o} \leq 0.3 \\
P A R^{e}=0.4342(H) & 0.3<H / H_{o}<0.7 \\
P A R^{e}=0.4286(H) & H / H_{o} \geq 0.7 \\
P A R^{e}=0.4381(H) & \text { All Sky }
\end{array}
$$

Nigeria.

Nwokolo et al. [70] calibrated the following MB models for several locations in

\section{Port Harcourt}

For January

$$
P A R^{e}=0.4682(H)
$$

For February

$$
P A R^{e}=0.4712(H)
$$

For March

$$
P A R^{e}=0.4838(H)
$$

For April

$$
P A R^{e}=0.4886(H)
$$

For May 
$P A R^{e}=0.4983(H)$

For June

$P A R^{e}=0.5199(H)$

For July

$P A R^{e}=0.5231(H)$

For August

PAR $^{e}=0.5127(H)$

For September

$P A R^{e}=0.5204(H)$

For October

$P A R^{e}=0.5134(H)$

For November

PAR $^{e}=0.4949(H)$

For December

$P A R^{e}=0.4738(H)$

For January-December

$P A R^{e}=0.4974(H)$

For Dry Season

$P A R^{e}=0.4843(H)$

For Rainy Season

$P A R^{e}=0.5064(H)$

Enugu

For January

$P A R^{e}=0.4880(H)$

For February

$P A R^{e}=0.4820(H)$

For March

$P A R^{e}=0.4811(H)$

For April

$P A R^{e}=0.4751(H)$

For May

$P A R^{e}=0.4726(H)$

For June

$P A R^{e}=0.4833(H)$

For July

Tr Ren Energy, 2018, Vol.4, No.2, 236-327. doi: 10.17737/tre.2018.4.2.0079 
$P A R^{e}=0.4974(H)$

For August

$P A R^{e}=0.4982(H)$

For September

$P A R^{e}=0.4965(H)$

For October

$P A R^{e}=0.5027(H)$

For November

$P A R^{e}=0.4807(H)$

For December

$P A R^{e}=0.4841(H)$

For January-December

$P A R^{e}=0.4868(H)$

For Dry Season

$P A R^{e}=0.4875(H)$

For Rainy Season

$P A R^{e}=0.4863(H)$

Abeokuta

For January

$P A R^{e}=0.4542(H)$

For February

$P A R^{e}=0.4601(H)$

For March

$P A R^{e}=0.4640(H)$

For April

$P A R^{e}=0.4780(H)$

For May

$P A R^{e}=0.4814(H)$

For June

$P A R^{e}=0.4925(H)$

For July

$P A R^{e}=0.5047(H)$

For August

$P A R^{e}=0.5103(H)$

For September

Tr Ren Energy, 2018, Vol.4, No.2, 236-327. doi: 10.17737/tre.2018.4.2.0079 
$P A R^{e}=0.5032(H)$

For October

$P A R^{e}=0.4877(H)$

For November

$P A R^{e}=0.4643(H)$

For December

PAR $^{e}=0.4542(H)$

For January-December

$P_{A R}^{e}=0.4798(H)$

For Dry Season

$P A R^{e}=0.4641(H)$

For Rainy Season

$P A R^{e}=0.4906(H)$

\section{Ilorin}

For January

$P A R^{e}=0.4486(H)$

For February

$P A R^{e}=0.4520(H)$

For March

$P A R^{e}=0.4559(H)$

For April

$P A R^{e}=0.4614(H)$

For May

$P A R^{e}=0.4663(H)$

For June

$P A R^{e}=0.4713(H)$

For July

$P A R^{e}=0.4884(H)$

For August

$P A R^{e}=0.4953(H)$

For September

$P A R^{e}=0.4796(H)$

For October

$P A R^{e}=0.4665(H)$

For November

Tr Ren Energy, 2018, Vol.4, No.2, 236-327. doi: 10.17737/tre.2018.4.2.0079 
$P A R^{e}=0.4433(H)$

(78aad)

For December

$P A R^{e}=0.4414(H)$

(78aae)

For January-December

$P A R^{e}=0.4647(H)$

For Dry Season

$P A R^{e}=0.4504(H)$

For Rainy Season

$P A R^{e}=0.4740(H)$

(78aah)

Sokoto

For January

$P A R^{e}=0.4492(H)$

(78aai)

For February

$P A R^{e}=0.4438(H)$

For March

$P A R^{e}=0.4419(H)$

(78aak)

For April

$P A R^{e}=0.4430(H)$

(78aaL)

For May

$P A R^{e}=0.4444(H)$

(78aam)

For June

PAR ${ }^{e}=0.4500(H)$

For July

$P A R^{e}=0.4596(H)$

(78aao)

For August

$P A R^{e}=0.4715(H)$

For September

$P A R^{e}=0.4595(H)$

For October

$P A R^{e}=0.4545(H)$

For November

$P A R^{e}=0.4453(H)$

For December

$P A R^{e}=0.4483(H)$

For January-December

Tr Ren Energy, 2018, Vol.4, No.2, 236-327. doi: 10.17737/tre.2018.4.2.0079 
PAR $^{e}=0.4535(H)$

For Dry Season

$P A R^{e}=0.4480(H)$

(78aav)

For Rainy Season

$P A R^{e}=0.5580(H)$

(78aaw)

Bauchi

For January

$P A R^{e}=0.4489(H)$

(78aax)

For February

$P A R^{e}=0.4481(H)$

(78aay)

For March

PAR $^{e}=0.4523(H)$

(78aaz)

For April

$P A R^{e}=0.4566(H)$

(78aaaa)

For May

$P A R^{e}=0.4535(H)$

(78aaab)

For June

$P A R^{e}=0.4534(H)$

(78aaac)

For July

$P A R^{e}=0.4636(H)$

(78aaad)

For August

$P A R^{e}=0.4625(H)$

(78aaae)

For September

$P A R^{e}=0.4596(H)$

(78aaaf)

For October

$P A R^{e}=0.4502(H)$

(78aaag)

For November

$P A R^{e}=0.4466(H)$

(78aaah)

For December

$P A R^{e}=0.4463(H)$

For January-December

$P_{A R}{ }^{e}=0.4974(H)$

(78aaaj)

For Dry Season

$P A R^{e}=0.4482(H)$

(78aaak)

For Rainy Season

Tr Ren Energy, 2018, Vol.4, No.2, 236-327. doi: 10.17737/tre.2018.4.2.0079 
$\operatorname{PAR}^{e}=0.4528(H)$

(78aaaL)

\subsubsection{Group 3}

Empirical models from this group are parameterized as the first-order polynomial function of the global solar radiation where photosynthetically active radiation $\left(P_{A R}{ }^{p}\right)$ is expressed in photon units $\left(\mu \mathrm{molJ} \mathrm{J}^{-1}, \mathrm{E} \mathrm{MJ}^{-1}\right.$ etc.) and photosynthetically active radiation $\left({ }_{P A R}{ }^{e}\right)$ is expressed in energy terms as shown below in the following forms:

$P A R^{p}=a(H)+b$

$P A R^{e}=a(H)+b$

where $\mathrm{a}$ and $\mathrm{b}$ are the regression coefficients and other symbols retain their usual meaning.

Meek et al. [41] fitted the following MB model for Fresno-West side located at the University of California, USA as:

$P_{A R}{ }^{p}=2.017(H)+0.163$

Aguiar et al. [66] obtained the following HB and DB models for Fazenda Nossa Senhora in Rondonia.

For Hour Basis, HB

$$
\begin{array}{ll}
\operatorname{PAR}^{e}=0.478(H)+0.747 & \\
P A R^{e}=0.471(H)-1.0689 & \text { (wet season) } \\
P A R^{e}=0.452(H)-4.578 & \text { (dry season) } \\
P^{e}=0.466(H)-0.877 & \text { (dry-wet season) }
\end{array}
$$

For Daily Basis, DB

$$
\begin{array}{ll}
P A R^{e}=0.466(H)+4.956 & \text { (wet season) } \\
P A R^{e}=0.466(H)+0.735 & \text { (wet-dry season) } \\
P A R^{e}=0.457(H)-6.762 & \text { (dry season) } \\
P A R^{e}=0.452(H)+4.244 & \text { (dry-wet season) }
\end{array}
$$

Finch et al. [67] obtained the following MB model for Zambia as:

$$
\operatorname{PAR}^{p}=1.8807(H)+1.9749
$$

Aguiar et al. [65] fitted the following HB and DB models for pasture and forest sites in South West Amazonia.

For Pasture Site (Hourly Basis, HB)

$$
\begin{array}{ll}
P A R^{e}=0.283(H)+0.474 & \text { (wet season) } \\
P A R^{e}=-0.88818(H)+0.467 & \text { (wet-dry season) } \\
P A R^{e}=-4.192(H)+0.449 & \text { (dry season) } \\
P A R^{e}=-1.160(H)+0.464 & \text { (dry-wet season) }
\end{array}
$$

Tr Ren Energy, 2018, Vol.4, No.2, 236-327. doi: 10.17737/tre.2018.4.2.0079 
$P A R^{e}=-1.162(H)+0.462$

(Annual)

For Forest Site (Hourly Basis, HB)

$$
\begin{array}{ll}
P A R^{e}=-0.407(H)+0.423 & \text { (wet season) } \\
P A R^{e}=0.766(H)+0.420 & \text { (wet-dry season) } \\
P A R^{e}=-3.444(H)+0.432 & \text { (dry season) } \\
P A R^{e}=0.594(H)+0.427 & \text { (dry-wet season) } \\
P A R^{e}=-0.482(H)+0.425 & \text { (Annual) }
\end{array}
$$

For Pasture Site (Daily Basis, DB)

$$
\begin{array}{ll}
P A R^{e}=3.847(H)+0.464 & \text { (wet season) } \\
P A R^{e}=2.363(H)+0.459 & \text { (wet-dry season) } \\
P A R^{e}=-4.044(H)+0.449 & \text { (dry season) } \\
P A R^{e}=5.389(H)+0.447 & \text { (dry-wet season) } \\
P A R^{e}=6.254(H)+0.443 & \text { (Annual) }
\end{array}
$$

For Forest Site (Daily Basis, DB)

$$
\begin{array}{ll}
P A R^{e}=1.881(H)+0.416 & \text { (wet season) } \\
P A R^{e}=-0.154(H)+0.422 & \text { (wet-dry season) } \\
P A R^{e}=-4.017(H)+0.433 & \text { (dry season) } \\
P A R^{e}=2.672(H)+0.422 & \text { (dry-wet season) } \\
P A R^{e}=0.795(H)+0.421 & \text { (Annual) }
\end{array}
$$

Melina-Maria et al. [77] stimulated the following HB model for Greece as:

$P A R^{e}=0.457(H)-7.424$

\subsection{Relative Humidity-Based Models}

Relative humidity-based computing models are often employed for estimating PAR in that it has been observed that when the total energy in the near infrared (NIR) portion of the solar spectrum greatly reduced, relative humidity is almost transparent to PAR wavelength. Thus, increasing global solar radiation in the NIR range will culminate into a lower PAR clearness index in the coastal region and higher PAR clearness index in the interior region. On this ground, it can be inferred that relative humidity can be employed for estimating PAR in geographical regions where relative humidity is greater than $64 \%$ annually. Hence, solar energy researchers have applied this meteorological parameter to stimulate computing models for estimating PAR as presented in this section. Therefore, empirical models from this group are parameterized as the first-order polynomial function 
of the relative humidity $(\mathrm{RH})$ where photosynthetically active radiation $\left(\operatorname{PAR}^{e}\right)$ is expressed in energy terms as shown below in the following form:

$$
\frac{P A R^{e}}{P A R_{O}}=a+b\left(\frac{R H}{100}\right)
$$

where $\mathrm{a}$ and $\mathrm{b}$ are the regression coefficients and other symbols retain their usual meaning.

Nwokolo et al. [60] developed the following MB models for several locations in Nigeria under various seasons and all sky conditions.

For Port Harcourt

$$
\begin{array}{ll}
\frac{P A R^{e}}{P A R_{O}}=2.300-2.209\left(\frac{R H}{100}\right) & \text { (All sky conditions) } \\
\frac{P A R^{e}}{P A R_{O}}=0.118+0.354\left(\frac{R H}{100}\right) & \text { (Rainy season) } \\
\frac{P A R^{e}}{P A R_{O}}=1.597-1.293\left(\frac{R H}{100}\right) & \text { (Dry season) }
\end{array}
$$

For Owerri

$$
\begin{array}{ll}
\frac{P A R^{e}}{P A R_{O}}=1.484-1.167\left(\frac{R H}{100}\right) & \text { (All sky conditions) } \\
\frac{P A R^{e}}{P A R_{O}}=1.277-0.941\left(\frac{R H}{100}\right) & \text { (Rainy season) } \\
\frac{P A R^{e}}{P A R_{O}}=1.074-0.603\left(\frac{R H}{100}\right) & \text { (Dry season) }
\end{array}
$$

For Ikeja

$$
\begin{aligned}
& \frac{P A R^{e}}{P A R_{O}}=1.651-1.364\left(\frac{R H}{100}\right) \quad \text { (All sky conditions) } \\
& \frac{P A R^{e}}{P A R_{O}}=0.990-0.600\left(\frac{R H}{100}\right) \quad \text { (Rainy season) } \\
& \frac{P A R^{e}}{P A R_{O}}=0.997-0.491\left(\frac{R H}{100}\right) \quad \text { (Dry season) }
\end{aligned}
$$

For Abuja

$$
\frac{P A R^{e}}{P A R_{O}}=0.866-0.369\left(\frac{R H}{100}\right) \quad \text { (All sky conditions) }
$$




$$
\begin{array}{ll}
\frac{P A R^{e}}{P A R_{O}}=2.111-1.875\left(\frac{R H}{100}\right) & \text { (Rainy season) } \\
\frac{P A R^{e}}{P A R_{O}}=0.763-0.095\left(\frac{R H}{100}\right) & \text { (Dry season) }
\end{array}
$$

For Maiduguri

$$
\begin{array}{ll}
\frac{P A R^{e}}{P A R_{O}}=0.790-0.247\left(\frac{R H}{100}\right) & \text { (All sky conditions) } \\
\frac{P A R^{e}}{P A R_{O}}=0.661+0.049\left(\frac{R H}{100}\right) & \text { (Rainy season) } \\
\frac{P A R^{e}}{P A R_{O}}=0.816-0.406\left(\frac{R H}{100}\right) & \text { (Dry season) }
\end{array}
$$

For Sokoto

$$
\begin{array}{ll}
\frac{P A R^{e}}{P A R_{O}}=0.779-0.141\left(\frac{R H}{100}\right) & \text { (All sky conditions) } \\
\frac{P A R^{e}}{P A R_{O}}=0.835-0.224\left(\frac{R H}{100}\right) & \text { (Rainy season) } \\
\frac{P A R^{e}}{P A R_{O}}=0.796-0.300\left(\frac{R H}{100}\right) & \text { (Dry season) }
\end{array}
$$

\subsection{Temperature-Based Models}

Temperature-based model is an adaptation of Hargreaves-Samani [114] type computing model for estimating Photosynthetically Active Radiation (PAR) especially where sunshine hour, global solar radiation, data, etc. are not readily available. This could be attributed to the availability of daily mean minimum and maximum temperature in most standard stations around the location of interest; hence, researchers employed this meteorological parameter for estimating PAR on the horizontal surface. The basis of temperature-based computing models is that the differences between the maximum and minimum temperature is directly proportional to the fraction of extraterrestrial PAR received at the surface of the earth. However, other factors that affect temperature difference include cloudiness, relative humidity, elevation, topography, latitude and proximity to a large body of water. In this temperature-based computing model, PAR clearness index is a function of maximum and minimum temperature as show in this section. Therefore, empirical models from this group were calibrated from Hargreaves and Samani [114] computing model where photosynthetically active radiation $\left({ }_{P A R}{ }^{e}\right)$ is expressed in energy terms as shown below in the following form: 


$$
P A R=a H \sqrt{\left(T_{\max }-T_{\min }\right)}
$$

where a being the regression coefficient and $\mathrm{T}_{\max }$ and $\mathrm{T}_{\min }$ are the maximum and minimum temperature and other symbols retain their usual meaning.

Abolfazi [61] calibrated the following MB model for Shiraz University in South Iran as:

$$
P A R=0.0993 H \sqrt{\left(T_{\max }-T_{\min }\right)}
$$

\subsection{Optical Air Mass-Based Models}

Optical air mass-based models have been employed by solar energy researchers for estimating PAR on hourly, daily and monthly time scales as a result of its observable influence on it. PAR changes as atmospheric parameters fluctuate. Experimental reports have revealed that PAR generally decrease with increasing optical air mass and the maxima were achieved when the sky conditions were cloudless. Meanwhile, PAR under clear skies decreased exponentially with optical air mass and the dispersion was much smaller than that under all sky conditions, which implies that PAR can be modelled using an exponential function of optical air mass in any region of the world as presented in these functional forms:

$$
\begin{aligned}
& P A R^{e}=a(m)^{-b} \\
& P A R^{p}=a(m)^{-b}
\end{aligned}
$$

where $\mathrm{m}$ being the optical air mass, $\mathrm{a}$ and $\mathrm{b}$ are the regression coefficients and symbols retain their usual meaning.

Wang et al. [9] stimulated the following DB model for Central China as:

$$
P A R^{e}=1721(\mathrm{~m})^{-1.06}
$$

$\mathrm{Hu}$ and Wang [62] developed the following MB model for Sanjiang in Northeast China under clear sky condition as:

$$
\text { PAR }^{p}=2253.7(\mathrm{~m})^{-1.3}
$$

Wang et al. [63] established the following MB model for Inner Mongolia, China as:

$$
\text { PAR }^{p}=1524.3(\mathrm{~m})^{-0.98}
$$

$\mathrm{Hu}$ et al. [64] fitted the following MB model for North China Plain as:

$$
\operatorname{PAR}^{p}=1886.1(\mathrm{~m})^{-1.1}
$$

\subsection{Cloud Amount-Based Models}

Cloud amount as a climate variable is the fraction of the sky obscured by clouds when observed from a given locality. Cloud amount data are periodically obtained from meteorological stations or satellites-derived and are expressed in percent (\%) of the maximum cloud amount. Cloud amount is mostly classified into several categories of $0-$ $24 \%, 25-49 \%, 50-74 \%$ and $75-100 \%$. The implication is that zero percent implies no visible cloud in the sky while hundred percent cloud amount indicates no clear sky is visible. Researchers in the domain of renewable energy in the past have investigated and 
simulated empirical computing models to relate cloud amount conditions and PAR owing to the fact that as PAR/H increases, cloud amount increases as well. This is because of the absorption of water vapour's waveband selective in the solar spectrum that is, in cloudy and humid conditions, the absorption of solar radiation in the infrared portion of the solar spectrum is enhanced whereas absorption in the PAR waveband does not vary significantly as shown in the relations below.

$$
\frac{P A R^{e}}{H}=a+b(C)
$$

where $\mathrm{a}$ and $\mathrm{b}$ are the regression coefficients, $\mathrm{C}$ is the cloud amount and other symbols retain their usual meaning.

Li et al. [55] obtained the following MB model for Northern Tibetan Plateau, China

as:

$$
\frac{P A R^{e}}{H}=0.4315+0.04581(C)
$$

\subsection{Water Vapour Pressure-Based Models}

Water vapour pressure-based models have been applied by researchers in the domain of renewable energy for estimating PAR in that it causes observable influence on the ratio of $\mathrm{PAR} / \mathrm{H}$. PAR $/ \mathrm{H}$ fluctuates with changes in the atmospheric parameters. Experimental reports have shown that $\mathrm{PAR} / \mathrm{H}$ increases with the increase in water vapour pressure. This could be attributed to the absorption of water vapour's waveband selective in the solar spectrum. That is, in cloudy and humid conditions, the absorption of solar radiation in the near infrared (NIR) portion of the solar spectrum is not vary significantly, hence, an increase in the PAR/H ratio occur under cloudy and humid conditions. Thus, in this section, water vapour is related to $\mathrm{PAR} / \mathrm{H}$ as shown below.

$$
\frac{P A R^{e}}{H}=a+\operatorname{In}\left(E^{*}\right)
$$

where $E^{*}=E \times P / P_{O}$. E is the monthly average value of water vapour pressure at the site. $\mathrm{P}_{\mathrm{o}}$ is the standard atmospheric pressure at the sea level $(1013 \mathrm{hPa}) . \mathrm{P}$ is the monthly average atmospheric pressure at the site. Where $\mathrm{a}$ and $\mathrm{b}$ are the regression coefficients and other symbols retain their usual meaning.

Li et al. [55] fitted the following model for Northern Tibetan Plateau, China as:

$$
\frac{P A R^{e}}{H}=0.4345+0.0087 \operatorname{In}\left(E^{*}\right)
$$

\subsection{Turbidity-Based Models}

Observable influence of turbidity $(\beta c)$ on the ratio of $\mathrm{PAR} / \mathrm{H}$ in recent experimental report have culminated into development of empirical computing models for relating turbidity to ratio of $\mathrm{PAR} / \mathrm{H}$. This could be attributed to the absorption of water vapour pressure and cloud amount waveband selective in the solar spectrum. In cloudy and 
humid conditions, the absorption of solar radiation in the near infrared (NIR) portion of the solar spectrum is enhanced, whereas absorption in the PAR waveband does not vary significantly, thus, an increase in the $\mathrm{PAR} / \mathrm{H}$ ratio is found under cloudy and humid conditions. Therefore, in this section, turbidity is related to $\mathrm{PAR} / \mathrm{H}$ as presented in the functional form below.

$$
\frac{P A R^{e}}{H}=a+b(\beta c)
$$

where $\mathrm{a}$ and $\mathrm{b}$ are the regression coefficients, $\left({ }_{\beta c}\right)$ being turbidity and other symbols retain their usual meaning.

Li et al. [55] fitted the following MB model for Northern Tibetan Plateau, China as:

$$
\frac{P A R^{e}}{H}=0.4547-0.247(\beta c)
$$

\subsection{Sunshine-Based models}

The relative sunshine duration is one of the most commonly employed meteorological parameter for estimating PAR globally since sunshine duration is measured routinely at numerous meteorological stations across the globe, researchers in the domain of renewable energy often apply this parameter for PAR estimating worldwide as presented in this section.

\subsubsection{Group 1}

Empirical models from this group are parameterized as the first-order polynomial function of the sunshine where photosynthetically active radiation $\left(P_{R} R^{p}\right)$ is expressed in photon units ( $\mu \mathrm{molJ}^{-1}, \mathrm{E} \mathrm{MJ}^{-1}$ etc.) and photosynthetically active radiation $\left({ }_{P A R}{ }^{e}\right)$ is expressed in energy terms as shown below in the following forms:

$$
\begin{aligned}
& \frac{P A R^{e}}{H}=a+b\left(\frac{S}{S_{O}}\right) \\
& \frac{P A R^{p}}{H}=a+b\left(\frac{S}{S_{O}}\right) \\
& \frac{P A R^{e}}{P A R_{O}}=a+b\left(\frac{S}{S_{O}}\right) \\
& \frac{P A R^{p}}{P A R_{O}}=a+b\left(\frac{S}{S_{O}}\right)
\end{aligned}
$$

where $\mathrm{a}$ and $\mathrm{b}$ are the regression coefficients, $\left(\frac{S}{S_{o}}\right)$ being sunshine fraction and other symbols retain their usual meaning. 
Udo and Aro [74] established the following MB models for Ilorin, Nigeria between 1993-1994.

For data obtained in 1993

$$
\frac{P A R^{p}}{P A R_{O}}=0.41+1.06\left(\frac{S}{S_{O}}\right)
$$

For data recorded in 1994

$$
\frac{P A R^{p}}{P A R_{O}}=0.53+0.89\left(\frac{S}{S_{O}}\right)
$$

For 1993-1994 data

$$
\frac{P A R^{p}}{P A R_{O}}=0.47+0.99\left(\frac{S}{S_{O}}\right)
$$

For dry season

$$
\frac{P A R^{p}}{P A R_{O}}=0.59+0.76\left(\frac{S}{S_{O}}\right)
$$

For rainy season

$$
\frac{P A R^{p}}{P A R_{O}}=0.39+1.18\left(\frac{S}{S_{O}}\right)
$$

For 1993-1994 data

$$
\frac{P A R^{e}}{P A R_{O}}=0.11+0.22\left(\frac{S}{S_{O}}\right)
$$

Li et al. [55] stimulated the following MB model for Northern Tibetan Plateau, China as:

$$
\frac{P A R^{e}}{H}=0.4861-0.0591\left(\frac{S}{S_{O}}\right)
$$

Abolfazi [61] obtained the following MB model for Shiraz University in South Iran as:

$$
\frac{P A R^{e}}{P A R_{O}}=0.188+0.338\left(\frac{S}{S_{O}}\right)
$$

\subsubsection{Group 2}

Empirical models from this group are parameterized as the second-order polynomial function of the sunshine where photosynthetically active radiation $\left(P_{A R}{ }^{p}\right)$ is expressed in photon units ( $\mu \mathrm{molJ} \mathrm{J}^{-1}, \mathrm{E} \mathrm{MJ}^{-1}$ etc.) as shown below in the following form:

$$
\frac{P A R^{p}}{P A R_{O}}=a+b\left(\frac{S}{S_{O}}\right)+c\left(\frac{S}{S_{O}}\right)^{2}
$$


where $\mathrm{a}, \mathrm{b}$ and $\mathrm{c}$ are the regression coefficients, $\left(\frac{S}{S_{o}}\right)$ being sunshine fraction and other symbols retain their usual meaning.

Udo and Aro [74] established the following MB models for Ilorin, Nigeria between 1993-1994.

$$
\frac{P^{P A R^{p}}}{P A R_{O}}=0.07+2.76\left(\frac{S}{S_{O}}\right)-1.85\left(\frac{S}{S_{O}}\right)^{2}
$$

\subsubsection{Group 3}

Empirical models from this group are parameterized as logarithmic fit of the sunshine where photosynthetically active radiation $\left(P_{A R}{ }^{p}\right)$ is expressed in photon units $\left(\mu \mathrm{molJ} \mathrm{J}^{-1}, \mathrm{E} \mathrm{MJ}^{-1}\right.$ etc.) as shown below in the following form:

$$
\frac{P A R^{p}}{P A R_{O}}=a+b \operatorname{In}\left(\frac{S}{S_{O}}\right)
$$

where $\mathrm{a}$ and $\mathrm{b}$ are the regression coefficients, $\left(\frac{s}{S_{o}}\right)$ being sunshine fraction and other symbols retain their usual meaning.

Udo and Aro [74] established the following MB models for Ilorin, Nigeria between 1993-1994.

$$
\frac{P A R^{p}}{P A R_{O}}=1.29+0.46 \operatorname{In}\left(\frac{S}{S_{O}}\right)
$$

\subsection{Clearness Index-Based Models}

Clearness index $\left(\mathrm{K}_{\mathrm{t}}\right)$ indicates that percentage depletion by the sky of the incoming solar variation and therefore gives both the level of availability of solar radiation and changes in the atmospheric condition in a given environment [1-2]. for this purpose, clearness index is closely related to PAR. Thus, clearness index has been known as a keynote determinant parameter for estimating PAR across the globe. One of the greatest characteristics of the model from this class is their convenient application in that utilizing them involve only measured global solar radiation data. Several functional forms and computing models have been employed for estimating PAR applying this parameter on $\mathrm{HB}, \mathrm{DB}$ and $\mathrm{MB}$ across the globe as outline in this section according to their developing year.

\subsubsection{Group 1}

Empirical models from this group are parameterized as the first-order polynomial function of the clearness index where photosynthetically active radiation $\left(P_{A R}{ }^{e}\right)$ is expressed in energy terms as shown below in the following forms: 


$$
\begin{aligned}
& \frac{P A R^{e}}{P A R_{O}}=a+b\left(\frac{H}{H_{O}}\right) \\
& \frac{P A R^{e}}{H_{O}}=a+b\left(\frac{H}{H_{O}}\right) \\
& \frac{P A R^{e}}{H}=a+b \operatorname{In}\left(\frac{H}{H_{O}}\right)
\end{aligned}
$$

Yu et al. [72] fitted the following MB model for contiguous United States as:

$$
\frac{P A R^{e}}{H}=0.4180-0.04095 \operatorname{In}\left(\frac{H}{H_{O}}\right)
$$

Etuk et al. [68] establish the following MB models for Calabar, Nigeria as follows:

$$
\begin{aligned}
\frac{P A R^{e}}{H_{O}} & =0.001+0.448\left(\frac{H}{H_{O}}\right) \\
\frac{P A R^{e}}{P A R_{O}} & =0.002+1.119\left(\frac{H}{H_{O}}\right)
\end{aligned}
$$

\subsubsection{Group 2}

Empirical models from this group are parameterized as the second-order polynomial function of the sunshine where photosynthetically active radiation $\left(\operatorname{PAR}^{p}\right)$ is expressed in photon units ( $\mu \mathrm{molJ}^{-1}, \mathrm{E} \mathrm{MJ}^{-1}$ etc.) and photosynthetically active radiation $\left({ }_{P A R}{ }^{e}\right)$ is expressed in energy terms as shown below in the following forms:

$$
\begin{aligned}
\frac{P A R^{e}}{H} & =a+b\left(\frac{H}{H_{O}}\right)+c\left(\frac{H}{H_{O}}\right)^{2} \\
\frac{P A R^{p}}{H} & =a+b\left(\frac{H}{H_{O}}\right)+c\left(\frac{H}{H_{O}}\right)^{2} \\
\frac{P A R^{e}}{H_{O}} & =a+b\left(\frac{H}{H_{O}}\right)+c\left(\frac{H}{H_{O}}\right)^{2} \\
\frac{P A R^{e}}{P A R_{O}} & =a+b\left(\frac{H}{H_{O}}\right)+c\left(\frac{H}{H_{O}}\right)^{2} \\
\frac{P A R^{e}}{H} & =a+b \operatorname{In}\left(\frac{H}{H_{O}}\right)+c I n\left(\frac{H}{H_{O}}\right)^{2}
\end{aligned}
$$

Tsubo and Walker [48] fitted the following MB and HB models for Bloemfontein, South Africa.

For Daily Basis (DB) 


$$
\frac{P A R^{p}}{H}=0.635-0.401\left(\frac{H}{H_{O}}\right)+0.150\left(\frac{H}{H_{O}}\right)^{2}
$$

For Hourly Basis (HB)

$$
\frac{P_{A R}^{p}}{H}=0.613-0.334\left(\frac{H}{H_{O}}\right)+0.121\left(\frac{H}{H_{O}}\right)^{2}
$$

Wang et al. [71] established the following HB model for Central China as:

$$
\frac{P A R^{p}}{H}=0.567-0.625\left(\frac{H}{H_{O}}\right)-0.659\left(\frac{H}{H_{O}}\right)^{2}
$$

Yu et al. [72] fitted the following MB model for contiguous United States as:

$$
\frac{P A R^{e}}{H}=0.4287+0.012238 \operatorname{In}\left(\frac{H}{H_{O}}\right)-0.01223 \operatorname{In}\left(\frac{H}{H_{O}}\right)^{2}
$$

Etuk et al. [69] calibrated the following MB models for several locations in Nigeria. For Port Harcourt

$$
\frac{P A R^{e}}{P A R_{O}}=0.001+1.126\left(\frac{H}{H_{O}}\right)-0.001\left(\frac{H}{H_{O}}\right)^{2}
$$

For Enugu

$$
\frac{P A R^{e}}{P A R_{O}}=0.005+1.101\left(\frac{H}{H_{O}}\right)-0.027\left(\frac{H}{H_{O}}\right)^{2}
$$

For Abeokuta

$$
\frac{P^{P A R^{e}}}{P A R_{O}}=-0.001+1.128\left(\frac{H}{H_{O}}\right)-0.003\left(\frac{H}{H_{O}}\right)^{2}
$$

For Ilorin

$$
\frac{P A R^{e}}{P A R_{O}}=0.053+0.919\left(\frac{H}{H_{O}}\right)-0.192\left(\frac{H}{H_{O}}\right)^{2}
$$

For Bauchi

$$
\frac{P A R^{e}}{P A R_{O}}=0.028+1.032\left(\frac{H}{H_{O}}\right)+0.076\left(\frac{H}{H_{O}}\right)^{2}
$$

For Sokoto

$$
\frac{P A R^{e}}{P A R_{O}}=-0.018+1.186\left(\frac{H}{H_{O}}\right)-0.051\left(\frac{H}{H_{O}}\right)^{2}
$$

Etuk et al. [68] proposed the following MB models for Calabar, Nigeria as follows: 


$$
\begin{aligned}
& \frac{P A R^{e}}{P A R_{O}}=0.020+1.034\left(\frac{H}{H_{O}}\right)+0.103\left(\frac{H}{H_{O}}\right)^{2} \\
& \frac{P A R^{e}}{H_{o}}=0.009+0.406\left(\frac{H}{H_{o}}\right)+0.050\left(\frac{H}{H_{o}}\right)^{2}
\end{aligned}
$$

Nwokolo et al. [70] calibrated the following MB models for numerous locations in Nigeria.

For Port Harcourt

$$
\frac{P A R^{e}}{H}=0.614-0.338\left(\frac{H}{H_{O}}\right)+0.126\left(\frac{H}{H_{O}}\right)^{2}
$$

For Enugu

$$
\frac{P A R^{e}}{H}=0.616-0.345\left(\frac{H}{H_{O}}\right)+0.134\left(\frac{H}{H_{O}}\right)^{2}
$$

For Abeokuta

$$
\frac{P A R^{e}}{H}=0.557-0.088\left(\frac{H}{H_{o}}\right)-0.142\left(\frac{H}{H_{o}}\right)^{2}
$$

For Ilorin

$$
\frac{P A R^{e}}{H}=0.576-0.201\left(\frac{H}{H_{o}}\right)+0.007\left(\frac{H}{H_{O}}\right)^{2}
$$

For Sokoto

$$
\frac{P A R^{e}}{H}=0.616-0.343\left(\frac{H}{H_{O}}\right)+0.129\left(\frac{H}{H_{O}}\right)^{2}
$$

For Bauchi

$$
\frac{P A R^{e}}{H}=0.615-0.341\left(\frac{H}{H_{O}}\right)+0.127\left(\frac{H}{H_{O}}\right)^{2}
$$

\subsubsection{Group 3}

Empirical models from this group are parameterized as the third-order polynomial function of the sunshine where photosynthetically active radiation $\left(P_{A R}{ }^{p}\right)$ is expressed in photon units ( $\mu \mathrm{molJ}^{-1}, \mathrm{E} \mathrm{MJ}^{-1}$ etc.) as shown below in the form:

$$
\text { PAR }^{p}=a+b\left(\frac{H}{H_{o}}\right)+c\left(\frac{H}{H_{o}}\right)^{2}+d\left(\frac{H}{H_{o}}\right)^{3}
$$

Wang et al. [98] obtained the following MB model for Wuhan, Central China as: 


$$
\text { PAR }^{p}=28.4+3130.2\left(\frac{H}{H_{O}}\right)-2210.3\left(\frac{H}{H_{O}}\right)^{2}+1926.4\left(\frac{H}{H_{O}}\right)^{3}
$$

Wang et al. [63] developed the following MB model for Inner Mongolia, China from 1990 to 2012 as:

$$
P A R^{p}=110.488+1185.2\left(\frac{H}{H_{O}}\right)+1823.3\left(\frac{H}{H_{O}}\right)^{2}-1470.0\left(\frac{H}{H_{O}}\right)^{3}
$$

Wang et al. [115] proposed the following MB model in China as:

$$
P_{A R}{ }^{p}=58.4+1771.2\left(\frac{H}{H_{O}}\right)+791.3\left(\frac{H}{H_{O}}\right)^{2}-734.4\left(\frac{H}{H_{O}}\right)^{3}
$$

Peng et al. [73] fitted the following MB model for Tibatan Plateau, Lhasa, China as:

$$
\text { PAR }^{p}=88.98+1486.1\left(\frac{H}{H_{O}}\right)+1094.6\left(\frac{H}{H_{O}}\right)^{2}-846.33\left(\frac{H}{H_{O}}\right)^{3}
$$

Hu et al. [116] stimulated the following model for Tibetan Plateau, China as:

$$
\operatorname{PAR}^{p}=73.5+2256.9\left(\frac{H}{H_{O}}\right)+1246.7\left(\frac{H}{H_{O}}\right)^{2}-1182.8\left(\frac{H}{H_{O}}\right)^{3}
$$

\subsection{Hybrid Parameter-Based Models}

In as much as input parameters for estimating PAR on the horizontal surface varies periodically with the local climate in a given geographical location, it therefore indicates that to accurately stimulate a computing model that can fit a specific geographical area, solar energy researchers must test the local climate with various input parameters depending on the availability of the measurable metrological parameters and atmospheric variables at the disposal of the researcher. Numerous solar energy researchers across the globe have observed that hybrid parameter-based computing models fit local climate more than one variable-global solar radiation-based models, relative humidity-based models, temperature-based models, relative humidity-based models, temperature-based models, optical air mass-based models, cloud amount-based models, water vapour pressure-based models, turbidity-based models, sunshine-based models and clearness index-based models employed for estimating PAR. In this section, several hybrid parameter-based models are presented and classified based on their input parameters and developing year.

\subsubsection{Group 1}

In this group, global solar radiation and clearness index were incorporated with PAR in the forms:

$$
P A R^{p}=a(H)+b\left(\frac{H}{H_{O}}\right)+c
$$


$P A R^{e}=a(H)+b\left(\frac{H}{H_{O}}\right)+c$

Aguiar et al. [65] established the following HB models for pasture and forest sites in South Amazonia under hourly and daily time scales.

For Pasture site (Hourly Basis, HB)

$$
\begin{array}{ll}
P A R^{e}=1.146(H)+0.478\left(\frac{H}{H_{O}}\right)-5.547 & \text { (wet season) } \\
P A R^{e}=1.336(H)+0.471\left(\frac{H}{H_{O}}\right)-6.911 & \text { (wet-dry season) } \\
P A R^{e}=-6.633(H)+0.445\left(\frac{H}{H_{O}}\right)+7.669 \text { (dry season) } \\
P A R^{e}=3.904(H)+0.480\left(\frac{H}{H_{O}}\right)-27.641 & \text { (dry-wet season) } \\
P A R^{e}=1.612(H)+0.469\left(\frac{H}{H_{O}}\right)-11.761 & \text { (Annual) }
\end{array}
$$

For Forest Site (Hourly Basis, HB)

$$
\begin{array}{ll}
P A R^{e}=3.074(H)+0.437\left(\frac{H}{H_{O}}\right)-22.882 \text { (wet season) } \\
P A R^{e}=3.121(H)+0.424\left(\frac{H}{H_{O}}\right)-8.042 & \text { (wet-8dry season) } \\
P A R^{e}=-0.8017(H)+0.436\left(\frac{H}{H_{O}}\right)-9.302 & \text { (dry season) } \\
P A R^{e}=5.544(H)+0.447\left(\frac{H}{H_{O}}\right)-32.168 & \text { (dry-wet season) } \\
P A R^{e}=2.939(H)+0.434\left(\frac{H}{H_{O}}\right)-16.509 & \text { (Annual) }
\end{array}
$$

For Pasture Site (Daily Basis, DB)

$$
\begin{array}{ll}
P A R^{e}=3.847(H)+0.466\left(\frac{H}{H_{O}}\right)-1.516 & \text { (wet season) } \\
P A R^{e}=2.737(H)+0.513\left(\frac{H}{H_{O}}\right)-39.827 \text { (wet-dry season) } & \\
P A R^{e}=-0.946(H)+0.335\left(\frac{H}{H_{O}}\right)+79.082 & \text { (dry season) } \\
P A R^{e}=4.109(H)+0.709\left(\frac{H}{H_{O}}\right)-234.374 & \text { (dry-wet season) }
\end{array}
$$


$P A R^{e}=5.257(H)+0.479\left(\frac{H}{H_{O}}\right)-27.375$ (Annual)

For Forest Site (Daily Basis, DB)

$P A R^{e}=2.738(H)+0.457\left(\frac{H}{H_{O}}\right)-41.467$ (wet season)

$P A R^{e}=-0.339(H)+0.410\left(\frac{H}{H_{O}}\right)+9.599($ wet-dry season $)$

$P A R^{e}=-4.142(H)+0.431\left(\frac{H}{H_{O}}\right)+1.893 \quad$ (dry season)

$P A R^{e}=2.128(H)+0.384\left(\frac{H}{H_{O}}\right)+39.020($ dry-wet season $)$

$\operatorname{PAR}^{e}=0.925(H)+0.426\left(\frac{H}{H_{O}}\right)-4.352 \quad$ (Annual)

$\mathrm{Hu}$ and Wang [62] reported the following HB model for Northern China as:

$P_{A R}{ }^{p}=61.9(H)+2.0\left(\frac{H}{H_{O}}\right)+209.0$

Hu et al. [64] developed the following HB models for Beijing site in North China Plain as:

$P_{A R}{ }^{p}=1.92(H)-242.7\left(\frac{H}{H_{O}}\right)+42.8$

4.10.2 Group 2

In this group, clearness index, daytime length $\left(\mathrm{L}_{\mathrm{D}}\right)$ and solar zenith angle $\left(\theta_{z}\right)$ were incorporated with PAR in the forms:

$$
\begin{aligned}
& P A R^{p}=\left(a+b\left(\frac{H}{H_{o}}\right)+c\left(\frac{H}{H_{o}}\right)^{2}+d\left(\frac{H}{H_{o}}\right)^{3}\right) \times \theta_{z}^{e} \times L_{D} \\
& P A R^{p}=\left(a+b\left(\frac{H}{H_{o}}\right)+c\left(\frac{H}{H_{o}}\right)^{2}+d\left(\frac{H}{H_{o}}\right)^{3}\right) \times \theta_{z}^{e} \\
& \text { PAR }^{e}=\left(a+b\left(\frac{H}{H_{o}}\right)+c\left(\frac{H}{H_{o}}\right)^{2}+d\left(\frac{H}{H_{o}}\right)^{3}\right) \times \theta_{z}^{e} \times L_{D} \\
& \text { PAR }^{e}=\left(a+b\left(\frac{H}{H_{o}}\right)+c\left(\frac{H}{H_{o}}\right)^{2}+d\left(\frac{H}{H_{o}}\right)^{3}\right) \times \theta_{z}^{e}
\end{aligned}
$$

Wang et al. [98] developed the following DB and I minute models for Wuhan, Central China.

For I minute Basis 
$P A R^{p}=\left(28.4+3130.2\left(\frac{H}{H_{o}}\right)-2210.3\left(\frac{H}{H_{o}}\right)^{2}+1926.4\left(\frac{H}{H_{o}}\right)^{3}\right) \times \theta_{z}^{1.045}$

For Daily Basis (DB)

$P A R^{p}=\left(6.21+684.9\left(\frac{H}{H_{o}}\right)-483.7\left(\frac{H}{H_{o}}\right)^{2}+421.5\left(\frac{H}{H_{o}}\right)^{3}\right) \times \theta_{z}^{1.045} \times L_{D}$

Wang et al. [63] fitted the following HB models for Inner Mongolia, China.

For Hourly Basis (HB)

$P A R^{e}=\left(110.48+1185.2\left(\frac{H}{H_{o}}\right)+1833.3\left(\frac{H}{H_{o}}\right)^{2}-1470\left(\frac{H}{H_{o}}\right)^{3}\right) \times \theta_{z}^{0.941}$

For Daily Basis (DB)

$P A R^{p}=\left(7.57+30.39\left(\frac{H}{H_{o}}\right)+126.64\left(\frac{H}{H_{o}}\right)^{2}-100.39\left(\frac{H}{H_{o}}\right)^{3}\right) \times \theta_{z}^{1.47}$

Peng et al. [73] fitted the following DB and I minute models for Lhasa (Tibetan Plateau) in China.

For Daily Basis (DB)

$P A R^{p}=\left(16.587-15.909\left(\frac{H}{H_{o}}\right)+182.544\left(\frac{H}{H_{o}}\right)^{2}-117.93\left(\frac{H}{H_{o}}\right)^{3}\right) \times \theta_{z}^{1.621} \times L_{D}$

For I minute Basis

$P A R^{p}=\left(88.98-1486.1\left(\frac{H}{H_{o}}\right)+1094.6\left(\frac{H}{H_{o}}\right)^{2}-846.33\left(\frac{H}{H_{o}}\right)^{3}\right) \times \theta_{z}^{1.027}$

Wang et al. [115] developed the following HB and DB model for LZ station, China.

For Hourly Basis (HB)

$P A R^{e}=\left(58.4+1771.2\left(\frac{H}{H_{o}}\right)+791.3\left(\frac{H}{H_{o}}\right)^{2}-734.4\left(\frac{H}{H_{o}}\right)^{3}\right) \times \theta_{z}^{1.045}$

For Daily Basis (DB)

$P A R^{p}=\left(3.75+67.22\left(\frac{H}{H_{o}}\right)+42.29\left(\frac{H}{H_{o}}\right)^{2}-35.77\left(\frac{H}{H_{o}}\right)^{3}\right) \times \theta_{z}^{1.622}$

Hu et al. [116] established the following HB and DB models for Lhasa and Huaibei, Tibetan Plateau, China as follows:

For Hourly Basis (HB)

$P A R^{e}=\left(73.5+2256.9\left(\frac{H}{H_{o}}\right)+1246.7\left(\frac{H}{H_{o}}\right)^{2}-1182.8\left(\frac{H}{H_{o}}\right)^{3}\right) \times \theta_{z}^{1.09}$

For Daily Basis (DB)

Tr Ren Energy, 2018, Vol.4, No.2, 236-327. doi: 10.17737/tre.2018.4.2.0079 
$P A R^{e}=\left(2.1-2.4\left(\frac{H}{H_{o}}\right)+23.9\left(\frac{H}{H_{o}}\right)^{2}-15.5\left(\frac{H}{H_{o}}\right)^{3}\right) \times \theta_{z}^{1.13} \times L_{D}$

4.10.3 Group 3

In this group, the attenuation factor in clear skies $\left(\mathrm{AF}_{\mathrm{C}}\right.$, ratio of measured to extraterrestrial $\left(\mathrm{PAR}_{\mathrm{O}}\right.$ ) under clear skies), the attenuation factor with clouds, which can be expressed as $\mathrm{H} / \mathrm{H}_{\mathrm{o}}$ were incorporated with $\mathrm{PAR}$ fraction in the form:

$\frac{P A R^{e}}{P A R_{o}}=a A F_{C}^{b}\left(\frac{H}{H_{o}}\right)^{c}$

where $\mathrm{a}, \mathrm{b}$ and $\mathrm{c}$ are the regression coefficients and other symbols retain their usual meaning.

Wang et al. [63] stimulated the HB model for Inner Mongolia, China as:

$\frac{P A R^{e}}{P A R_{o}}=1.06 A F_{C}^{0.34}\left(\frac{H}{H_{o}}\right)^{0.88}$

\subsubsection{Group 4}

In this group, clearness index and optical air mass (m) were incorporated with PAR clearness index in the form:

$\frac{P A R^{p}}{P A R_{o}}=a\left(\frac{H}{H_{o}}\right)^{b} m^{c}$

where $\mathrm{a}, \mathrm{b}$ and $\mathrm{c}$ are the regression coefficients and other symbols retain their usual meaning.

$\mathrm{Hu}$ and Wang [62] developed the HB model for Northern China under all sky conditions as:

$\frac{P A R^{p}}{P A R_{o}}=0.92\left(\frac{H}{H_{o}}\right)^{-0.0012} m^{0.7925}$

Hu et al. [64] fitted the following HB model for Beijing site as:

$\frac{P A R^{p}}{P A R_{o}}=0.80\left(\frac{H}{H_{o}}\right)^{0.84} m^{0.09}$

\subsubsection{Group 5}

In this group, global solar radiation $(\mathrm{H})$, solar zenith angle $\left(\theta_{z}\right)$, columnar perceptible water vapour (wv), and aerosol optical depth (AOD) were incorporated with PAR in the form:

$$
P A R^{e}=a\left(\theta_{z}\right)+b(H)+c(w v)+d(A O D)+e
$$

Melina-Maria et al. [77] stimulated the following HB model for Greece as:

Tr Ren Energy, 2018, Vol.4, No.2, 236-327. doi: 10.17737/tre.2018.4.2.0079 


$$
P A R^{e}=-0.375\left(\theta_{z}\right)+0.431(H)+3.673(w v)-3.447(A O D)+19.940
$$

\subsubsection{Group 6}

In this group, water vapour pressure and relative sunshine duration were incorporated with ratio of $\mathrm{PAR} / \mathrm{H}$ in the form:

$$
\frac{P A R^{e}}{H}=a+b\left(E^{*}\right)+c\left(\frac{S}{S_{O}}\right)
$$

where $E^{*}=E \times P / P_{O}$. E is the monthly average value of water vapour pressure at the site. $\mathrm{P}_{\mathrm{o}}$ is the standard atmospheric pressure at the sea level $(1013 \mathrm{hPa}) . \mathrm{P}$ is the monthly average atmospheric pressure at the site, while $\mathrm{a}, \mathrm{b}$ and $\mathrm{c}$ are the regression coefficients and other symbols retain their usual meaning.

Li et al. [55] obtained the following MB model for Northern Tibetan Plateau, China as:

$$
\frac{P A R^{e}}{H}=0.453+0.0161\left(E^{*}\right)-0.024\left(\frac{S}{S_{O}}\right)
$$

\subsubsection{Group 7}

In this group, clearness of the sky $(\varepsilon)$, brightness of the skylight $(\Delta)$, solar zenith angle $\left(\theta_{z}\right)$, clearness index, site elevation (h) and perceptible water (wv) were incorporated with $\mathrm{PAR} / \mathrm{H}$ ratio in the forms:

$$
\begin{aligned}
& \frac{P A R^{p}}{H}=a+b(\operatorname{In} \Delta)+c(\operatorname{In} \varepsilon)+d(\operatorname{In} w v)+e(\sinh ) \\
& \frac{P A R^{p}}{H}=a+b\left(\operatorname{In} \frac{H}{H_{O}}\right)+c(\sinh )+d(\operatorname{In} w v)
\end{aligned}
$$

Wang et al. [71] fitted the following HB models for Wuhan, Central China as:

$$
\begin{aligned}
& \frac{P A R^{p}}{H}=0.444-0.054(\operatorname{In} \Delta)-0.05(\operatorname{In} \varepsilon)+0.029(\operatorname{Inw} v)+0.1(\sinh ) \\
& \frac{P A R^{p}}{H}=0.33-0.058\left(\operatorname{In} \frac{H}{H_{o}}\right)+0.027(\sinh )+0.025(\operatorname{Inw} v)
\end{aligned}
$$

\subsubsection{Group 8}

In this group, water vapour pressure, global solar radiation and clearness index were incorporated with PAR in the form:

$$
P A R^{e}=a(H)+b\left(\frac{H}{H_{O}}\right)+c(E)+d
$$

Aguiar et al. [65] developed the following DB and HB models for Pasture and Forest Sites in South West Amazonia 
For Pasture Site (Hourly Basis)

$$
\begin{array}{ll}
P A R^{e}=11.196(H)+0.478\left(\frac{H}{H_{O}}\right)-6.088(E)+0.385 & \text { (wet season) } \\
P A R^{e}=-4.534(H)+0.470\left(\frac{H}{H_{O}}\right)-6.511(E)+0.246 & \text { (wet-dry season) } \\
P A R^{e}=-14.164(H)+0.444\left(\frac{H}{H_{O}}\right)+10.533(E)+0.339 & \text { (dry season) } \\
P A R^{e}=7.102(H)+0.480\left(\frac{H}{H_{O}}\right)-27.739(E)-0.127 & \text { (dry-wet season) } \\
P A R^{e}=-26.505(H)+0.464\left(\frac{H}{H_{O}}\right)-3.210(E)+1.105 & \text { (Annual) }
\end{array}
$$

For Forest Site (Hourly Basis)

$$
\begin{array}{ll}
P A R^{e}=-12.054(H)+0.441\left(\frac{H}{H_{O}}\right)-27.446(E)+0.686 & \text { (wet season) } \\
P A R^{e}=-6.610(H)+0.425\left(\frac{H}{H_{O}}\right)-8.972(E)+0.436 & \text { (wet-dry season) } \\
P A R^{e}=-15.891(H)+0.435\left(\frac{H}{H_{O}}\right)-4.325(E)+0.606 & \text { (dry season) } \\
P A R^{e}=0.518(H)+0.447\left(\frac{H}{H_{O}}\right)-34.066(E)+0.274 & \text { (dry-wet season) } \\
P A R^{e}=-7.072(H)+0.435\left(\frac{H}{H_{O}}\right)-18.125(E)+0.467 & \text { (Annual) }
\end{array}
$$

For Pasture Site (Daily Basis)

$$
\begin{array}{ll}
P A R^{e}=4.447(H)+0.466\left(\frac{H}{H_{O}}\right)-1.362(E)-0.023 & \text { (wet season) } \\
P A R^{e}=-8.390(H)+0.487\left(\frac{H}{H_{O}}\right)-22.223(E)+0.499 & \text { (wet-dry season) } \\
P A R^{e}=-27.462(H)+0.347\left(\frac{H}{H_{O}}\right)+86.718(E)+0.927 & \text { (dry season) } \\
P A R^{e}=20.423(H)+0.766\left(\frac{H}{H_{O}}\right)-286.430(E)-0.629 & \text { (dry-wet season) } \\
P A R^{e}=-34.302(H)+0.435\left(\frac{H}{H_{O}}\right)+17.944(E)+1.495 & \text { (Annual) }
\end{array}
$$

For Forest Site (Daily Basis) 


$$
\begin{array}{ll}
P A R^{e}=-16.421(H)+0.453\left(\frac{H}{H_{O}}\right)-40.867(E)+0.903 & \text { (wet season) } \\
P A R^{e}=-8.834(H)+0.418\left(\frac{H}{H_{O}}\right)+3.108(E)+0.396 & \text { (wet-dry season) } \\
P A R^{e}=-35.878(H)+0.442\left(\frac{H}{H_{O}}\right)+9.893(E)+1.069 & \text { (dry season) } \\
P A R^{e}=-10.179(H)+0.398\left(\frac{H}{H_{O}}\right)+17.392(E)+0.773 & \text { (dry-wet season) } \\
P A R^{e}=-13.566(H)+0.426\left(\frac{H}{H_{O}}\right)-6.702(E)+0.703 & \text { (Annual) }
\end{array}
$$

\subsubsection{Group 9}

In this group, solar zenith angle $\left(\theta_{z}\right)$, solar elevation angle $(\beta)$, clearness of the sky $(\varepsilon)$, brightness of skylight $(\Delta)$ and dew temperature $\left(T_{d}\right)$ were incorporated with ratio of PAR with $\mathrm{H}$ in the form:

$$
\begin{aligned}
& \frac{P A R^{p}}{H}=a+b(\operatorname{In} \varepsilon)+c(\operatorname{In} \Delta)+d\left(T_{d}\right)+e\left(\sin ^{2} \beta\right) \\
& \frac{P A R^{p}}{H}=a+b(\operatorname{In} \varepsilon)+c(\operatorname{In} \Delta)+d\left(T_{d}\right)+e\left(\cos ^{2} \theta\right)
\end{aligned}
$$

site as:

Alados et al. [5] developed the following HB model at the University of Almeria

$$
\frac{P A R^{p}}{H}=1.786-0.192(\operatorname{In} \varepsilon)-0.202(\operatorname{In} \Delta)+0.005\left(T_{d}\right)+0.032\left(\sin ^{2} \beta\right)
$$

Alados and Alados-Arboledas [117] calibrated the following HB model at the University of Almeria site as:

$$
\frac{P A R^{p}}{H}=1.786-0.192(\operatorname{In} \varepsilon)-0.202(\operatorname{In} \Delta)+0.005\left(T_{d}\right)+0.032\left(\cos ^{2} \theta\right)
$$

Wang et al. [9] developed the following HB models for Wuhan, Central China as:

$$
\frac{P A R^{p}}{H}=0.454-0.052(\operatorname{In} \Delta)-0.064(\operatorname{In} \varepsilon)+0.072\left(\sin ^{2} \theta\right)
$$

\subsubsection{Group 10}

In this group, clearness of the solar zenith angle $\left(\theta_{z}\right)$, solar elevation angle $(\beta)$, clearness of the sky $(\varepsilon)$ and brightness of skylight $(\Delta)$ were incorporated with ratio of PAR with $\mathrm{H}$ in the form: 


$$
\begin{aligned}
& \frac{P A R^{p}}{H}=a+b(\operatorname{In} \varepsilon)+c(\operatorname{In} \Delta)+d\left(\sin ^{2} \beta\right) \\
& \frac{P A R^{p}}{H}=a+b(\operatorname{In} \varepsilon)+c(\operatorname{In} \Delta)+d\left(\cos ^{2} \beta\right)
\end{aligned}
$$

Alados et al. [5] fitted the following HB model for University of Almeria site as:

$$
\frac{P A R^{p}}{H}=1.854-0.194(\operatorname{In} \varepsilon)-0.19(\operatorname{In} \Delta)+0.076\left(\sin ^{2} \beta\right)
$$

Alados and Alados-Arboledas [117] calibrated the following $\mathrm{HB}$ model for University of Almeria site as:

$$
\frac{P A R^{p}}{H}=1.854-0.194(\operatorname{In} \varepsilon)-0.195(\operatorname{In} \Delta)+0.076\left(\cos ^{2} \beta\right)
$$

\subsubsection{Group 11}

In this group, clearness index $\left(\mathrm{H} / \mathrm{H}_{\mathrm{o}}\right)$, dew point temperature $\left(\mathrm{T}_{\mathrm{d}}\right)$, solar zenith angle $\left(\theta_{z}\right)$ or solar elevation angle $(\beta)$ were incorporated with ratio of PAR with $\mathrm{H}$ in the form:

$$
\begin{aligned}
& \frac{P A R^{p}}{H}=a+b\left(\operatorname{In} \frac{H}{H_{O}}\right)+c\left(T_{d}\right)+d(\sin \beta) \\
& \frac{P A R^{p}}{H}=a+b\left(\operatorname{In} \frac{H}{H_{O}}\right)+c\left(T_{d}\right)+d(\cos \theta)
\end{aligned}
$$

Alados et al. [5] developed the following HB model for University of Almeria site as:

$$
\frac{P A R^{p}}{H}=1.791-0.190\left(\operatorname{In} \frac{H}{H_{O}}\right)+0.005\left(T_{d}\right)+0.049(\sin \beta)
$$

Alados and Alados-Arboledas [117] calibrated the following HB model for University of Almeria site as:

$$
\frac{P A R^{p}}{H}=1.791-0.190\left(\operatorname{In} \frac{H}{H_{O}}\right)+0.005\left(T_{d}\right)+0.049(\cos \theta)
$$

Yu et al. [72] fitted the following HB models for contiguous United States as:

$$
\begin{aligned}
& \frac{P A R^{e}}{H}=0.0138\left(\operatorname{In} \frac{H}{H_{O}}\right)^{2}-0.005396\left(\operatorname{In} \frac{H}{H_{O}}\right)+0.0001159\left(T_{d}\right)-0.049\left(\cos \theta_{z}\right)+0.4680 \\
& \frac{P A R^{p}}{H}=0.45-0.0385\left(\operatorname{In} \frac{H}{H_{O}}\right)-0.0001166\left(T_{d}\right)-0.06031(\cos \theta)
\end{aligned}
$$

\subsubsection{Group 12}

In this group, clearness index, solar elevation angle $(\beta)$ or solar zenith angle $\left(\theta_{z}\right)$ were incorporated with PAR to $\mathrm{H}$ ratio in the form:

$$
\frac{P A R^{p}}{H}=a+b\left(\operatorname{In} \frac{H}{H_{O}}\right)+c(\sin \beta)
$$


$\frac{P A R^{p}}{H}=a+b\left(\operatorname{In} \frac{H}{H_{o}}\right)+c\left(\cos \theta_{z}\right)$

Alados et al. [5] fitted the following HB model for University of Almeria site as:

$\frac{P A R^{p}}{H}=1.832-0.191\left(\operatorname{In} \frac{H}{H_{O}}\right)+0.099(\sin \beta)$

Alados and Alados-Arboledas [117] calibrated the following HB model for University of Almeria site as:

$$
\frac{P A R^{p}}{H}=1.832-0.191\left(\operatorname{In} \frac{H}{H_{o}}\right)+0.099\left(\cos \theta_{z}\right)
$$

Wang et al. [71] reported the following HB model for Wuhan, Central China as:

$\frac{P A R^{e}}{H}=0.336-0.061\left(\operatorname{In} \frac{H}{H_{o}}\right)+0.045(\sin \beta)$

Yu et al. [72] developed the following HB models for Contiguous United States as:

$\frac{P A R^{e}}{H}=0.4511178-0.03853\left(\operatorname{In} \frac{H}{H_{o}}\right)-0.06099\left(\cos \theta_{z}\right)$

$\frac{P A R^{e}}{H}=0.4641+0.01344\left(\operatorname{In} \frac{H}{H_{o}}\right)^{2}-0.006911\left(\operatorname{In} \frac{H}{H_{o}}\right)-0.0631\left(\cos \theta_{z}\right)$

\subsubsection{Group 13}

In this group, clearness index and dew point temperature were incorporated to PAR to $\mathrm{H}$ ratio, $\mathrm{PAR}$ to $\mathrm{H}_{\mathrm{o}}$ ratio, and $\mathrm{PAR}$ fraction in the forms:

$$
\begin{aligned}
\frac{P A R^{e}}{H_{O}} & =a+b\left(\frac{T_{d}}{100}\right)+c\left(\frac{H}{H_{O}}\right) \\
\frac{P A R^{e}}{P A R_{O}} & =a+b\left(\frac{T_{d}}{100}\right)+c\left(\frac{H}{H_{O}}\right) \\
\frac{P A R^{e}}{H} & =a\left(\operatorname{In} \frac{H}{H_{O}}\right)^{2}+b\left(\operatorname{In} \frac{H}{H_{O}}\right)+c\left(T_{d}\right)+d
\end{aligned}
$$

Yu et al. [72] developed the following HB model for Contiguous United States as:

$$
\frac{P A R^{e}}{H}=0.01102\left(\operatorname{In} \frac{H}{H_{O}}\right)^{2}-0.01632\left(\operatorname{In} \frac{H}{H_{O}}\right)+0.0005011\left(T_{d}\right)+0.4283
$$

Etuk et al. [68] fitted the following MB models for Calabar, Nigeria as:

$$
\frac{P A R^{e}}{H_{O}}=0.001+0.001\left(\frac{T_{d}}{100}\right)+0.009\left(\frac{H}{H_{O}}\right)
$$


$\frac{P A R^{e}}{P A R_{O}}=0.002+0.003\left(\frac{T_{d}}{100}\right)+1.120\left(\frac{H}{H_{O}}\right)$

\subsubsection{Group 14}

In this group, diffuse fraction $\left(\mathrm{H}_{\mathrm{d}} / \mathrm{H}\right)$, brightness of the skylight $(\Delta)$, or solar zenith angle $\theta_{z}$ or dew point temperature $\left(\mathrm{T}_{\mathrm{d}}\right)$ were incorporated with PAR and $\mathrm{H}$ ratio in the forms:

$$
\begin{aligned}
\frac{P A R^{e}}{H} & =a\left(\operatorname{In} \frac{H_{d}}{H}\right)+b(\operatorname{In} \Delta)+c\left(T_{d}\right)+d\left(\cos ^{2} \theta_{z}\right)+e \\
\frac{P A R^{e}}{H} & =a\left(\operatorname{In} \frac{H_{d}}{H}\right)+b(\operatorname{In} \Delta)+c\left(\cos ^{2} \theta_{z}\right)+d \\
\frac{P A R^{e}}{H} & =a\left(\operatorname{In} \frac{H_{d}}{H}\right)+b(\operatorname{In} \Delta)+c
\end{aligned}
$$

Yu et al. [72] obtained the following HB models for Contiguous United State as:

$$
\frac{P A R^{e}}{H}=0.039\left(\operatorname{In} \frac{H_{d}}{H}\right)-0.041(\operatorname{In} \Delta)-0.000089\left(T_{d}\right)-0.0521\left(\cos ^{2} \theta_{z}\right)+0.4318
$$

$\frac{P A R^{e}}{H}=0.0387\left(\operatorname{In} \frac{H_{d}}{H}\right)-0.041(\operatorname{In} \Delta)-0.05728\left(\cos ^{2} \theta_{z}\right)+0.4332$

$\frac{P A R^{e}}{H}=0.04094\left(\operatorname{In} \frac{H_{d}}{H}\right)-0.040(\operatorname{In} \Delta)+0.4186$

\subsubsection{Group 15}

In this group, clearness index and sunshine fraction were incorporated with PAR fraction or PAR to $\mathrm{H}_{\mathrm{o}}$ in the forms:

$$
\begin{gathered}
\frac{P A R^{e}}{H_{O}}=a+b\left(\frac{H}{H_{O}}\right)+c\left(\frac{S}{S_{O}}\right) \\
\frac{P A R^{e}}{P A R_{O}}=a+b\left(\frac{H}{H_{O}}\right)+c\left(\frac{S}{S_{O}}\right)
\end{gathered}
$$

Etuk et al. [68] recorded the following MB models for Calabar, Nigeria as:

$$
\frac{P A R^{e}}{H_{O}}=-0.002+0.448\left(\frac{H}{H_{O}}\right)+0.004\left(\frac{S}{S_{O}}\right)
$$


$\frac{P A R^{e}}{P A R_{O}}=-0.003+1.120\left(\frac{H}{H_{O}}\right)+0.007\left(\frac{S}{S_{O}}\right)$

\subsubsection{Group 16}

In this group, relative humidity $(\mathrm{RH})$ or sunshine fraction, clearness index was incorporated to PAR fraction in the forms:

$$
\begin{aligned}
& \frac{P A R^{e}}{P A R_{O}}=a+b\left(\frac{R}{100}\right)+c\left(\frac{H}{H_{O}}\right) \\
& \frac{P A R^{e}}{P A R_{O}}=a+b\left(\frac{R}{100}\right)+c\left(\frac{H}{H_{O}}\right)+d\left(\frac{H}{H_{O}}\right)^{2} \\
& \frac{P A R^{e}}{P A R_{O}}=a+b\left(\frac{R}{100}\right)+c\left(\frac{H}{H_{O}}\right)^{2} \\
& \frac{P A R^{e}}{P A R_{O}}=a+b\left(\frac{R}{100}\right)+c\left(\frac{S}{S_{O}}\right)+d\left(\frac{H}{H_{O}}\right)
\end{aligned}
$$

Etuk et al. [68] reported the following MB models for Calabar, Nigeria as:

$$
\begin{aligned}
& \frac{P A R^{e}}{P A R_{O}}=0.005-0.02\left(\frac{R}{100}\right)+1.118\left(\frac{H}{H_{O}}\right) \\
& \frac{P A R^{e}}{P A R_{O}}=0.025-0.003\left(\frac{R}{100}\right)+1.025\left(\frac{H}{H_{O}}\right)+0.111\left(\frac{H}{H_{O}}\right)^{2} \\
& \frac{P A R^{e}}{P A R_{O}}=0.253-0.022\left(\frac{R}{100}\right)+1.326\left(\frac{H}{H_{O}}\right)^{2} \\
& \frac{P A R^{e}}{P A R_{O}}=0.001-0.008\left(\frac{R}{100}\right)+0.014\left(\frac{S}{S_{O}}\right)+1.114\left(\frac{H}{H_{O}}\right)
\end{aligned}
$$

\subsubsection{Group 17}

In this group, dew point temperature, sunshine fraction, clearness index and ratio of minimum and maximum temperature were incorporated to PAR fraction and PAR to $\mathrm{H}_{\mathrm{o}}$ ratio in the forms:

$$
\begin{aligned}
& \frac{P A R^{e}}{P A R_{O}}=a+b\left(\frac{T_{d}}{100}\right)+c\left(\frac{S}{S_{O}}\right)+d\left(\frac{H}{H_{O}}\right) \\
& \frac{P A R^{e}}{P A R_{O}}=a+b\left(T_{R}\right)+c\left(\frac{H}{H_{O}}\right)+d\left(\frac{S}{S_{O}}\right)
\end{aligned}
$$




$$
\frac{P A R^{e}}{H_{o}}=a+b\left(T_{R}\right)+c\left(\frac{H}{H_{O}}\right)+d\left(\frac{H}{H_{O}}\right)^{2}
$$

Etuk et al. [68] proposed the following MB models for Calabar, Nigeria as:

$$
\begin{aligned}
& \frac{P A R^{e}}{P A R_{O}}=-0.008+0.016\left(\frac{T_{d}}{100}\right)+0.009\left(\frac{S}{S_{O}}\right)+1.121\left(\frac{H}{H_{O}}\right) \\
& \frac{P A R^{e}}{P A R_{O}}=-0.001-0.003\left(T_{R}\right)+0.448\left(\frac{H}{H_{O}}\right)+0.005\left(\frac{S}{S_{O}}\right) \\
& \frac{P A R^{e}}{H_{O}}=0.011-0.002\left(T_{R}\right)+0.402\left(\frac{H}{H_{O}}\right)+0.055\left(\frac{H}{H_{O}}\right)^{2}
\end{aligned}
$$

\section{Discussion}

As a result of the various empirical computing models reported by peers and researchers for estimating photosynthetically active radiation (PAR) applying astronomical parameters, meteorological parameters, geographical parameters, geometrical factors and atmospheric parameters resulting in a rigorous task for introducing a set input parameter with a particular functional form for optimal estimation PAR across the globe because of the nature of PAR and PAR/H dependence on latitude and altitude of the site and movement of the earth culminating in variations of local climate.

For this purpose, the author has classified numerous PAR and PAR/H computing models into ten (10) categories based on their dependence on atmospheric parameters, meteorological parameters, geometrical factors, geographical parameters, astronomical factors etc. via: global solar radiation-based models, relative humidity-based models, temperature-based models, optical air mass-based models, clouds, cloud amount-based models, water vapour pressure-based models, turbidity-based models, sunshine-based models, cleanness index-based models and hybrid parameter-based models as mentioned earlier.

The influence of water vapour pressure on $\mathrm{PAR} / \mathrm{H}$ has been roughly reported in literature in season variations such as the higher in summer (wet season) and lower in winter (dry season) [51, 59, 107]. This report is in agreement with recent report of dependence of PAR/H on water vapour pressure by Akitsu et al. [49] who observed that the monthly mean PAR/H recorded higher values $(0.465)$ in summer and lower value $(0.420)$ in winter as shown in Fig. 3. In another study, Li et al. [55] observed that $\mathrm{PAR} / \mathrm{H}$ increases with the increase in water vapour pressure and low-level cloud amount. According to the authors, this could be attributed to the absorptions of water vapour's waveband selective in the solar spectrum. That is, in cloudy and humid conditions, the absorption of solar radiation in the near infrared (NIR) portion of the solar spectrum is enhanced, whereas absorption in the PAR waveband does not vary significantly. 

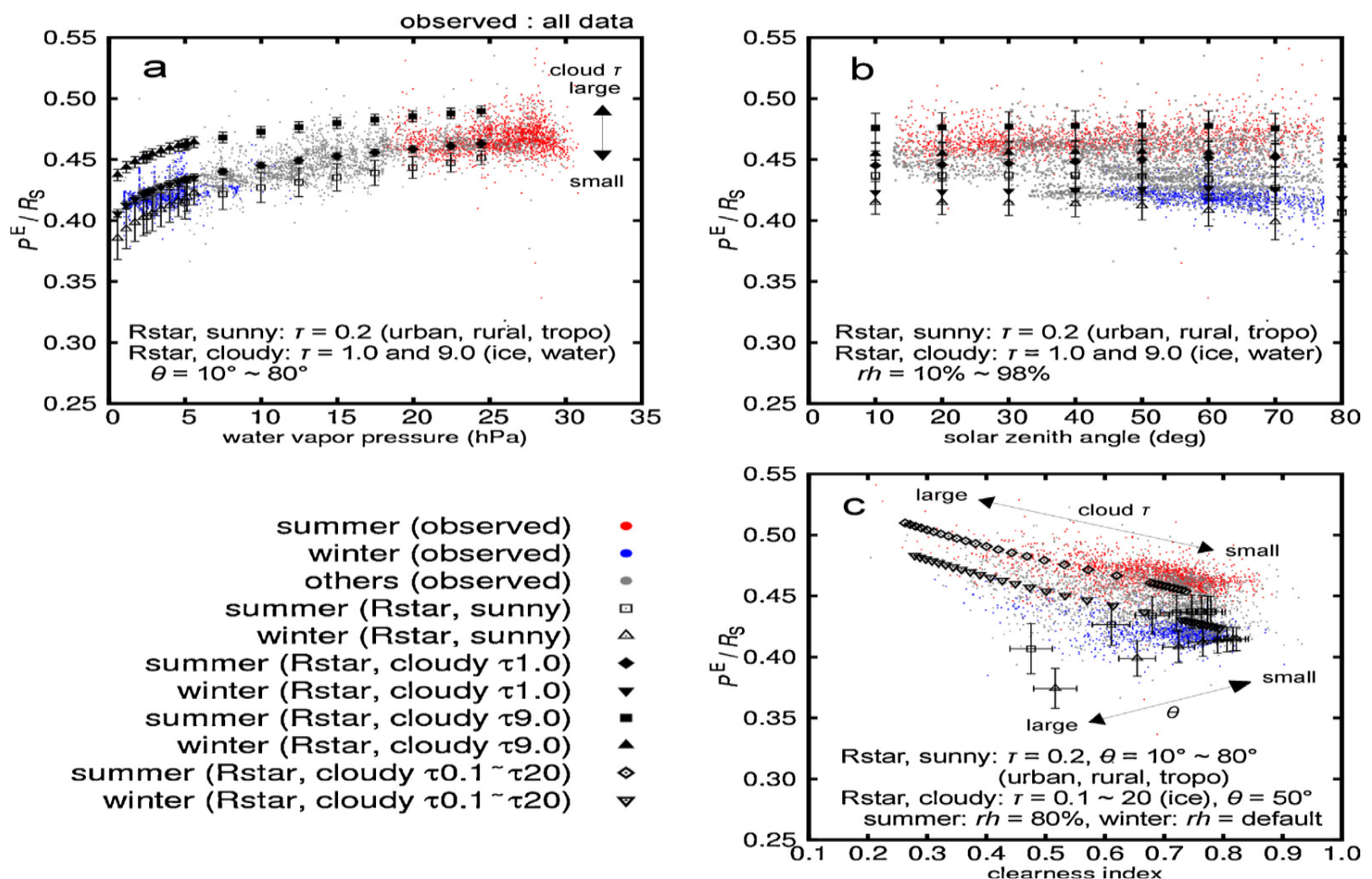

Fig. 3. Comparison between $\mathrm{P}^{\mathrm{E}} / \mathrm{R}^{\mathrm{S}}$ and climatic factors ((a) water vapor pressure e, (b) solar zenith angle _, (c) clearness index $\mathrm{k}_{\mathrm{t}}$ ). Small dots denote observed data, while symbol marks denote mean value of simulation output (Rstar). Error bars denote the std. (For interpretation of the references to color in this figure text, the reader is referred to the web version of this article.) Akitsu et al. [55]

Moreover, Bat-Oyun et al. [59] equally observed that increases in $\mathrm{PAR}^{\mathrm{e}} / \mathrm{H}$ were found under cloudy and humid conditions. The authors equally recorded a significant correlation between $\mathrm{PAR}^{\mathrm{e}} / \mathrm{H}$ and water vapour pressure $(\mathrm{r}=0.49, \mathrm{P}<0.001)$ for day time (08:00 - 17:00, local time). However, the correlation was stronger during April September $(\mathrm{r}=0.70, \mathrm{P}<0.001)$ compared to the rest of the study period, i.e. October March $(r=0.26, P<0.001)$. McCree [37] recorded that during cloudy skies the energy in the PAR region formed a greater part of global solar radiation than on clear days. Another researcher, Hu et al. [118] observe similar seasonal variations in PAR/H for Beijing where lower PAR/H was observed during the dry season and higher PAR/H recorded in the wet season.

Since water vapour pressure, relative humidity and cloud amount are similar in atmospheric behaviour, it can be inferred that increases in PAR/H or PAR culminate in a corresponding increase in water vapour pressure [37, 49, 51, 55, 59, 64, 107, 118], low level cloud amount [55] and relative humidity [60].

Considering clearness index, optical air mass, Angstrom turbidity coefficient and relative sunshine, these four factors (classes) increases with decreasing PAR/H. Li et al. [55] observed that the correlations between $\mathrm{PAR}^{\mathrm{e}} / \mathrm{H}$ and relative sunshine and clearness index are relatively good to some degree with the coefficient of correlation (R) value of 0.65 and 0.69 respectively. According to the authors, compared with relative sunshine and clearness index, the correlation coefficient between PAR/H and Angstrom turbidity coefficient is relatively poor $(0.38)$. They equally stated that the reason for poor relation 
between PAR/H and Angstrom turbidity coefficient $(\beta)$ is that the $(\beta)$ values are determined under the clear sky conditions; they influence PAR significantly with clear sky conditions, whereas the PAR/H values are under the real sky conditions.

Wang et al. [63] observed the dependence of hourly PAR on optical air mass defined by Kasten and Young [119] as a measure of length of the path through the atmosphere to earth surface, under several sky conditions in inner Mongolia, China that PAR generally decreased with increasing optical air mass and the maxima were achieved when sky conditions were cloudless as shown in Fig. 4. The same trend was observed by other researchers $[9,62,64]$.

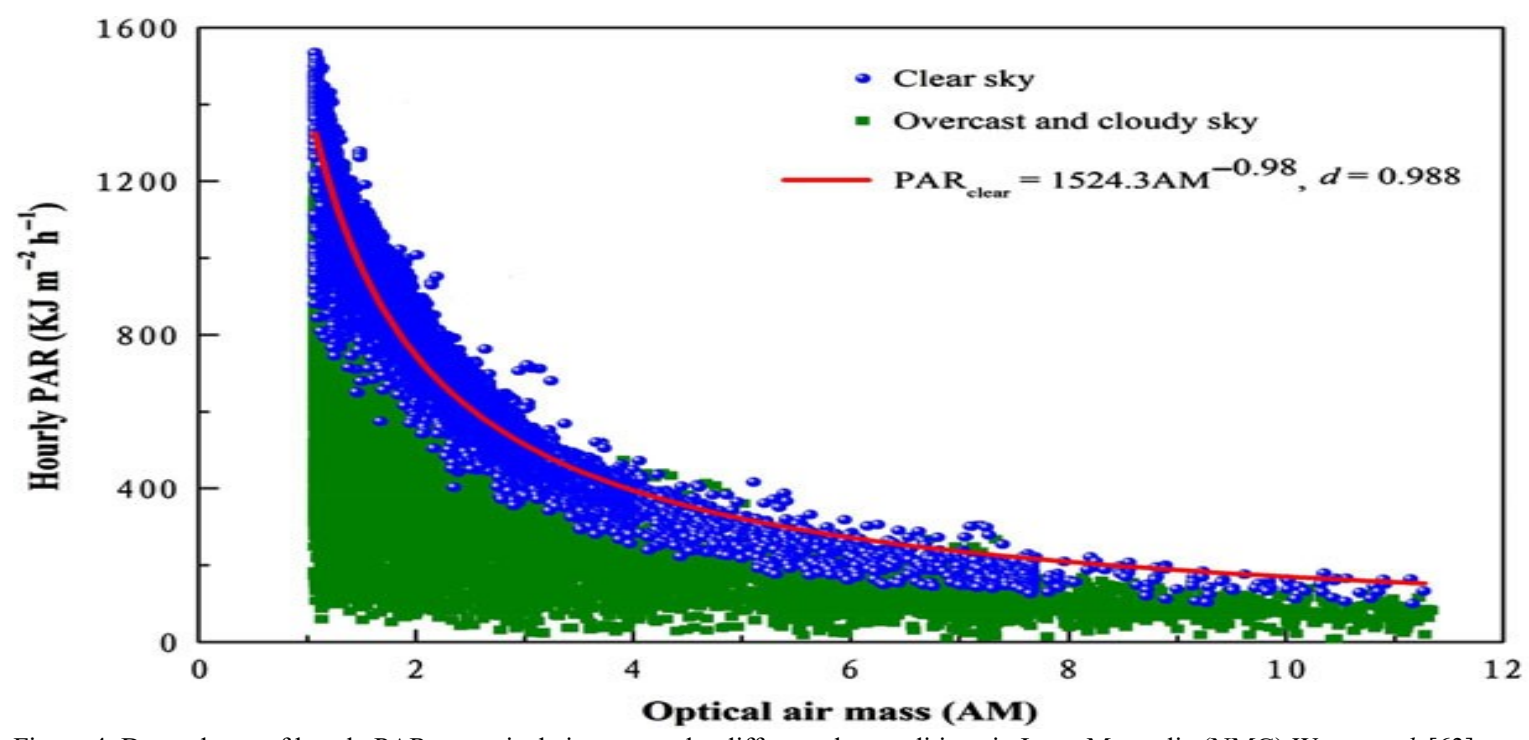

Figure 4. Dependence of hourly PAR on optical air mass under different sky conditions in Inner Mongolia (NMG) Wang et al. [63]

In as much as clearness index, optical air mass, Angstrom turbidity coefficient and relative sunshine possessed similar characteristics of atmospheric trend, it can be stated that increases in PAR/H or PAR brings about a corresponding decrease in clearness index $[48,55,59,68,72]$; Angstrom turbidity coefficient [55]; relative sunshine [55, 61, 74]; optical air mass [62-63, 80].

Generally, it is impossible to introduce a set of input parameter with a singular functional form for optimal estimation of photosynthetically active radiation. In fact, the tendency of enhancing the accuracy of estimation by combing some sets of input parameters is solely dependent on local climate and regional geography etc. To restate this, a brief review of the qualitative effort of solar energy researchers to enhance the accuracy of estimation of photosynthetically active radiation computing models by employing varieties of influencing factors are as represented in the following.

Wang et al. [63] calibrated hybrid empirical consist of the attenuation factor in clear skies $\left(\mathrm{AF}_{\mathrm{c}}\right.$, ratio of measured to extraterrestrial PAR under clear skies); attenuation factor with clouds, which can be expressed as $\mathrm{H} / \mathrm{H}_{\mathrm{o}}$ with PAR coefficient (PAR/PAR ) under hourly time scale (model 1) parameters. The authors equally fitted another hybrid model comprises clearness index $\left(\mathrm{H} / \mathrm{H}_{\mathrm{o}}\right)$ - attenuation factor with clouds and cosine of solar zenith angle $\left(\theta_{z}\right)$ under hourly and daily time scales (model 2 ). From the statistical indices, model 
2 was chosen for reconstructing hourly and daily time scales PAR records in Inner Mongolia, China. This indicates that cosine of zenith angle $\left(\theta_{z}\right)$ and clearness index is more suitable compared to attenuation factor in clear skies, extraterrestrial PAR and clearness index in Inner Mongolia under clear skies in China as shown in Fig. 5 and 6.
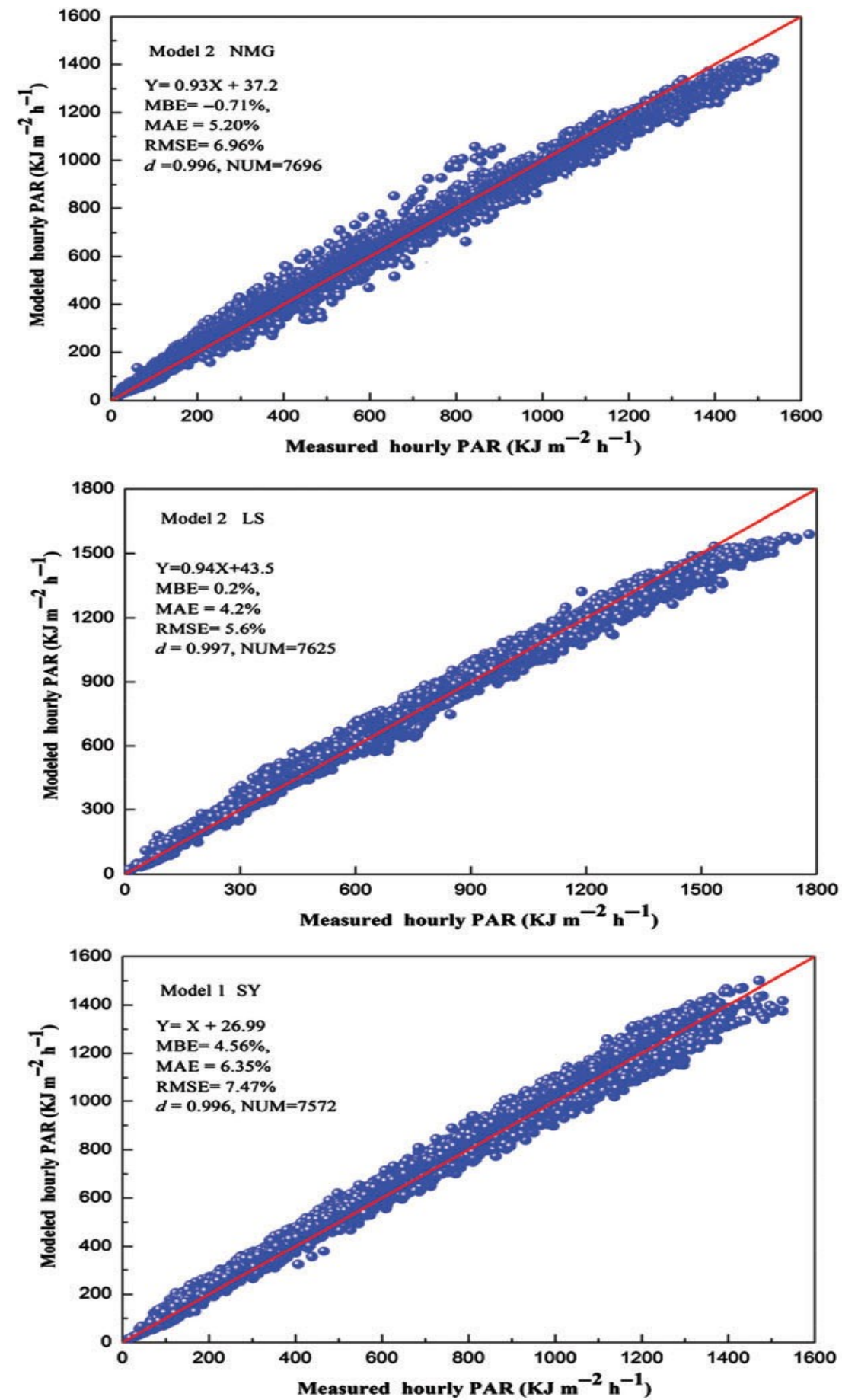

Figure 5. Scatterplot of hourly measured PAR and estimates in Inner Mongolia (NMG) using model 2 (grey line means $1: 1$ relationship) Wang et al. [63]. 

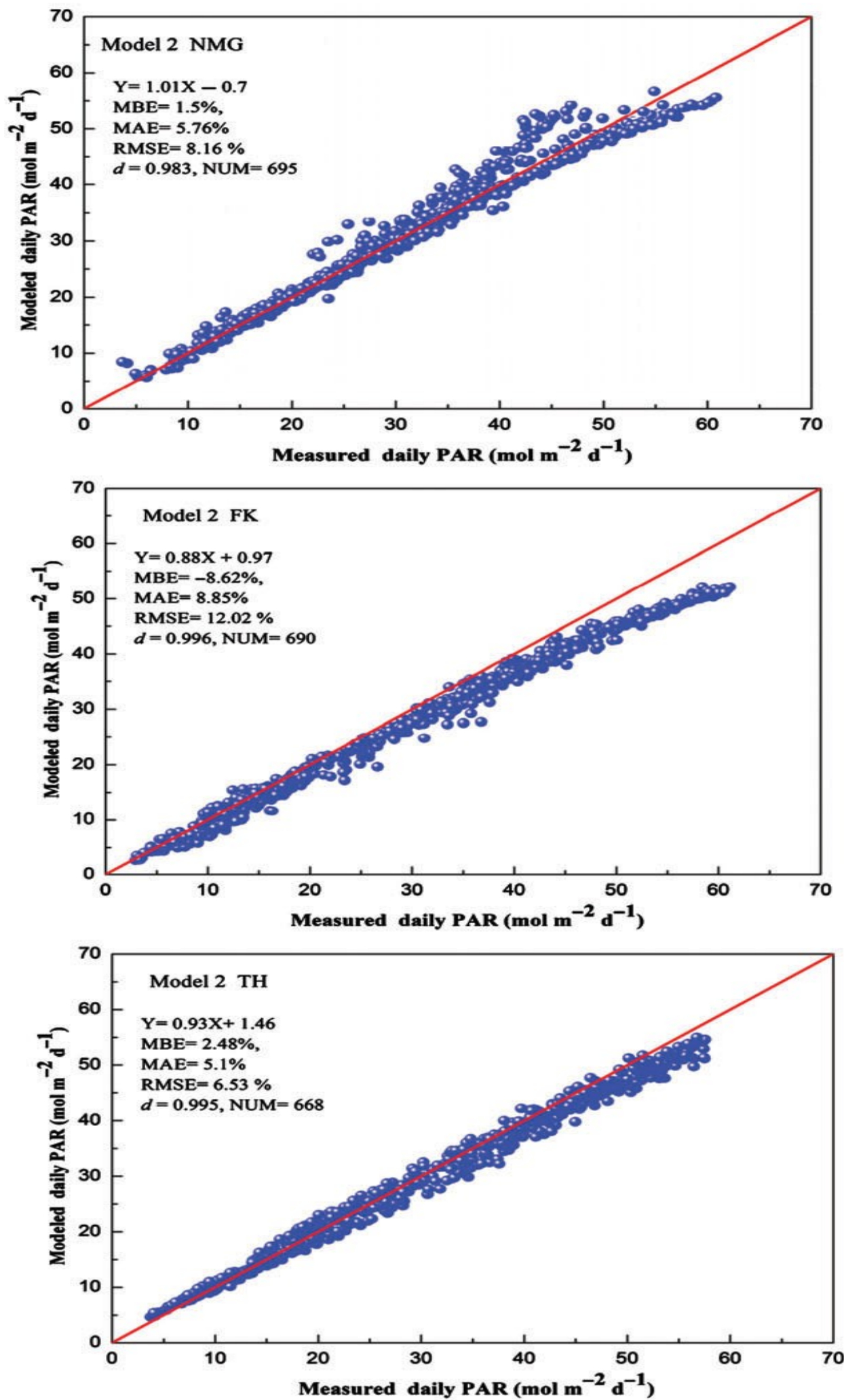

Figure 6. Scatterplot of daily measured PAR and estimates in Inner Mongolia (NMG) using model 2 (grey line means $1: 1$ relationship) Wang et al. [63]. 
$\mathrm{Yu}$ and Guo [76] calibrated Alados et al. [5] computing models to generate the relationship between PAR fraction and model parameters for Bondville station (BON) and Sioux Falls Station (SXF) in Midwestern United States using data from $2009-2011$. The authors employed diffuse fraction $(\mathrm{Hd} / \mathrm{H})$, the sky brightness $(\Delta)$, the dew point temperature and cosine of sun zenith angle $\left(\cos \theta_{z}\right)$ as model 1 input parameters; diffuse fraction, the sky brightness and the cosine of sun zenith angle as model 2 input parameters; clearness index, dew point temperature and the cosine of sun zenith angle as model 4 input parameters under several sky conditions. From the statistical indices, it was discovered that model 1 was more suitable for estimating PAR in Midwestern United States followed by model 3 next by model 2 and model 4 recorded the least performance under Overcast Sky (OS). Under partially cloudy sky (PS), model 3 was most suitable, followed by model 2 , next by model 3 and model 4 was the least suitable empirical model for estimation of PAR in Midwestern United States. Whereas, under Clear Sky (CS) model 3 recorded the most suitable, followed by model 4, next by model 3 and lastly by model 4 for PAR estimation in Midwestern United States. Under all sky conditions, model 2 recorded the best, followed by model 3, next by model 1 and model 4 reported the least computing model for PAR estimation in Midwestern United States as shown in Table 2.

$\mathrm{Yu}$ et al. [72] synthesized ten (10) empirical computing models from previous studies to compare with their measure PAR in the contiguous United States. Model $1-4$ were purposed by Alados et al. [5]. Model 5-6 were suggested by Zhang et al. [97]. Model $7-10$ were obtained from previous studies [55, 109, 120-121]. From the statistical indices, the ten synthetized computing models for estimating PAR from $\mathrm{H}$ show that the quadratic function model taking $\left(\mathrm{ln} H / \mathrm{H}_{\mathrm{o}}\right)$ as main parameter plus $\cos \theta_{\mathrm{z}}$ has the best performance. According to the authors, the results equally show that clearness index $\left(\mathrm{H} / \mathrm{H}_{\mathrm{o}}\right)$ is capable to be the indicator for estimating PAR from $\mathrm{H}$ as one substitute of the combination of diffuse fraction $(\mathrm{Hd} / \mathrm{H})$ and the skylight brightness $(\Delta)$. They also observed that the role of dew point temperature in the models is not significant to improve the overall performance.

$\mathrm{Yu}$ and Wang [62] employed only ratio of $\mathrm{PAR} / \mathrm{H}$ as input parameter for model 1; global solar radiation $(\mathrm{H})$ and clearness index as input parameter for model 2; and clearness index and optical air as input parameter for model 3 for estimation of PAR in Sanjiang site, Northeast China for hourly time scale under all sky conditions. The statistical indicators revealed that model 3 is the most suitable computing model for PAR estimation in Sanjiang site as shown in Table 1.

Table 1: Comparison results of empirical estimation model for hourly PAR at Sanjiang site Yu and Wang [62].

\begin{tabular}{|c|c|c|c|c|c|c|}
\hline Models & $\begin{array}{l}\text { Slope } \\
\text { (a) }\end{array}$ & $\begin{array}{c}\text { Intercept } \\
\text { (b) }\end{array}$ & $\begin{array}{c}\text { Coefficient of } \\
\text { Determination } \\
\left(\mathbf{R}^{2}\right)\end{array}$ & $\begin{array}{c}\text { MBE } \\
\left(\mu \mathrm{molm}^{-2} \mathrm{~s}^{-1}\right)\end{array}$ & $\begin{array}{c}\text { RMSE } \\
\left(\mu \mathrm{molm}^{-2} \mathrm{~s}^{-1}\right)\end{array}$ & $\begin{array}{l}\text { RE } \\
(\%)\end{array}$ \\
\hline $\mathrm{A}$ & 1.03 & 5.6 & 0.98 & 35 & 75.5 & 10.7 \\
\hline B & 1.01 & 4.2 & 0.97 & 15.3 & 76.7 & 11.4 \\
\hline $\mathrm{C}$ & 1.01 & 1.5 & 0.97 & 19.5 & 67.8 & 9.4 \\
\hline
\end{tabular}

Wang et al. [71] employed sky clearness $(\varepsilon)$, sky brightness $(\Delta)$, precipitate water (w), and sin of solar elevation angle (h) as an input parameter for model 1; clearness index, sin of solar elevation angle $(\mathrm{h})$ and perceptible water (wv) as input parameter for model 2; 
only clearness index as input parameter for model 3 ; sky clearness $\left(\mathrm{k}_{\mathrm{t}}\right)$, sky brightness $(\Delta)$, and sin of solar elevation angle for input parameter for model 4; and clearness index and sin of solar elevation angle as input parameter for Sanya station (SY), Lasa Station (LS), Yingtan station (YT), Fergqiv station (FQ), Changshu Station (CS), and other stations in central China for estimating PAR under hourly time scale. According to the authors, as shown in Fig. 7. the slopes of all the models were higher than expected and the estimated values were slightly smaller than the observed results. This reveals that there are some influencing factors on $\mathrm{PAR} / \mathrm{H}$ not being taken into consideration, for example, the influence of ozone absorption and surface albedo. The authors equally stated that model 2 and 3 may be better for calculating PAR from measurement in Wuhan. In order to check the level of reliability of the models ( 2 and 3 ), the author tested the two models (model 2 and 3) at seven (7) stations in Central China. The authors revealed that the two models work well in most stations in that the relative error in DH station was about 5.9\%, which produced a better result than that in other stations in China. For instance, Hu et al. [118] reported relative error between measured and estimated PAR as about $20 \%$ in Beijing. On the whole, the statistical results revealed that PAR could be estimated with a high level of precision using global solar radiation and a variable that accounts for the sky condition dependence of $\mathrm{PAR} / \mathrm{H}$ in Central China. However, a larger derivation was still found at Huitong Station (HS), Taoyuan station (TY), and Qianyanzhou station (QYS), with relative error higher than $10 \%$. This according to the authors may be attributed to the higher absorption effects for extraterrestrial solar radiation in the above three sites (clouds and water vapour), which lie south of Wuhau and close to the tropical regions.

Li et al. [55] employed water vapour pressure-based model, cloud amount-based models, relative sunshine-based models, clearness index-based models and hybrid model consisting of relative sunshine and water vapour pressure input parameters to estimate PAR in Northern Tibetan Plateau (NTP). From the statistical indices, the hybrid model performed better than other four models mentioned above. To check the applicability of the model, the authors tested the models in five stations outside the location the models were fitted (Wudaoliang, WDL) since PAR is local climate and geographical site dependent. The result revealed that the model is practicable for Tibetan Plateau, and Southeast of China. They further stated that the model is considered acceptable for Northwest of China; but for the East of China, the model is not applicable. 

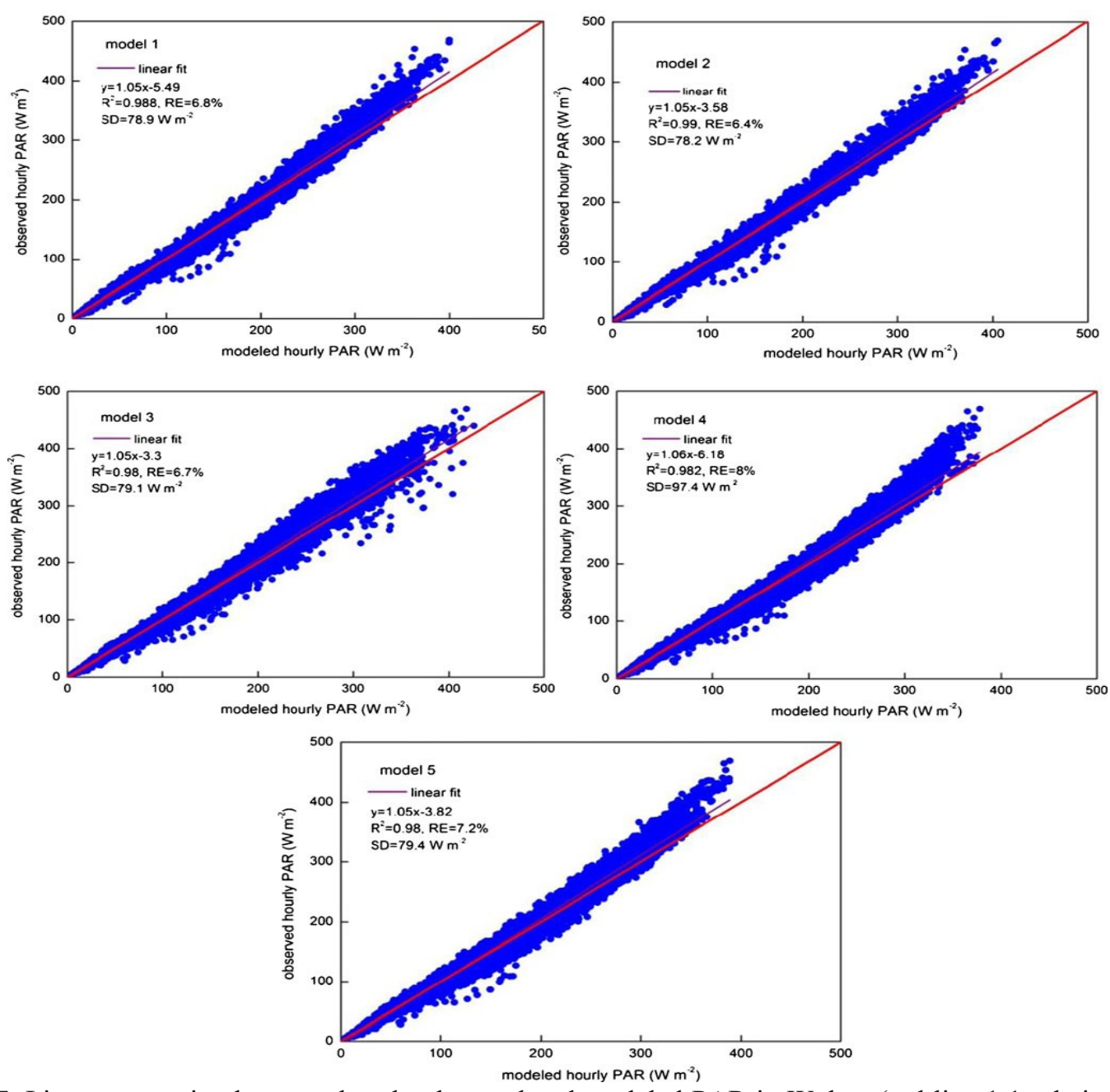

Fig. 7. Linear regression between hourly observed and modeled PAR in Wuhan (red line 1:1 relationship) Wang et al. [71].

Aguiar et al. [65] developed three empirical models for estimating PAR in South West Amazonia both hourly and daily time scale. The authors employed global solar radiation as the only input parameter to develop model 1. Model 2 was fitted by applying global solar radiation and clearness index as input parameter while global solar radiation, cleanness index and water vapour pressure was employed as input parameter for simulating model 3. From the statistical indices on both hourly and daily time scale, the authors reported that the least accurate estimates were usually obtained by model 3 for seasonal models as well as annual models, which employed solar radiation, clearness index and water vapour as input parameters. The exception to this general trend was during the transition between the dry and the wet seasons on the pasture site, whereas model 1 (hourly time scale) and 2 (daily time scale) reported the worst performance respectively. The authors stressed that the relative inferior performance of model 3 is probably due to lack of a clear relationship between the ratio of PAR/H and water vapour pressure. However, the researchers stated that the models showed no significant differences among themselves. That is, significantly, no single model was superior throughout the year, with the best fit 
alternating between model 1 (global solar radiation as input parameter) and model 2 (global solar radiation and cleanness index as input parameters). The authors concluded that the results suggest that simple models of PAR based on one or two parameters are robust and may provide a strong basis for regionally or ecosystem-based Ecophysiological models in this ecologically important part of Brazil. This finding is similar to report found in literature. Yu and Guo [76] in an attempt to identify the most relevant input parameter for estimating PAR in Midwestern United States excluded relative humidity, dew point temperature and perceptible water related to water vapour pressure indicating that water vapour pressure is not a key factor for hourly PAR estimation compared with other parameters. Lopez et al. [122] suggested that input parameters related to water vapour are less important than other sky condition parameters for PAR estimation.

Also, Wang et al. [63] discovered that employing global solar variation, clearness index and cosine of solar zenith angle are sufficient for PAR estimation. However, Jacovides et al. (2015) recommended that only the combination of sunshine fraction and global solar radiation can estimate the daily PAR with reasonable accuracy.

In general, out of the ten (10) different classes of empirical models for estimation PAR across the globe identified in this paper, seven hundred and fifty-seven (757) theoretical models were reported with 62 functional forms and 32 groups (sub-class). Five hundred and seventy (570) models with the corresponding 4 functional forms and 3 groups were recorded from global solar radiation-based models representing 75.29 \%; 18 models with the corresponding 1 functional form and 1 group resulting to $2.37 \%$ were applied for relative humidity-based models; 1 model with 1 functional form and 1 group amounting to $0.13 \%$ for temperature-based model; 1 model with 1 functional form and 1 group yielding to $0.13 \%$ for cloud amount-based model; 1 model with 1 functional form and 1 group yielding to $0.13 \%$ for water vapour pressure-based model; 1 model with 1 functional form and 1 group yielding to $0.13 \%$ for turbidity-based model; 4 models with 2 functional forms and 1 group yielding to $0.52 \%$ for optical air mass-based models; 10 models with 6 functional forms and 3 groups yielding to $1.32 \%$ for sunshine-based models; 27 models with 9 functional forms and 3 group yielding to $3.56 \%$ for clearness index-based models; and 91 models with 36 functional functions and 17 groups resulting to $12.02 \%$ for hybrid parameter-based models as presented in Fig 8. 


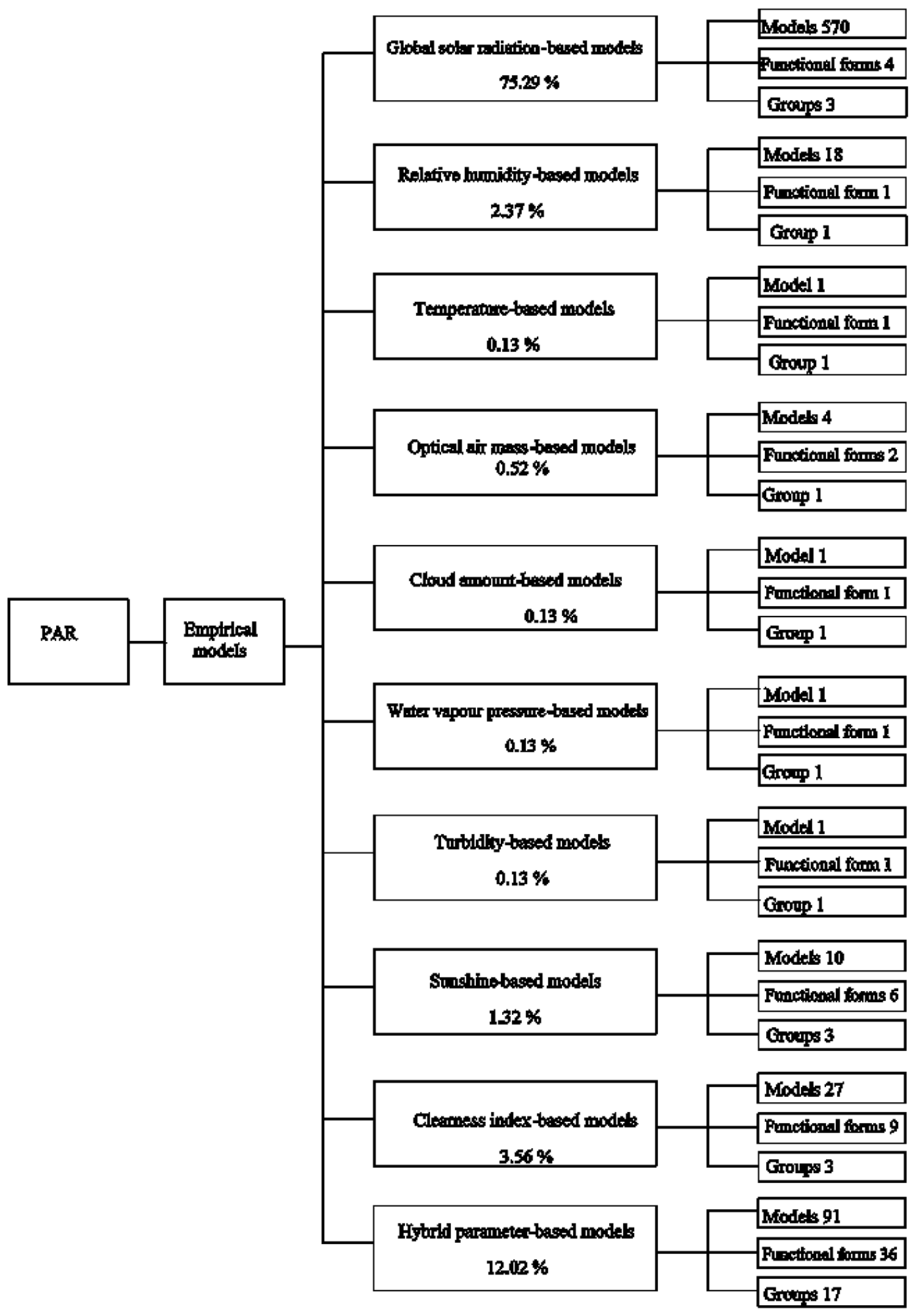

Fig. 8: Classification of photosynthetically active radiation (PAR) and corresponding values of models, functional forms and groups 
It is clear that from above literature that introducing an appropriate set of input that is hybrid model for photosynthetically active radiation estimation in any site of interest is not a viable work. This could be attributed to its complexity involved because of using numerous numbers of required input parameters, inaccuracies associated with irrelevant parameters, difficulty in explaining the model and time consuming task for selecting the required parameter and its inability to accept many input parameters.

The artificial neutral network (ANN) and other soft computer techniques often applied for estimating other component of solar radiation such as diffuse solar radiation, direct normal irradiance and global solar radiation etc. can be adopted for estimating PAR or PAR/H. Several applications of artificial neural networks are reported in numerous fields such image impression, defense, mathematics, character recognition, aerospace, neurology, meteorology and engineering [1-2]. These techniques have been employed for prediction and empirical analysis in market trend forecasting, solar and weather.

For instance, Yu and Guo [76] applied artificial neural networks (multiple layers' perception, MLP) and conventional Multiple Linear Regression (MLP) models for estimating PAR on hourly time scale under different sky conditions in Midwestern United States. The result from the statistical indices revealed that ANN models show higher accuracy than the Multiple Linear Regression (MLR) models especially for overcast sky and clear sky as shown in Table 2. The authors also commented that using water vapour parameters (relative humidity, dew point temperature and precipitable water) do not improve the accuracy significantly. They equally concluded that ANN model that combine the sky clearness, the cosine of sun zenith angle and the hourly global solar radiation as inputs estimated PAR most accurately. This report is in line with findings in literature [63, $75,122]$.

Wang et al. [75] applied ANN models (multi-layer perception, MLP; Radial Basis Neural Network, RBNN; and Generalized Regression Neural Networks, GRNN) and allsky regression PAR model (ALSKY) to estimate hourly PAR under ecosystem such as farmland, forest, lake, desert, grassland, bay and wetland. Global solar radiation $(\mathrm{H})$ was applied as the only input parameter; combination of $\mathrm{H}$ and air pressure (PA); combination of $\mathrm{H}$ and dew point temperature $\left(\mathrm{T}_{\mathrm{d}}\right)$; combination of $\mathrm{H}$ and relative humidity $(\mathrm{RH})$; combination of $\mathrm{H}$ and Water Vapour Pressure $\left(\mathrm{E}^{*}\right)$; combination of $\mathrm{H}$ and air temperature (T); combination of $\mathrm{H}, \mathrm{T}$ and $\mathrm{RH}$; finally, combination of $\mathrm{H}, \mathrm{T}, \mathrm{RH}, \mathrm{T}_{\mathrm{d}}, \mathrm{E}^{*}$ and $\mathrm{PA}$ as input parameters for PAR estimation. From the statistical indicators, MLP and RBNN models perform better than GRNN and ALSYK models and the combinations of air temperature and air pressure parameters recorded more effects on hourly PAR compared with relative humidity, dew point temperature and water vapour pressure parameters under agricultural farmland ecosystem stations. This report is in line with the findings in literature that water vapour parameters are less important than other sky condition parameters for PAR estimation [76, 122]. The author also pointed that under forest ecosystem stations, the GRNN model produces the lowest root mean square error and mean absolute error by combining global solar radiation and air pressure variables inputs at HLF station while MLP, BNN and ALSKY models perform better than the GRNN model. It is also indicated that relative humidity is not a key parameter influencing the hourly PAR parameter as reported by other researchers [76, 122]. Moreover, under the 
Bay ecosystem, the ANN models generally provide better estimates than the ALSKY model, and MLP and GRNN models significantly overestimate low PAR values while the RBNN and the ALSKY model slightly overestimates and underestimates respectively. For the grassland stations, the researcher recorded that the MLP and AKSKY model yielded more accurate hourly PAR estimates compared with the GRNN and RBNN models at NMG ecosystem station, while GRNN model with global solar radiation input parameter provides the lowest statistical indices at HBG station whereas for the wetland ecosystem SJM ecosystem station, the GRNN model comprising global solar radiation input parameter produces slightly lower RMSE values. Under the desert ecosystem stations, the MLP model performs better than the GRNN, RBNN and ALSKY models at FKD station, and the dew temperature parameter generally has more effect on hourly PAR estimates compared with air temperature, relative humidity, air pressure and water vapour pressure. While under lake ecosystem stations, the GRNN model yielded better estimates than other models at DHI station and the water vapour pressure is the most important parameter influencing the hourly PAR fluctuations. The researcher finally concluded that the MLP and RBNN models are more accurate in estimating hourly PAR at different ecosystems in China compared with GRNN and ALSKY models, which will be of vital importance for terrestrial photosynthesis modeling and surface energy budget as shown in Fig. 9 - 15.

Table 2: Statistical comparison between observed hourly PAR and modeled PAR from ANN and conventional regression models $\mathrm{Yu}$ and Guo [76]

\begin{tabular}{|c|c|c|c|c|c|c|c|c|c|c|c|c|c|c|c|c|c|}
\hline & \multicolumn{4}{|c|}{$\mathrm{k}_{\mathrm{i}} \leq 0.35(0 \mathrm{~S})$} & \multicolumn{5}{|c|}{$0.35<\mathrm{k}<0.65$ (PS) } & \multicolumn{2}{|c|}{$\mathrm{k}_{\mathrm{a}} \geq 0.35$ (CS) } & \multicolumn{5}{|c|}{$0<\mathrm{k}_{\mathrm{i}}<1$} & \multirow[b]{2}{*}{ RSD } \\
\hline & & $\mathrm{R}^{2}$ & NRMSE & MPE & RSD & $\mathrm{R}^{2}$ & NRMSE & MPE & RSD & $\mathrm{R}^{2}$ & NRMSE & MPE & RSD & $\mathrm{R}^{2}$ & NRMSE & MPE & \\
\hline \multirow[t]{3}{*}{ ANN1 } & $\overline{B O N}$ & 0.999 & 3.32 & 3.26 & 4.36 & 0.998 & 2.75 & 0.23 & 1.98 & 0.996 & 4.17 & -4.30 & 6.15 & 0.996 & 3.98 & -1.23 & 6.43 \\
\hline & SXF & 0.999 & 2.93 & 2.74 & 3.36 & 0.999 & 1.98 & -1.32 & 2.36 & 0.997 & 4.56 & -3.73 & 4.96 & 0.997 & 3.73 & 0.96 & 4.71 \\
\hline & ALL & 0.999 & 3.17 & 3.01 & 3.98 & 0.999 & 2.53 & -0.31 & 2.05 & 0.997 & 4.43 & -3.96 & 5.61 & 0.996 & 3.86 & -0.15 & 5.96 \\
\hline \multirow[t]{3}{*}{$\mathrm{ANN} 2$} & BON & 0.999 & 3.12 & 1.29 & 4.36 & 0.997 & 3.03 & 1.06 & 3.77 & 0.993 & 3.92 & -2.23 & 3.16 & 0.996 & 3.46 & 0.12 & 5.11 \\
\hline & SXF & 0.998 & 2.79 & -2.28 & 3.78 & 0.999 & 2.64 & -1.38 & 3.39 & 0.999 & 3.78 & -3.72 & 4.35 & 0.997 & 3.11 & -2.78 & 3.95 \\
\hline & ALL & 0.999 & 2.94 & -1.07 & 4.01 & 0.998 & 2.88 & -0.33 & 3.51 & 0.995 & 3.89 & -2.98 & 3.83 & 0.997 & 3.27 & 1.45 & 4.87 \\
\hline \multirow[t]{3}{*}{ ANN3 } & BON & 0.996 & 4.03 & 2.10 & 3.02 & 0.999 & 3.79 & 0.36 & 2.73 & 0.996 & 3.99 & -5.37 & 7.21 & 0.999 & 4.01 & -3.23 & 6.98 \\
\hline & SXF & 0.997 & 3.72 & 0.76 & 2.99 & 0.996 & 3.31 & -0.23 & 2.85 & 0.995 & 4.21 & -6.02 & 6.99 & 0.998 & 3.85 & -3.36 & 5.84 \\
\hline & ALL & 0.996 & 3.85 & 1.79 & 3.01 & 0.997 & 3.56 & 0.24 & 2.79 & 0.996 & 4.06 & -5.77 & 7.08 & 0.998 & 3.68 & -3.27 & 6.03 \\
\hline \multirow[t]{3}{*}{ ANN4 } & BON & 0.993 & 2.96 & 0.33 & 3.71 & 0.999 & 2.81 & 0.32 & 3.68 & 0.998 & 5.12 & -3.98 & 5.36 & 0.995 & 3.81 & -1.32 & 4.69 \\
\hline & SXFF & 0.996 & 3.51 & 3.56 & 4.58 & 0.999 & 3.13 & -2.09 & 4.36 & 0.999 & 4.23 & -4.76 & 5.99 & 0.997 & 3.67 & -0.98 & 5.77 \\
\hline & ALL & 0.995 & 3.32 & 2.75 & 4.17 & 0.999 & 2.94 & -1.78 & 4.07 & 0.999 & 4.76 & -4.58 & 5.71 & 0.996 & 3.79 & -1.17 & 5.21 \\
\hline \multirow[t]{3}{*}{ ANN5 } & BON & 0.998 & 4.20 & 3.38 & 5.12 & 0.993 & 3.77 & 1.88 & 4.76 & 0.982 & 5.79 & 0.23 & 1.07 & 0.993 & 4.42 & 1.96 & 5.04 \\
\hline & SXF & 0.996 & 4.10 & 4.01 & 5.69 & 0.995 & 3.96 & -2.02 & 4.35 & 0.973 & 4.73 & -4.29 & 6.02 & 0.989 & 4.28 & -0.39 & 5.67 \\
\hline & ALL & 0.998 & 4.13 & 3.77 & 5.41 & 0.994 & 3.95 & -0.17 & 4.43 & 0.979 & 5.16 & -2.17 & 3.51 & 0.990 & 4.37 & 0.75 & 5.52 \\
\hline \multirow[t]{3}{*}{ ANN6 } & BON & 0.997 & 3.67 & 2.96 & 4.35 & 0.996 & 3.50 & -0.39 & 3.56 & 0.999 & 4.23 & -3.76 & 4.97 & 0.998 & 3.69 & -0.36 & 4.23 \\
\hline & SXF & 0.999 & 3.56 & -1.97 & 3.96 & 0.998 & 3.47 & 1.96 & 3.76 & 0.979 & 3.99 & 0.11 & 1.21 & 0.999 & 3.61 & 0.03 & 3.97 \\
\hline & ALL & 0.998 & 3.47 & 0.58 & 4.07 & 0.998 & 3.48 & 0.72 & 3.63 & 0.981 & 4.02 & -2.88 & 3.09 & 0.999 & 3.72 & -0.12 & 4.16 \\
\hline \multirow[t]{3}{*}{ Model 1} & BON & 0.996 & 4.53 & 6.75 & 7.07 & 0.969 & 2.88 & 2.36 & 3.65 & 0.965 & 5.32 & -5.59 & 7.05 & 0.996 & 4.43 & 1.17 & 6.71 \\
\hline & SXF & 0.993 & 3.76 & 5.32 & 6.81 & 0.978 & 3.46 & -0.70 & 1.24 & 0.962 & 6.01 & -2.37 & 3.56 & 0.993 & 4.63 & 0.75 & 5.32 \\
\hline & ALL & 0.994 & 4.29 & 6.01 & 6.98 & 0.972 & 3.23 & 0.90 & 2.46 & 0.963 & 5.80 & -3.93 & 5.21 & 0.994 & 4.57 & 0.91 & 6.01 \\
\hline \multirow[t]{3}{*}{ Nodel 2} & BON & 0.995 & 5.61 & 2.10 & 3.53 & 0.998 & 4.02 & -2.33 & 4.05 & 0.943 & 4.33 & -4.79 & 5.98 & 0.989 & 4.32 & -1.67 & 5.92 \\
\hline & SXF & 0.996 & 4.96 & $\begin{array}{l}1.30 \\
1.37\end{array}$ & 1.99 & 0.995 & 3.17 & 1.91 & 3.01 & 0.986 & $\begin{array}{l}.53 \\
5.17\end{array}$ & -5.01 & 6.76 & 0.977 & $\frac{1.32}{4.45}$ & -0.76 & 6.07 \\
\hline & ALL & 0.995 & 5.30 & 1.77 & 2.78 & 0.996 & 3.59 & 0.23 & 3.56 & 0.963 & 4.71 & -4.87 & 6.133 & 0.980 & $\begin{array}{l}4.41 \\
4.41\end{array}$ & -1.21 & 5.98 \\
\hline \multirow[t]{3}{*}{ Nodel 3} & BON & 0.983 & 4.99 & -0.32 & 1.07 & 0.956 & 2.98 & 2.79 & 4.43 & 0.997 & 3.76 & 1.36 & 2.49 & 0.969 & 4.93 & 1.35 & 4.79 \\
\hline & SXF & 0.979 & 4.78 & 2.30 & 3.33 & 0.969 & 3.01 & 1.31 & 2.19 & 0.965 & 4.09 & -4.03 & 6.70 & 0.956 & 4.01 & 0.59 & 5.98 \\
\hline & ALL & 0.980 & 4.85 & 1.19 & 2.17 & 0.962 & 2.99 & 2.03 & 3.37 & 0.979 & 3.98 & -1.43 & 4.23 & 0.963 & 4.51 & 0.98 & 5.63 \\
\hline \multirow[t]{3}{*}{ Model 4} & BON & 0.967 & 6.01 & 2.38 & 3.96 & 0.997 & 4.10 & 3.14 & 5.01 & 0.959 & 4.98 & -2.77 & 3.98 & 0.960 & 4.71 & 0.93 & 4.39 \\
\hline & SXF & 0.976 & $\frac{0.01}{5.72}$ & $\begin{array}{l}3.38 \\
3.06\end{array}$ & $\frac{3.50}{4.59}$ & 0.992 & $\frac{7.10}{3.77}$ & $\frac{3.14}{-1.29}$ & 2.01 & 0.963 & 5.96 & -1.76 & 2.98 & 0.972 & 5.05 & 0.93 & 5.79 \\
\hline & ALL & 0.977 & 5.91 & 2.66 & 4.23 & 0.995 & 3.92 & 0.93 & 3.59 & 0.960 & 5.01 & -2.20 & 3.61 & 0.965 & 4.88 & 0.58 & 5.08 \\
\hline
\end{tabular}




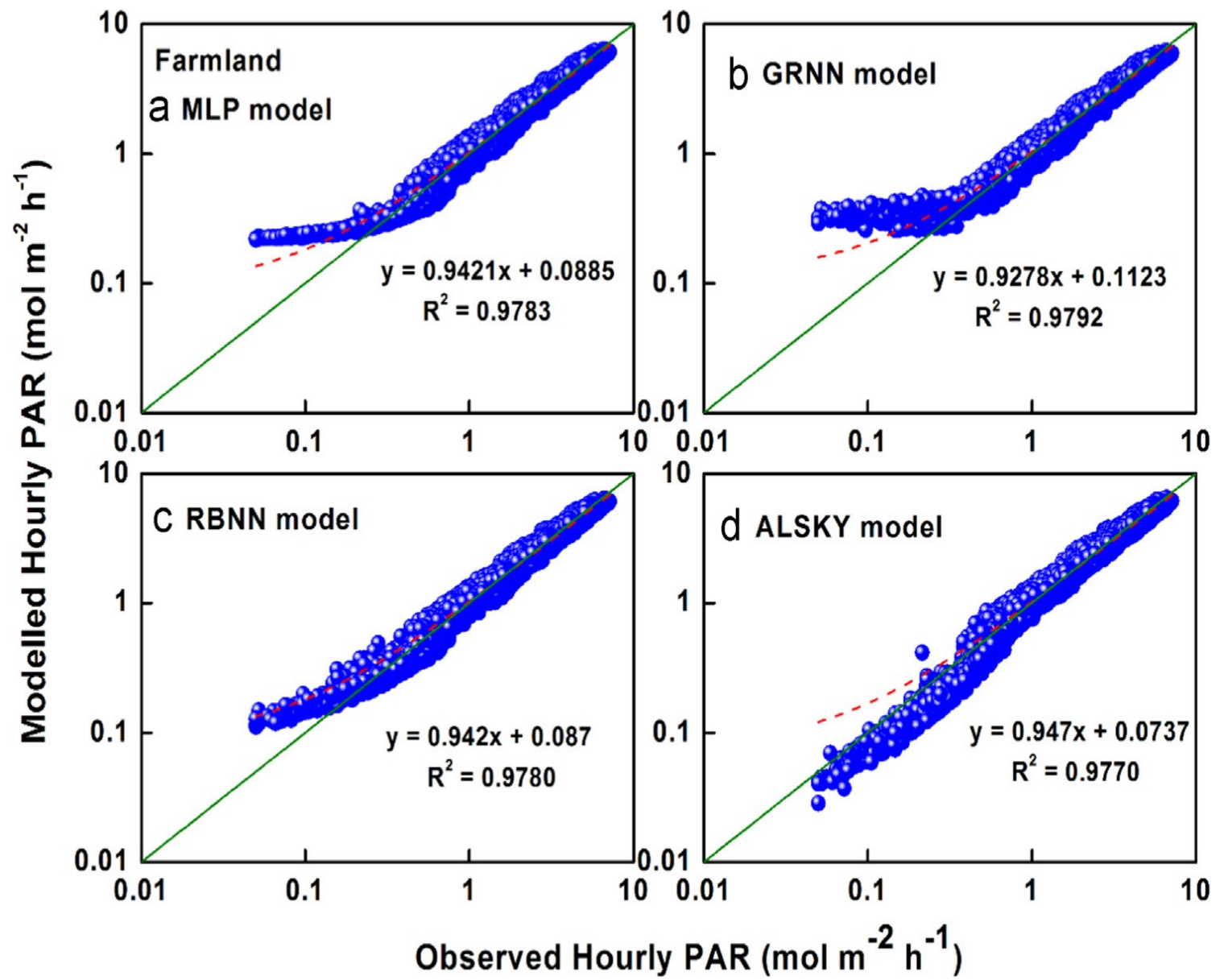

Fig. 9. The PAR estimates of the optimal models for the FQA station in farm land ecosystem Wang et al. $[75]$. 


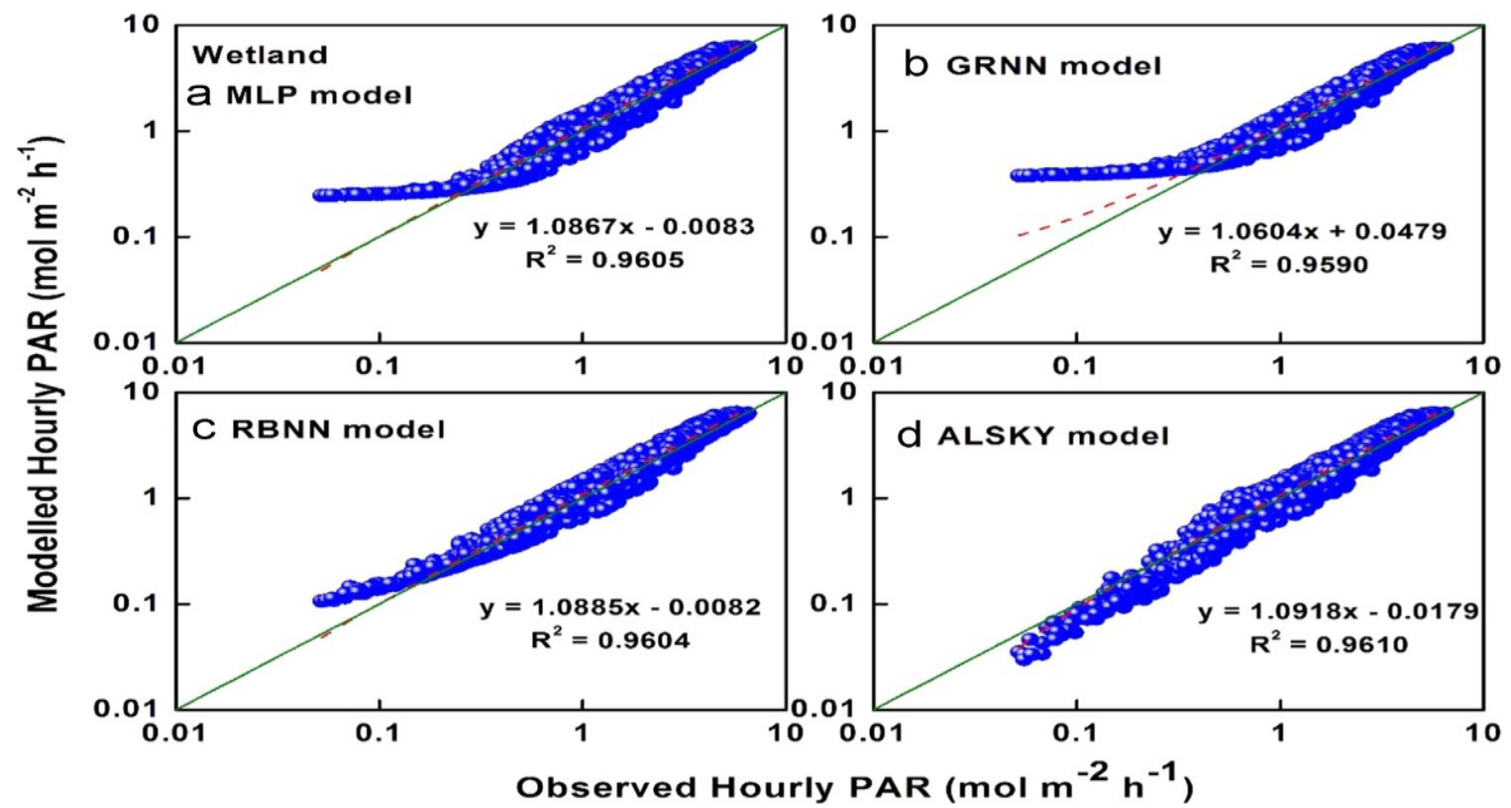

Fig. 10. The PAR estimates of the optimal models for the SJM station in wetland ecosystem Wang et al. [75].

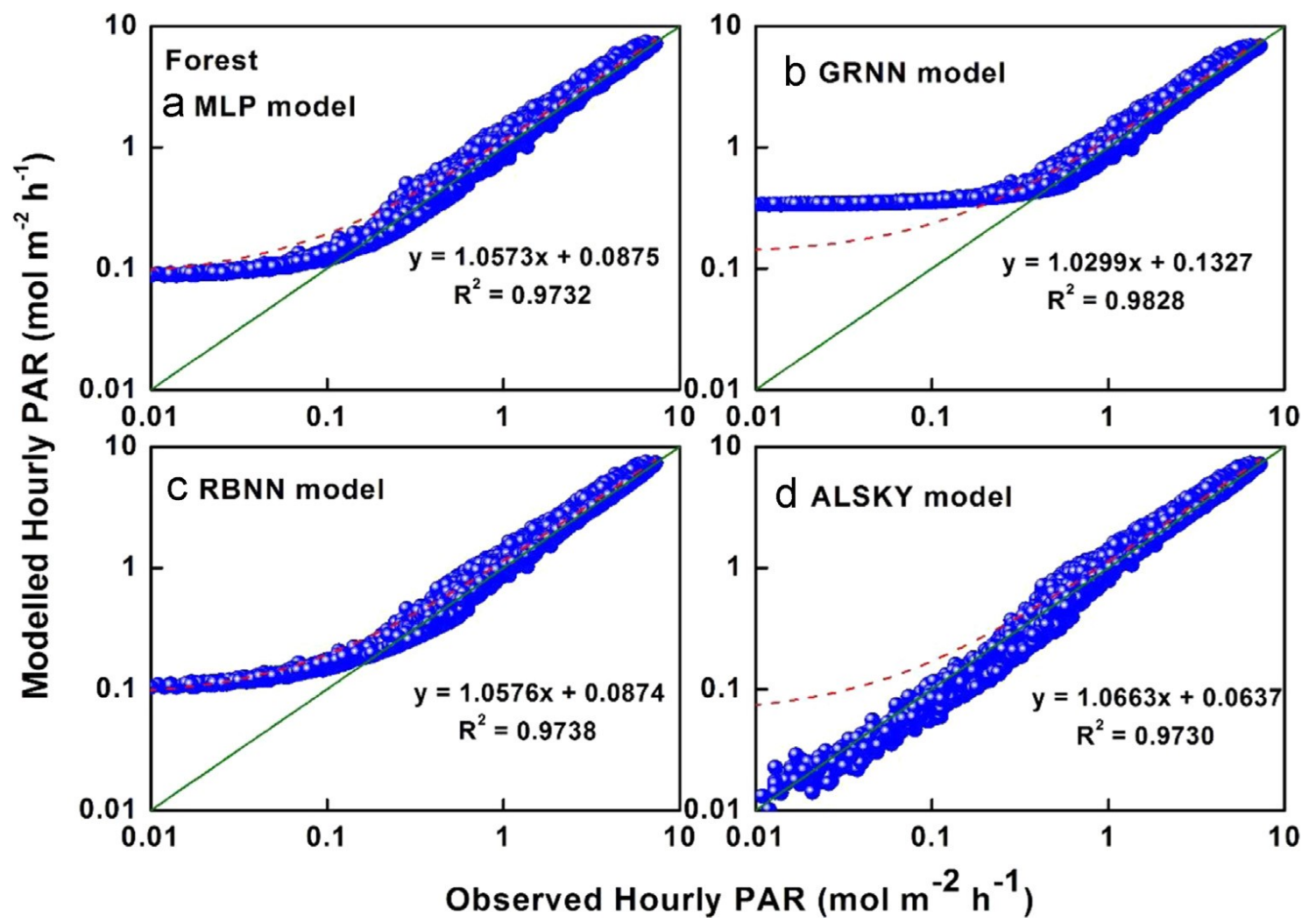

Fig. 11. The PAR estimates of the optimal models for the ALF Station in forest ecosystem Wang et al. [75]. 


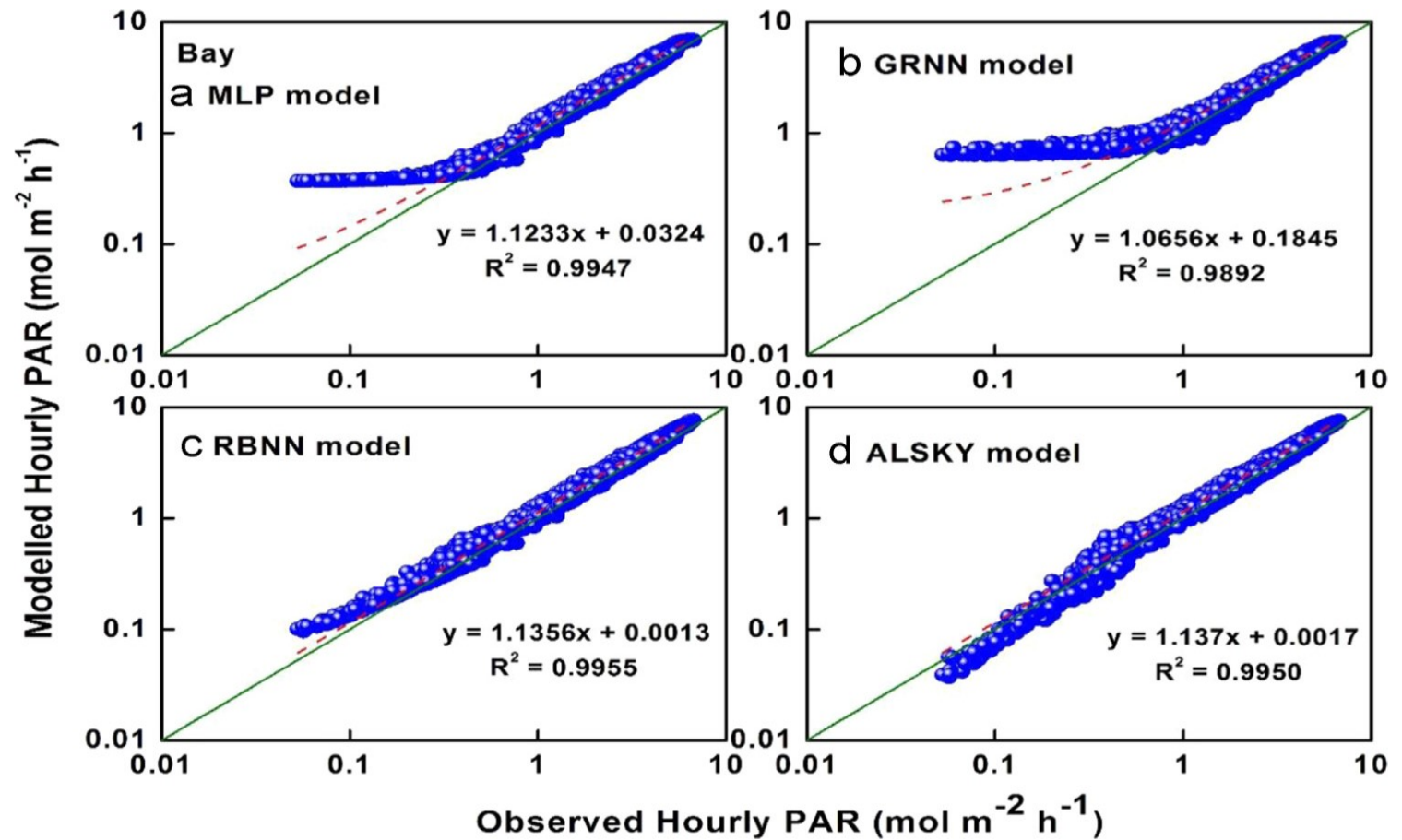

Fig. 12. The PAR estimates of the optimal models for the SYB station in bay ecosystem Wang et al. [75].

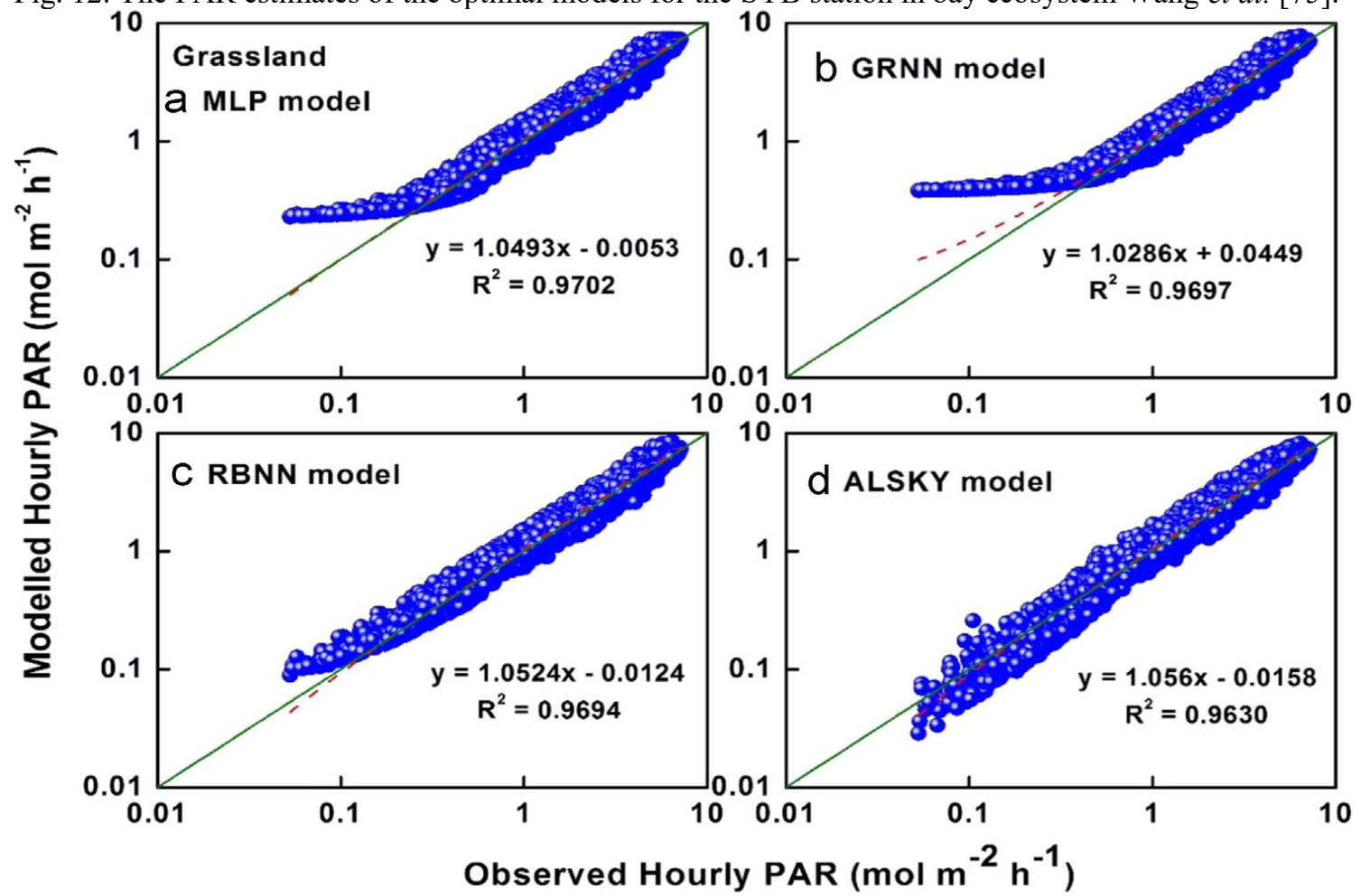

Fig. 13. The PAR estimates of the optimal models for the HBG station in grassland ecosystem Wang et al. [75]. 


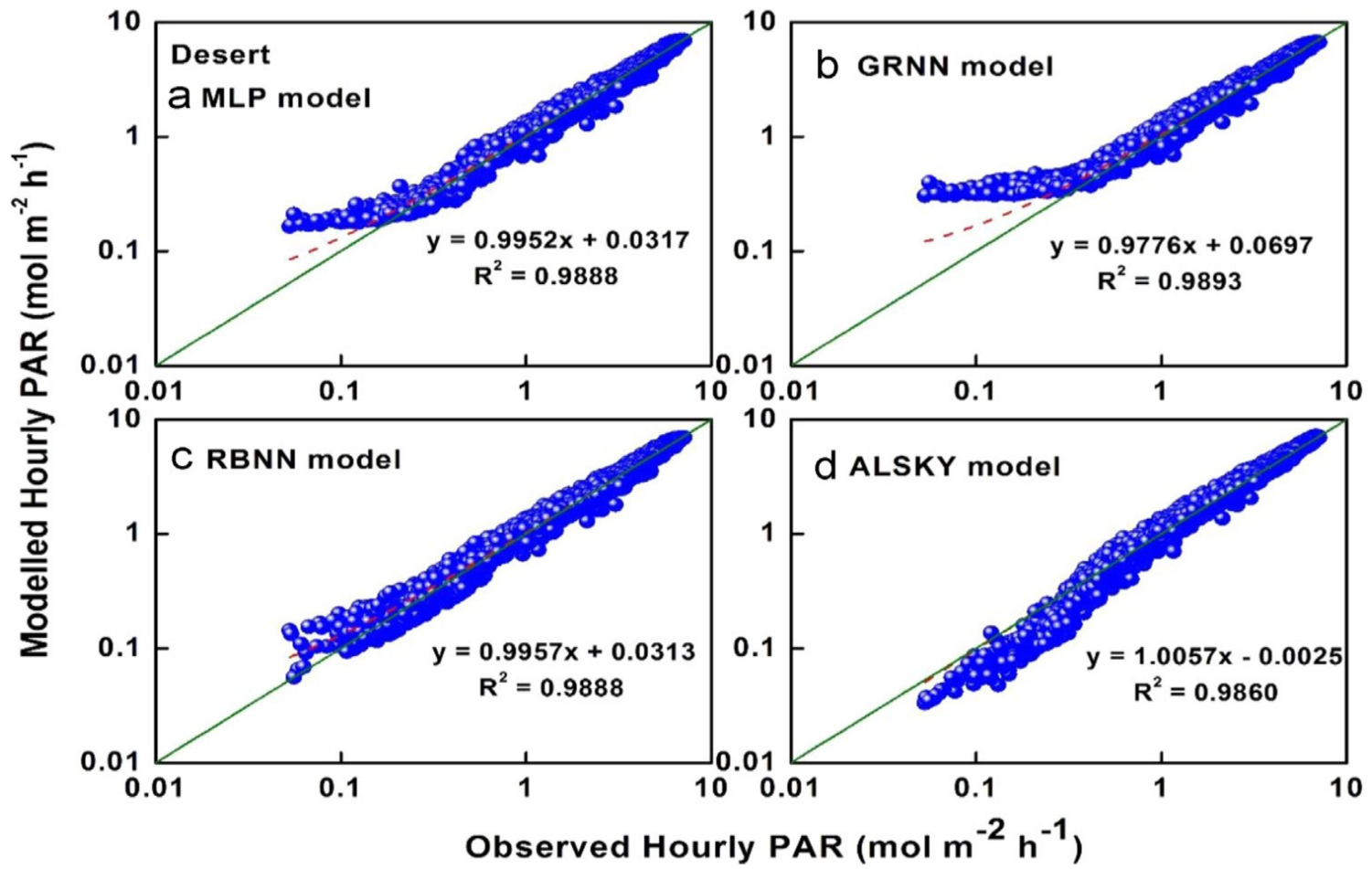

Fig. 14. The PAR estimates of the optimal models for the SPD station in desert ecosystem Wang et al. [75].

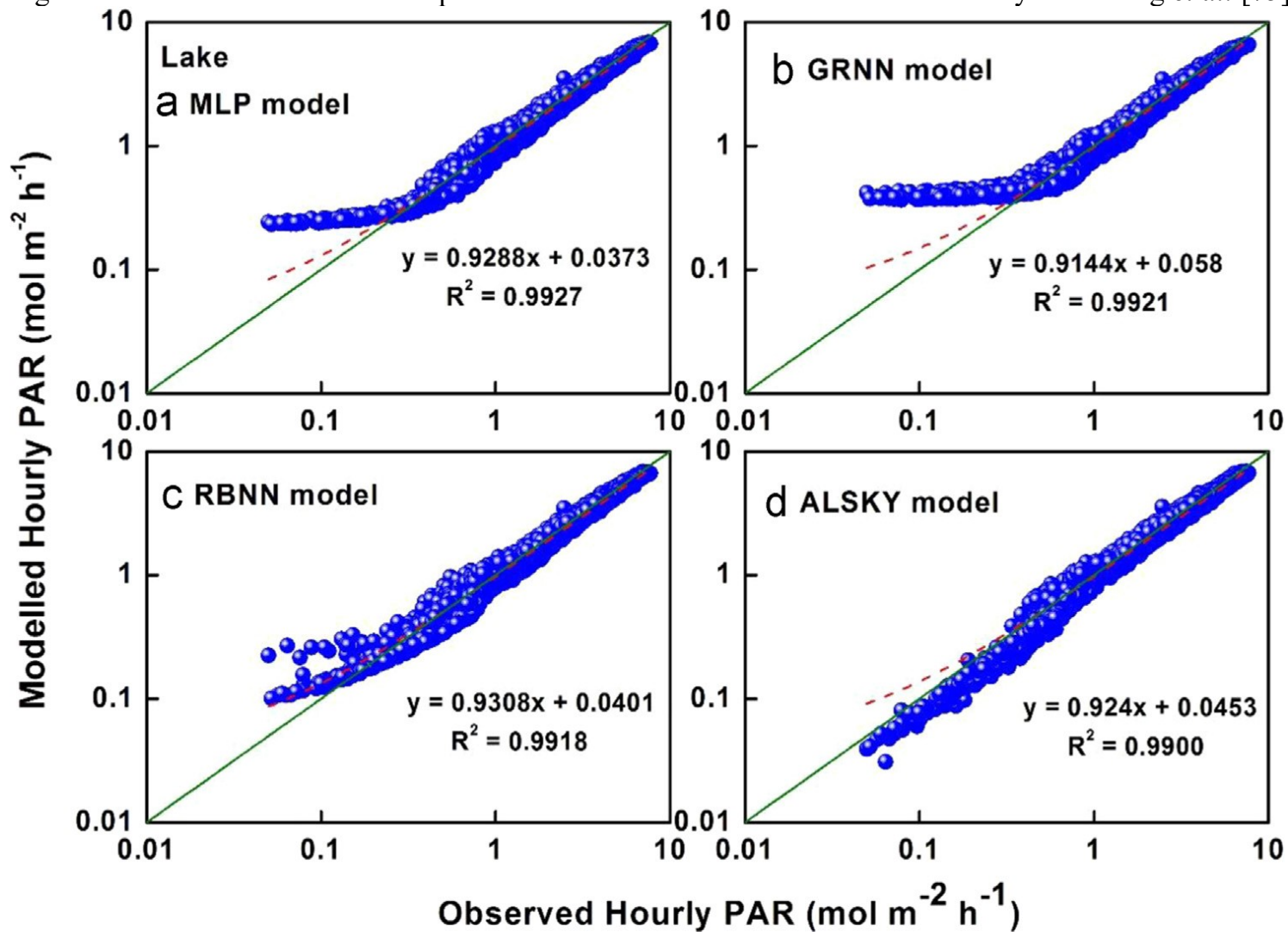

Fig. 15. The PAR estimates of the optimal models for the THL station in lake ecosystem Wang et al. [75].

Tr Ren Energy, 2018, Vol.4, No.2, 236-327. doi: 10.17737/tre.2018.4.2.0079 


\section{Research Gaps}

The photosynthetically active radiation (PAR) empirical models examine in this paper is distinctive and provide valuable outcome for numerous circumstances. The models regarded as capable and convenient for hourly models, temperature-based models, optical air mass-based models, relative humidity-based models, cloud amount-based models, water vapour pressure-based models, turbidity-based models, sunshine-based models, clearness index-based models and hybrid parameter-based models. A number of essential areas identified in literature as well as shortcomings with solutions recommended in this paper are summed up subsequently below.

1. In previous studies, authors employed one, two, three, or more years of photosynthetically active radiation data as available to build ANN models is not a viable work. Thus, employing training and testing data of minimum three years and one year respectively can be adopted to estimate photosynthetically active radiation accurately; however, further comparative analysis on the aspect can be under taken also.

2. During the development of ANN models, the neurons in ANN hidden layer are changed one by one and mean absolute percentage error (MAPE) are calculated which is time consuming. Therefore, considerable techniques should be developed to find out hidden layer neurons at which estimation error is minimum.

3. Different artificial neural networks models need to be stimulated employing latitude, longitude, altitude, extraterrestrial solar radiation, solar declination, cosine of solar zenith angle, optical air mass and other atmospheric and meteorological input parameters that can be calculated with standardized formulas and checked for accuracy. The goal is that, if an appropriate modelling of this radiometric flux (PAR) could be developed, a large data resource of it will be created without the substantial cost of the instrumentation network that would otherwise be needed thereby meeting the needed meteorological stations and countries (Africa) that cannot measure PAR routinely.

4. Comparison of Niching genetic algorithm, automatic relevance determination methodology need to be employed in selecting most relevant input parameters in addition with ANN models for estimation

5. Additional studies are needed for the estimation of beam and diffuse photosynthetically active radiation (PAR) using ANN and other soft computing models

6. Drawing from findings in literature, a single model based on the variations of the ratio photosynthetically active radiation to global solar radiation under different sky conditions, ecosystem, local climate and geographical regions over several sites employing empirical models so as to developed weather-dependent functions of this ratio should been considered and emerged. The goal is to develop a model transferable to these locations that routinely measured the broadband solar radiation for appropriation calibration of the model using their measured meteorological data to generate and probably recommend a model transferable to other sites, ecosystem, local climate and geographical areas as in what was obtainable in Food and 
Agriculture Organization (FAO) Penman-Monteith model recommended for estimating reference evapotranspiration developed by Allen et al. [123] without local calibration globally.

7. It is also essential to mention that soft computing models has newly been initiated for estimating renewable energy resources (e.g. PAR), but additional work is necessary to increase solar radiation or PAR estimation accuracy pertaining to numerous seasons, climate change to supply increasingly reliable efficient solar systems on the market.

\section{Concluding Remarks}

This review paper presents a comprehensive review of literature on photosynthetically active radiation across the globe. 757 empirical models, 62 functional forms, and 32 groups were identified employing global solar radiation-based models, relative humidity-based models, temperature-based models, optical air mass-based models, cloud amount-based models, water vapour pressure-based models, turbidity-based models, sunshine-based models, clearness index-based models, and hybrid parameter-based models. The findings in this paper provide future dimension to industry and research practitioners for further studies on solar system and photosynthetically active radiation estimation in particular.

From this review, ANN models are found to estimate PAR accurately in different climate conditions and ecosystem across the globe. This could be attributed to the fact that these models can accept many input parameters as compared with empirical models that strengthen its reliability. Moreover, it can also be concluded that ANN models estimations offer greater accuracy as compared with empirical models, e.g. Tables 2 and Fig. $9-15$ show estimation error in a range (less than 20\%) and this could be very good in terms of PAR estimation. Therefore, ANN and other soft computing models are much more demanding in the domain of renewable energy (e.g PAR) estimation and solar system design. It is finally recommended that future studies on PAR estimation should consider employing both empirical and soft computing models in order to observe the research gap between the two techniques in sites where PAR estimation has not been carried out before particularly in Africa continent where few meteorological station are capable of measuring this radiometric flux.

\section{Acknowledgements:}

Our thanks go to all the authors cited in this paper for their research works that has made this research possible.

\section{Funding}

This research did not receive any specific grant from funding agencies in the public, commercial, or not-for-profit sectors. 


\section{CONFLICTS OF INTEREST}

The authors declare that there is no conflict of interests regarding the publication of this paper.

\section{References}

[1] Nwokolo SC. A comprehensive review of empirical models for estimating global solar radiation in Africa. Renewable and sustainable energy reviews, 2017, 78: 955 995.

[2] Nwokolo SC, Ogbulezie JC. A single hybrid parameter-based model for calibrating hargreaves-samani coefficient in Nigeria. International Journal of Physical Research, 2017, 5(2): 49-59

[3] Pohlert T. Use of empirical global radiation models for maize growth simulator. Agricultural and Forest Meteorology, 2004, 126 (1): 47 - 58.

[4] Dye DG. Spectral composition and quanta-to-energy ratio of diffuse photosynthetically active radiation under diverse clouds condition. J. Geophys Res: Atmos, 2004. DOI:10.1029/2003JD 004251

[5] Alados I, Foyo-Moreno I, Alados-Arboledas L. Photosynthetically active radiation. Measurements and Modeling. Agricultural and Forest Meteorology, 1996, 78: 121 131.

[6] Dye DG, Shibasaki R. Intercomparison of Global PAR data set. Geophy Res Lett, 1995, 22: 2013 - 2016.

[7] Zhao MS, Running SW. Drought-induced reduction in global territorial net primary production from 2000 through 2009. Science, 2010, 329: 940 - 943.

[8] Asaf D, Rotenberg E, Tatarinor F, Dicken U, Montzka SA, Yakir D. Ecosystem Photosynthesis inferred from measurements of carbonyl sulphide flux. Nat Geosci, 2013, 6:186 - 190 .

[9] Wang L. Gong W, Lin A, Hu B. Analysis of photosynthetically active radiation under various sky conditions in Wuhan, Central China. Int J. Biometeorol., 2013. DOI:1007/500484-013-0775-3

[10] Cooter EJ, Dhakhua GB. A solar radiation model for use in biological applications in the south and southeastern USA. Agricultural and Forest Meteorology, 1995, 78: 31 -51 .

[11] Hunt LA, Kuchar L, Swanto CJ. Estimation of solar radiation for use in crop modeling. Agricultural and Forest Meteorology, 1998, 91: 293 - 300.

[12] Hoogenboom G. Contribution of agrio meteorology to the simulation of crop production and its applications. Agricultural and Forest Meteorology, 2000, 103: 137 $-157$.

[13] Loutzenhiser PG, Manz H, Felsmann C, Stranchan PA, Frank T. Empirical Validation of models to compute solar irradiance on inclined surfaces for building energy simulation. Solar Energy, 2007, 81: $254-267$. 
[14] Holyle CR, Myher G, Isaksen I. Present - day contribution of anthropogenic emissions from China to the global burden and radiative forcing of aerosol and Ozone. Tellus B, 2009, 61: 618-624.

[15] Frouin R, Pinker RT. Estimating photosynthetically active radiation (PAR) at the earth's surface from satellite observations. Remote Sensing Environ, 1995, 51: 98 107.

[16] Wang LC, Gong W. Ma YY, Zhang M. Modeling regional vegetation NPP variations and their relationships with climatic parameters in Wuhan, China. Earth Interaction, 2013, 17: $1-20$.

[17] Wang Q, Tenhunen J, Schmidt M, Otieno D, Kolcuu O. Diffuse Par irradiance under clear skies in complex alpine tenain. Agricultural and Forest Meteorology, 2005, 128: $1-15$.

[18] Zarzo M, Marti P. Modeling the variability of solar radiation doctor among weather station by means of principal component analysis. Applied Energy, 2011, 88: 2775 2784.

[19] Cao MK, Prince SD, Tao B, Li KK. Regional Pattern and international variations in global terrestrial carbon intake in response to changes in climate and atmospheric Co2. Tellus B, 2005, 57: $210-217$.

[20] Gallo KP, Daughtry CST, Bauer ME. Spectral estimation of absorbed photosynthetically active radiation in corn canopies. Remote Sens. Environ., 1985, 17: 221-232.

[21] Beer C, Reichstein M, Tomelleri E, Ciais P. Terrestrial gross carbon dioxide uptake: global distribution and covariation with climate. Science, 2010, 329: 834-838.

[22] Pinker RT, Laszlo I. Global distribution of photosynthetically active radiation as observed from satellites. J. Chem., 1992, 5: 56-65.

[23] Knorr W. Annual and Internal $\mathrm{Co}_{2}$ exchanges of the terrestrial biosphere: processbased stimulations and uncertainties. Glob. Ecol. Biogeogr., 2000, 9: 225 - 252.

[24] Trenberth KE, Fasullo JT, Kiehl J. Earth's global energy budget. Bull. Am. Meteorol. Soc., 2009, 90: $311-323$.

[25] Garnaud C, Sushama L, Arora VK. The effect of driving climate data on the simulated terrestrial carbon pools and fluxes over North America. International Journal of Climatology, 2014, 34:1098 - 1110.

[26] Jonathan AP, Colin P, Navin R, Samuel L, David P. An Integrated biosphere model of band surface process, territorial carbon balance, and vegetation dynamics - Global Biogeochem. Cycles, 1996, 10:603 - 628.

[27] Van RL, Sanchez GA. Mapping PAR using MODIS atmospheric products. Remote Sens. Environ., 2005, 94; 554 - 563.

[28] Nwokolo SC, Ogbulezie JC. Relationship between photosynthetically active radiation with global solar radiation using empirical model over selected climatic zones in Nigeria. Journal of Scientific Research in Allied Sciences, 2017, 3(3): 1-17.

[29] Mizoguchi Y, Ohtani Y, Aoshima T, Hirakata A, Yuta S, Takanashi S, Iwata H, Nakai Comparison of the characteristics of five quantum sensors. Bull. FFPRI, 2010, 9(3): $113-120$. 
[30] Mizoguchi Y, Yasuda Y, Ohtani Y, Watanabe T, Komianami Y, Yamanoi K. A practical model to estimate photosynthetically active radiation using general meteorological elements in a temperate humid area and comparison among models. Theor. Appl Chimatol, 2014, 15: 583 - 589.

[31] Ross J, Sulvev M. Sources of errors in measurements of PAR. Agricultural and Forest Meteorology, 2000, 100:103 - 125.

[32] Gueymard C. An atmospheric transmittance model for the clear sky beam, diffuse and global photosynthetically active radiation. Agricultural and Forest Meteorology, 1989, 45: 215 - 229.

[33] Gueymard C. A two-band model for the calculation of clear sky solar irradiance, illuminance, and photosynthetically active radiation at the Earth's surface. Solar Energy, 1989, 43: $253-265$.

[34] Olseth JA, Skartvert A. Luminous efficacy models and their application for calculation of photosynthetically active radiation. Solar Energy, 1993, 52: 391 - 399.

[35] Eck TF, Dye DG. Satellite estimation of incident photosynthetically active radiation using ultraviolet reflectance. Remote Sens. Environ., 1991, 38: 135 - 146.

[36] Moon P. Proposed standard solar - radiation curves for engineering use. J Franklin Inst, 1940, 230: $583-618$.

[37] McCree KJ. A solarimeter for measuring photosynthetically active radiation. Agricultural and Forest Meteorology, 1966, 3: 353 - 366.

[38] McCartney HA. Spectral distribution of solar radiation. Part II: Global and diffuse. Q.J.R. Meteorol. Soc., 1978, 104; 911 - 926.

[39] Karalis JD. Characteristic of direct photosynthetically active radiation. Agricultural and Forest Meteorology, 1989, 48: 225 - 234.

[40] Escobedo JF, Gomes EN, Oliveirol AP, Soares J. Modeling hourly and daily fraction of UV, PAR and NIR to global solar radiation under various sky conditions at Botucoctu, Brazil. Applied Energy, 2009, 86: 299 - 309.

[41] Meek DW, Hatfied JL, Howell TA, Idso SB, Reginato RJ. A generalized relationship between photosynthetically active radiation and solar radiation. Agronomy Journal, 1983, 76: 939 - 945.

[42] Finch DA, Bailey WG, McArthur LJB, Nasitivitwi M. Photosynthetically active radiation in Zambia. 2004. https://www.researchgate.net/publication/238088149 Photosynthetically active radi ation in Zambia (accessed on 10/4/2018)

[43] Finch DA, Bailey WG, McArthur LJB, Nasitivitivi M. Photosynthetically active radiation regimes in a southern African Savanna environment. Agricultural and Forest Meteorology, 2004, 122: 229 - 238.

[44] Walczak T, Maczek W, Czainowsk M. Quantum radiometer for measurement of photosynthetically active radiation. Zesz. Probl. Post. Nauk. Rol., 1989, 263 - 265.

[45] McCree KJ. Test of current definition of measuring photosynthetically active radiation against leaf photosynthesis data. Agricultural and Forest Meteorology, 1972, 10: $441-453$. 
[46] Jacovides CP, Timbios FS, Asimakopoulos DN, Steven MD. Urban aerosol and clear skies spectra for global and diffuse photosynthetically active radiation.

Agricultural and Forest Meteorology, 1997, 87: 91-104

[47] Mizoguchi Y, Yasuda Y, Ohtani Y, Watanabe T, Komianami Y, Yamanoi K. A practical model to estimate photosynthetically active radiation using general meteorological elements in a temperate humid area and comparison among models. Theor. Appl Chimatol, 2014, 15: 583 - 589.

[48] Tsubo M, Walker S. Relationship between photosynthetically active radiation and clearness index in Bloemfontein, South Africa. Theor. Appl. Climatol, 2005, 80:17 25.

[49] Akitsu T, Kume A, Hirose Y, Ijima O, Nasahara KN. On the stability of radiometric of photosynthetically active radiation to global solar radiation in Tsukuba, Japan. Agricultural and Forest Meteorology, 2015, 209: 59-68.

[50] Udo SO, Aro TO. Calobal PAR related to global solar radiation for central Nigeria. Agricultural and Forest Meteorology, 1999, 97: 21 - 31.

[51] Rao CR. Photosynthetically active components of global solar radiation: measurements and model computations. Arch meteorol. Geophys. Bioclim. Ser. B, 1984, 34: 353 - 364.

[52] Papaioannou G, Papanikolaou N, Retalis D. Relationships of Photosynthetically active radiation and shortwave irradiance. Theor Appl Climatol, 1993, 48: 23 - 27.

[53] Jacovides CP, Tymrios FS, Papaioannou G, Assimakopoulos DN, Theofilou CM. Ratios of PAR to broadband solar radiation measured in Cyprus. Agricultural and Forest Meteorology, 2004, 121: $134-140$.

[54] Wang Q, Kakabari Y, Kubota M, Tenhunen J. Variation of PAR to global solar radiations ratio along altitude gradient in Naeba Mountain. Theor Appl Climatol, 2007, 87: 239-253.

[55] Li R, Zhao, L, Ding Y, Wang S, Ji G, Xiao Y, Liu G, Sun L. Monthly ratios of PAR to global solar radiation measured of northern Tibetan Plateau, China. Solar Energy, 2010, 84: 964-973.

[56] Britton CM, Dodd JD. Relationships of Photosynthetically active radiation and structure irradiance. Agricultural and Forest Meteorology, 1976, 17: 1 - 7.

[57] Szeicz G. Solar radiation for plant growth. J Appl Ecol., 1984, 11: 617 - 636.

[58] Monteith JL, Unsworth M. Principle of environmental physics, second ed. Edward Armold, London: 1990.

[59] Bat-Oyun T, Shinoda M, Tsubo M. Effects of Cloud, Atmospheric water vapor, dust on photosynthetically active radiation and total solar radiation in a Mongolian grassland. Journal of Arid Land, 2012, 4(4): 349 - 356.

[60] Nwokolo SC, Ogbulezie JC. Modeling the influence of relative humidity on photosynthetically active radiation from global horizontal irradiation in six tropical ecological zones in Nigeria. New York Science Journal, 2016, 9(11): 40-55.

[61] Abolfazi MH. Estimating Photosynthetically active radiation (PAR) using air temperature and sunshine duration. Journal of Biodiversity and Environmental Sciences, 2014, 5(4): $371-377$. 
[62] Hu B, Wang Y, Comparison of multi-empirical estimation models of photosynthetically active radiation under all sky conditions in Northeast China. Theor Appl Climatol, 2014, 116: 119-129.

[63] Wang L, Gong W, Feng L, Lin A, Hu B, Zhou M. Estimation of hourly and daily photosynthetically active radiation in Inner Mongolia, China, from 1990 to 2012. International Journal of Climatology, 2014. DOI: 10:1002/joc.4197

[64] Hu B, Yu Y, Lin Z, Wang Y. Analysis of photosynthetically active radiation and applied parameterization model for estimating of PAR in the North China plain. J. Atoms Chem, 2016. DOI:10.1007/510874-016-9330-2

[65] Aguiar LJG, Fischer GR, Ladle RJ, Malhado ACM, Justino FB, Aguiar RG, Da Costa JMN. Modeling the photosynthetically active radiation in South West Amazonia under all sky conditions. Theor Appl. Climatol, 2011. DOI:10.1007/s00704-011-0556-2

[66] Aguiar LJG, Da Costa JMN, Aguiar RG, Fischer GR. Estimates and measurements of photosynthetically active radiation and global solar irradiance in Rondonia. 2006. DOI: 10.1063/1.3117013

[67] Finch DA, Bailey WG, McArthur LJB, Nasitivitivi M. Photosynthetically active radiation regimes in a southern African Savanna environment. Agricultural and Forest Meteorology, 2004, 122: 229 - 238.

[68] Etuk SE, Okechukwu AE, Nwokolo SC. Modelling and estimating pohotosynthetically active radiation over six tropical ecological zones in Nigeria. Journal of Geography, Environment and Earth Science International, 2016, 12(2): 112.

[69] Etuk SE, Nwokolo SC, Okechukwu AE, John-Jaja SA. Analysis of photosynthetically active radiation over six tropical ecological zones in Nigeria. Journal of Geography, Environment and Earth Science Internal, 2016, 7(4): 1 - 15.

[70] Nwokolo SC, Ogbulezie JC, Toge CK, John-Jaja SA. Photosynthetically active radiation estimation and modeling over different climatic zone in Nigeria. 2017, DOI:10.9734/JAERI/2017/30000

[71] Wang L, Gong W, Ma Y, Hu B. Photosynthetically active radiation and its relationship with global solar radiation in Central China. Int J Biometeorol, 2013. DOI:10.1007/s00484-013-0690-7

[72] Yu X, Wu Z, Jiang W, Guo X. Predicting daily photosynthetically active radiation from global solar radiation in the contiguous United States. Energy Conversion and Management, 2015, 89: 71-82.

[73] Peng S, Du, Lin A, Hu B, Xiao K, Xi Y. Observation and estimation of photosynthetically active radiation in Lhasa (Tibetan Plateau). Advances in space research, 2015, 55: 1604-1612.

[74] Udo SO, Aro TO, New medical relationships for determining global PAR from measurement of global solar radiation, infrared radiation or sunshine duration. International Journal of Climatology, 2000, 20: 1265-1274.

[75] Wang L, Kisi O, Zounemat-Kermani M, Hu B, Gong W. Modeling and Comparison of hourly photosynthetically active radiation in different ecosystems. Renewable and sustainable energy reviews, 2016, 56: $436-453$. 
[76] Yu X, Guo X. Hourly photosynthetically active radiation estimation Midwestern United States from artificial neural networks and conventional regression models. Int J. Biometeorol, 2016, 60(8):1247-59. DOI: 10.1007/s00484-015-1120-9

[77] Melina-Maria Z, Michael T, Alkiviadis B, Stelios K. Modeling the relationship between photosynthetically active radiation and global horizontal irradiance using singular spectrum analysis. Journal of Qualitative Spectroscopy and Radiative Transfer, 2016, 182: 240-263.

[78] Yaniktepe B, Genc YA. New Model for predicting the global solar radiation on horizontal surface. International Journal of Hydrogen, 2015, 40: 15278 - 15283.

[79] Zhang J, Zhao L, Deng S, Xn W, Zhang Y. A Critical review of models used to estimate solar radiation. Renewable and sustainable Energy Reviews, 2017, 70: 314 $-329$.

[80] Yu, Y, Chen HB, Xia XA. Significant variation of surface Albedo during a snow period at Xiaughe observatory China. Adv. Atmos Sci., 2010, 27: $80-86$.

[81] Lauret P, Voyant C, Soubdhan T, David M, Poggi P. A benchmarking of machine learning techniques for solar radiation forecasting in an insular context. Solar Energy, 2015, 112: 446-457.

[82] Sperati S, Alessandrini S, Pinson P, Kariniotakis G. The "Weather Intelligence for Renewable Energies" Benchmarking Exercise on Short-Term Forecasting of Wind and Solar Power Generation. Energies, 2015, 8:9594-9619.

DOI:10.3390/en8099594.

[83] COST | About COST, (n.d.). http://www.cost.eu/about_cost (accessed on June 31, 2017).

[84] Pelland S, Galanis G, Kallos G. Solar and photovoltaic forecasting through postprocessing of the Global Environmental Multiscale numerical weather prediction model, Prog. Photovolt. Res. Appl., 2013, 21: 284-296. DOI:10.1002/pip.1180.

[85] Trapero JR, Kourentzes N, Martin A. Short-term solar irradiation forecasting based on Dynamic Harmonic Regression. Energy, 2015, 84: 289-295.

[86] Monteith JL. Solar radiation and productivity in tropical ecosystems. J. Appl. Ecol., 1972, 9: $747-766$.

[87] Hodges T, Kanemasu E. Modeling daily dry matter production of winter wheat. Agronomy Journal, 1977, 69: 974 - 978.

[88] Stanhill G, Fuchs M. The relative flux density of photosynthetically active radiation. J Appl Ecol, 1977, 14: 317 - 322.

[90] Hodges T, Kanemasu E, Teare I. Modeling dry matter accumulating and yield of grain soighum. Can. J. Plant Sci., 1979, 59: 803 - 818.

[91] Howell TA, Meek DW, Hatfield JL. Relationship of photosynthetically active radiation to shortwave radiation in the San Joaquin Valley. Agricultural and Forest Meteorology, 1983, 28: 157 - 175.

[92] Kvifte G, Hegg K, Hansen V. Spectral distribution and characteristics distribution of solar radiation in the Nordic countries. J. Climate Appl Meteorol, 1983, 22: 143 152.

[93] Rodskjer N. Spectral daily insolation at Uppsala, Sweden. Arch meteorol Geophys Bioclim Ser B, 1983, 33: 89 - 98. 
[94] Blackbum WJ, Proctor JTA. Estimating photosynthetically active radiation from measured solar irradiance. Solar Energy, 1983, 31: 233 - 234.

[95] Weiss A Norman JM. Partitioning solar radiation into direct and diffuse, visible and near - infrared components. Agricultural and Forest Meteorology, 1985, 34: 205 213.

[96] Slomka J. photosynthetic photon inflow in relation to sunshine duration of Belsk. Inst. Geophys. Pol. Acad. Sci., 1977, D-32 (230): 85 - 87.

[97] Zhang X, Zhang Y. Zhou Y. Measuring and Modelling photosynthetically active radiation in Tibet Plateau during April - October. Agricultural and Forest Meteorology, 2000, 102: $207-212$.

[98] Wang L. Gong W, Li C, Lin A, Hu B, Ma Y. Measurement and estimation of photosynthetically active radiation from 1961 to 2011 in Central China. Applied Energy, 2013, 111: 1010-1017.

[99] Anjorin OF, Utah EU, Likita MS. Estimation of hourly photosynthetically Active radiation (PAR) from hourly global solar radiation (GSR) in Jos, Nigeria. Asian Review of Environmental and Earth Sciences, 2014, 1 (2): 43 - 50.

[100] Pankaew P, Milton EJ, Dash J. Estimating hourly variation in photosynthetically active radiation across the UK using MSG SEVIRI data. 35th International Symposium on Remote Sensing of Environment (ISRSE35); IOP Conference Series: Earth and Environmental Science, 2015, 17: 012069, DOI: 10.1088/17551315/17/1/012069

[101] Peng S, Du O, Lin A, Hu B, Xiao K, Xi Y. Observation and estimation of photosynthetically active radiation in Lhasa Tibetean Plateau. Advances in Space Research, 2015, 55: 1604-1612.

[102] Yocum CS, Allen LH, Lemon ER. Photosynthesis under field conditions. VI. Solar radiation balance and photosynthesis efficiency. Agronomy Journal, 1964, 56: 249 $-253$.

[103] Williams JG. Small variation in the photosynthetically active fraction of solar radiation on clear days. Arch Meteorol Geophys Bioclim Ser B, 1976, 33: 89 - 98.

[104] Goldberg B, Klein WH. Variation in the spectral distribution of daylight as various geographical locations on the earth's surface. Solar Energy, 1977, 19: 3 - 13.

[105] Stigter CJ, Musabillia MM. The conservative ratio of photosynthetically active radiation to total radiation in the tropics. J. Appl Ecol, 1982, 19:853 - 858.

[106] Hansen V. spectral distribution of solar radiation on clear days. A comparison between measurements and model estimates. J. Climate Appl Meteorol, 1984, 23: $772-780$.

[107] Papaioannou G, Nikolidakis G, Asimakopoulos D, Retalis D. Photosynthetically active radiation in Athens. Agricultural and Forest Meteorology, 1996, 81: 287 298.

[108] Zhou Y, Xiang Y, Luan L. Climatological estimation of photosynthetically active quantity flux. Acta Meteol. Sinica, 1996, 54(4): 447-454.

[109] Jacovides CP, Tymuios FS, Assimakopoulos VD, Kaltsounides NA. The dependence of global and diffuse PAR radiation components on sky condition at Athens, Greece. Agricultural and Forest Meteorology, 2007, 143: 277 - 287. 
[110] Escobedo JF, Gomes EN, Oliveira AP, Soares J. Ratios of UV, PAR and NIR components to global solar radiation measured at Botucatu site in Brazil.

Renewable Energy, 2011, 36:169 - 178.

[111] Guefeng W, De Leeuw J, Skidmore AK, Yaolin L, Prins HHT. Comparison of extrapolation and interpolation methods for estimating daily photosynthetically active radiation (PAR). Geo-spatial Information Science, 2010, 13(4): 235-242.

[112] Escobedo JF, Gomes EN, Oliveirol AP, Soares J. Modeling hourly and daily fraction of UV, PAR and NIR to global solar radiation under various sky conditions at Botucoctu, Brazil. Applied Energy, 2009, 86: 299 - 309.

[113] Yu X, Wu Z, Jiang W, Guo X. Predicting daily photosynthetically active radiation from global solar radiation in the Contiguous United States. Energy Conversion and management, 2015, 89: 71-882

[114] Hargreaves GH, Samani ZA. Estimating potential evaporation. Journal of Irrigation and Drainage Engineering, 1982, 108: 223-230.

[115] Wang L, Gong W, Hu B, Lin A, Li H, Zou. Modeling and analysis of the spatiotemporal variations of photosynthetically active radiation in China during 1961 - 2012. Renewable and sustainable energy reviews, 2015, 49: 1019 - 1032.

[116] Hu B, Liu H, Wang Y. Investigation of the Variability of photosynthetically active radiation in the Tibetan Plateau, China. Renewable and Sustainable Energy Reviews, 2016, 55: $210-248$.

[117] Alados I, Alados-Arboledas L. Validation of an empirical model for photosynthetically active radiation. International Journal of Climatology, 1999, 19: $1145-1152$.

[118] Hu B, Wang YS, Liu GR. Measurements and estimation of photosynthesis active radiation in Beijing. Atmospheric Research, 2007, 85: $361-371$.

[119] Kasten F, Young AT. Revised optical air mass tables and approximation formula. Appl Opt, 1989, 28: 4735 - 4738.

[120] Al-Shooshan AA. Estimations of photosynthetically active radiation under an arid climate. J. Agric Eng Res., 1997, 66: 9 - 13.

[121] Alados I, Olmo FJ, Foyo-Moreno I, Alados-Arboledas L. Estimation of photosynthetically active radiation under cloudy conditions Agricultural and forest meteorology, 2000, 102: 39 - 50.

[122] Lopez G, Rubio MA, Martinez M, Batlles FJ. Estimation of hourly global photosynthetically active radiation using artificial neural network models. Agricultural and Forest Meteorology, 2001, 107: 279 - 291.

[123] Allen RG, Pereina LS, Raes D, Smith M. Crop evapotranspiration guideline for computing croup matter requirement. FAO Imitation and Drainage Paper, Rome, Italy. 1998, 56: 290. 
Article copyright: (C) 2018 Samuel Chukwujindu Nwokolo and Solomom Okechukwu Amadi. This is an open access article distributed under the terms of the Creative Commons Attribution 4.0 International License, which permits unrestricted use and distribution provided the original author and source are credited. 